INTERNATIONAL MONETARY FUND

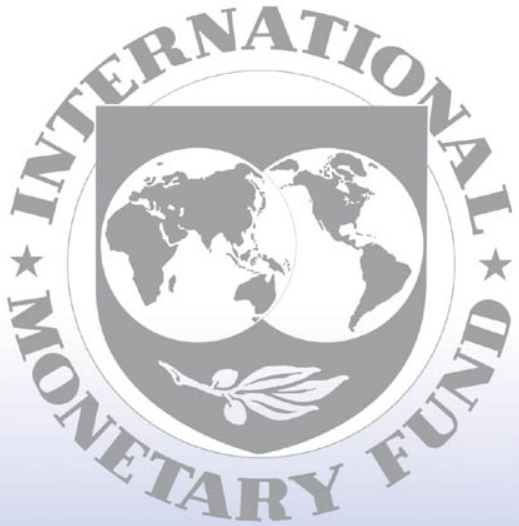

Staff

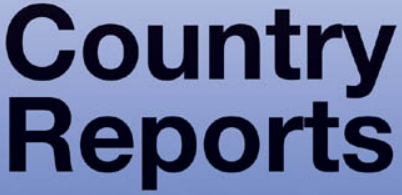




\section{Vietnam: Poverty Reduction Strategy Paper}

Poverty Reduction Strategy Papers (PRSPs) are prepared by member countries in broad consultation with stakeholders and development partners, including the staffs of the World Bank and the IMF. Updated every three years with annual progress reports, they describe the country's macroeconomic, structural, and social policies in support of growth and poverty reduction, as well as associated external financing needs and major sources of financing. This updated country document for Vietnam, dated November $\mathbf{2 0 0 3}$, is being made available on the IMF website by agreement with the member country as a service to users of the IMF website.

To assist the IMF in evaluating the publication policy, reader comments are invited and may be sent by e-mail to publicationpolicy@imf.org.

Copies of this report are available to the public from

International Monetary Fund $\bullet$ Publication Services

$70019^{\text {th }}$ Street, N.W. • Washington, D.C. 20431

Telephone: (202) 623-7430 • Telefax: (202) 623-7201

E-mail: publications@imf.org •Internet: http://www.imf.org

Price: $\$ 15.00$ a copy

\section{International Monetary Fund \\ Washington, D.C.}




\section{THE SOCIALIST REPUBLIC OF VIETNAM}

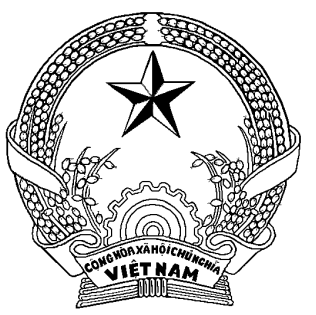

\section{The comprehensive poverty reduction \\ And growth strategy \\ (CPRGS)}

HANOI, NOVEMBER 2003 


\section{The Comprehensive poverty reduction and growth strategy (CPRGS)}

(Approved by the Prime Minister

at Document No. 2685/VPCP-QHQT, date $21^{\text {th }}$ May 2002 and at Document No ..... November, 2003)

HANOI, NOVEMBER 2003 


\title{
PREFACE
}

Poverty is a pressing problem of countries all over the world. Governments, leaders, international organizations, therefore, are actively searching for solutions to contain and eliminate poverty globally.

The Government of Vietnam takes poverty reduction as a cutting-through objective in the process of country socio-economic development. Vietnam has also declares its commitment to implement the Millennium Development Goals and poverty reduction objectives that had been agreed upon in the National Summit in September 2000. The poverty reduction and economic development process in Vietnam had attained significant achievements, which are highly appreciated by international community.

Poverty reduction is the basic element to ensure social justice and sustainable growth; and in-return, high and sustainable growth could bring about physical energy to support and provide opportunities for the poor to get out of poverty holes. Therefore, poverty reduction is considered as integrated part of the National, Sectoral and Provincial 10-Year Socio-Economic Development Strategy (2001-2010), 5-Year Socio-Economic Development Plan (2001-2005) and Annual Socio-Economic Development Plan.

The Comprehensive Poverty Reduction and Growth Strategy is a document that elaborates all general objectives, institutional arrangements, policies and solutions of the 10-Year Strategy and 5-Year Plan into detailed specific action plans.

In order to successfully implement this Strategy, I call upon ministries, sectors, government agencies, local authorities and mass organizations in your own capacity to reflex the objectives and institutional arrangements of this document in your annual implementation plan. As the same time, we wish to receive continue realistic and effective support from donor communities, international organizations and NGOs involve in economic development and poverty reduction.

\author{
Prime Minister \\ Socialist Republic of Vietnam \\ Phan Van Khai \\ (signed)
}


GOVERNMENT

No : 825/QD-TTg
THE SOCIALIST RUPUBLIC OF VIETNAM

Independence - Freedom - Happiness

Hanoi September $20^{\text {th }} 2002$

\section{DECISION OF PRIME MINISTER}

\section{On establishment of the Steering Committee for implementation of \\ The Comprehensive Poverty Reduction and Growth Strategy (CPRGS); \\ The Poverty Reduction and Growth Facility Programme (PRGF); \\ The Poverty Reduction Support Credit Programme (PRSC)}

\section{THE PRIME MINISTER DECIDES}

Based on the Law of Government organization dated of 12 December 2001;

Based on the proposal of the governor of State Bank of Viet Nam; of the Minister of Planning and Investment and opinion of other lines ministries, agencies;

Article 1. To establish a Steering Committee for the Comprehensive Poverty Reduction and Growth Strategy (CPRGS); the Poverty Reduction and Growth Facility Programme (PRGF); the Poverty Reduction Support Credit Programme (PRSC) to help the Prime Minister in guiding the implementation of the Strategy and Programmes.

Article 2. Membership of the Steering Committee consists of

1. Head of the Committee: Deputy Prime Minister Nguyen Tan Dung

2. Standing Deputy Head of the Committee in charge of PRGF and PRSC: 01 Deputy Governor of the State Bank of Vietnam.

3. Deputy Head of the Board for CPRGS: 01 Vice Minister of Planning and Investment.

4. Members of the Committee: 01 Vice Minister each from the following Ministries: Finance, Trade, Labor, War Invalids and Social Affairs, Foreign Affairs, Justice, Agriculture and Rural Development, Industry, Transports, Health, Education and Training, Construction, Science, Technology, Resouces and Environment, Interior; 01 representative each from the following: Government's Office, Minorities Committee, Statistics Directorate General, Committee for Enterprise Renovation \&Reform. 01 representative each from CPV's Economic Committee and the Women Association Central Committee.

Article 3. Tasks of the Steering Committee include:

1. To study and recommend guidelines, policies and measures for the implementation of CPRGS, the PRGF and PRSC Programmes in line with the goals of the national socio-economic development in each stage; to help the Prime Minister in leading the relevant Ministries, Government and local agencies in negotiation with the International Monetary Fund (IMF), the World Bank (WB) and other donors with regard to questions arising and solutions along the course of implementation of the Strategy and Programmes. 
2. To prepare and carry out a programme for supervision and monitoring of the implementation of items agreed upon in CPRGS, PRGF and PRSC; to incorporate relevant contents of CPRGS, PRGF and PRSC into the Government's routine working programme; to define and establish an inter-ministerial co-ordination mechanism.

3. To co-ordinate different donors, international organizations and other relevant agencies in support of the implementation of CPRGS.

4. To make periodical report to the Prime Minister on the process of implementation of CPRGS, PRGF and PRSC and make necessary recommendations.

Article 4. To assist the Steering committee is the inter-ministerial working group for CPRGS and the inter-ministerial working group for PRGF and PRSC.

1. The inter-ministerial working group for PRGF and PRSC is headed by the State Bank's Director for International Relations and the group's members include officials from the Ministries of Planning and Investment, Finance, Trade, Labor, War Invalids and Social Affairs, Foreign Affairs, Justice, the State Bank, Government's Office, Statistics Directorate General, committee for Enterprise Renovation \&Reform, and an invited member from the CPV's Economic Committee.

2. A Department-level official of the Ministry heads the inter-ministerial working group for CPRGS for Planning and Investment, the group's members include officials assigned by relevant ministries and agencies based on proposals by the Deputy Head of the Committee for CPRGS.

3. The inter-ministerial working group for PRGF and PRSC and the inter-ministerial working group for CPRGS function as a project managing Unit, which commands a working programme, budget and is allowed to receive technical assistance in realizing its tasks.

Article 5. Work distribution and tasks of members of the Steering Committee and two inter-ministerial working groups:

1. The Head of the Steering Committee has the tasks of

a) To organize and co-ordinate the work of the Committee in order to implement the functions assigned.

b) Authorized by the Prime Minister to response to recommendations with regard to CPRGS and PRGF, PRSC Programmes; to decide on specific responsibility sharing and guide the ministries and agencies concerned in the implementation process.

Head of the Steering Committee commands an assisting group led by a Deputy Head of the Government's Office and comprising relevant officials of the Government's Office. The Minister for the Government's Office will decide on the formation and assign the tasks for the assisting group.

2. The Standing Deputy Head of the Steering Committee performs the tasks regarding PRGF and PRSC as follows:

a) To assist Head of the Committee in managing the work of the Committee; prepare working programme for the Committee, convene and organize meetings of the Committee.

b) To supervise and co-ordinate the work of the Committee's members. 
c) To lead the inter-ministerial working group for PRGF and PRSC and sign relevant documents for submission to the Deputy Prime Minister, Head of the Committee, or in relation with ministries, agencies or local authorities in question.

d) To chair, on behalf of Head of the Steering Committee, meetings with ministries, agencies or local authorities on questions related to PRGF and PRSC Programmes and meetings with IMF and WB to review the implementation process.

e) To perform other tasks to be assigned by Head of the Committee.

3. The Deputy Head of the Steering Committee for CPRGS performs the tasks as follows:

a) To assist the Head of the Committee in managing and co-ordinating the work by relevant ministries, agencies and local authorities in the implementation of CPRGS.

b) To lead the inter-ministerial working group for CPRGS and sign relevant documents for submission to the Deputy Prime Minister, Head of the Committee, or in relation with ministries, agencies or local authorities in question.

c) To chair, on behalf of Head of the Steering Committee, meetings with ministries, agencies or local authorities on questions related to CPRGS and meetings with donors and international organizations related to CPRGS.

d) To perform other tasks to be assigned by Head of the Committee.

4. Members of the Committee, while performing their regular jobs, have the following tasks:

a) Responsible to the Head of the Committee on implementation questions related to his or her own ministry; present recommendations made by his or her ministry with regard to the implementation of CPRGS or PRGF and PRSC Programmes, or related to cooperation with IMF, WB or other donors for the Committee's approval.

b) To participate in all meetings and activities of the Committee. In case of failure to participate, member(s) must report and submit opinions in writing to the Head of the Committee or the Chair of the meeting. The Committee will convey the meeting's outcomes to the absent member(s).

c) To co-ordinate with ministries, agencies or local authorities on questions related to the implementation of CPRGS or PRGF and PRSC Programmes.

d) To assign one Department-level official and one expert to participate in the inter-ministerial working group for PRGF and PRSC and assign representatives to participate in the inter-ministerial working group for CPRGS.

5. The inter-ministerial Working Group:

a) Head of the Working Group performs the task of co-coordinating the work in the Group; convene Group members to meetings and report results to the Standing Deputy Head of the Steering Committee or to the Deputy Head for CPRGS; recommend meetings of the Committee when necessary.

b) Members of the Working Groups will act as co-ordinators for Departments, Directorate General in his or her Ministry in questions related to the implementation of CPRGS or PRGF and PRSC 
programmes; take part in all meetings and activities of their inter-ministerial Working Group; report to their ministry management for decisions on arising issues.

c) Heads of the inter-ministerial Working Groups convene regular or irregular Group meetings in accordance with the working programme of the Steering Committee and in time with the WB or IMF visiting delegations for review of PRGF and PRSC, and when discussions with WB or IMF's Representative Offices or other donors are needed.

d) To prepare documents and contents, if required, for working sessions at technical or policy-making levels with WB and IMF delegations or other donors under the guideline of the Steering Committee.

e) To recommend to the Committee to decide on the organization of supporting activities such as seminars, studies or inviting specialists on related fields.

f) To perform other tasks to be assigned by the Steering Committee.

Article 6. Budget for the Steering Committee.

Budget for the work of the Steering Committee will be supported partly from the Bank account deposit interests from disbursed amounts for PRGF and PRSC Programmes pending Government's decision to use these amounts. This allocation will be made once a year and no more than VND 200 million for each year of implementing PRGF and PRSC Programmes, no more than VND100 million for each year implementing CPRGS.

The specific mechanism for spending and accounting the above-mentioned budget will be decided by the Head of the Steering Committee upon submission of proposals by Ministry of Finance in co-ordination with relevant organizations, based on existing financial system and depending on the available deposit interests. In case the deposit interests are not sufficient, Ministry of Finance will recommend, in consultation with State Bank of Vietnam and Ministry for Planning\&Investment, allocations from State budget.

Article 7. The Steering Committee will dissolve upon completion of the implementation of CPRGS and PRGF, PRSC Programmes.

Article 8. This Decision replaces Decision No.131/2001/QD-TTg issued on August 31, 2001 by the Prime Minister regarding the forming of an Inter-Ministerial Steering Committee for PRGF and PRSC, and will take effect upon signature.

Ministers, Heads of ministry-level and Government's agencies, Chairmen of the People's Committees of provinces and cities under Central authority are responsible for the implementation of this decision./.

Cc:

- CPV's Secretariat,

- Prime Minister, Deputy PM

- Ministries, ministry-level and Government's agencies,

- People's Committees and People's Councils

of provinces and cities under Central authority,

- CPV's Economic Board,

- Vietnam Women's Association Central Committee,

- Board for Enterprise Renovation\&Development,

- Public Bulletin,

\section{PRIME MINISTER}

(signed)

\section{PHAN VAN KHAI}

vii 


\section{Table of content}

Error! No table of contents entries found.

viii 
The Socialist republic of Vietnam

\section{THE COMPREHENSIVE POVERTY REDUCTION AND GROWTH STRATEGY (CPRGS)}

\section{Introduction}

1. Even as Vietnam seized independence in 1945, President Ho Chi Minh emphasized that poverty is an "enemy", just as illiteracy and foreign invaders are considered enemies. He therefore defined the nation's mission: strive to enable working people to escape from wretched poverty, to be gainfully employed, and to enjoy a prosperous and happy life.

Poverty reduction is not only a basic social policy that is accorded special attention from the State of Vietnam, but it is also an important development objective.

2. The process of renovation and acceleration of rapid economic growth in parallel with implementation of the task of poverty reduction and social equity have narrowed the gap between rich and poor among different population strata and different regions within the country. Over the past ten years, Vietnam recorded many achievements in economic reform and development, gradually improved the material conditions and quality of life of its people, and effected a structural adjustment of economic sectors and industries in accordance with market signals, with the goal of establishing a state regulated market economy. These achievements reflect success of Renovation in releasing the power of our domestic resources. In these endeavors, the Government of Vietnam has received active and effective support from the international community.

During this period, effective implementation of mechanisms and policies brought about remarkable gains in poverty reduction. Vietnam witnessed a relatively high rate of economic growth in the decade from 1991 to 2000. The average annual growth rate of its gross domestic product (GDP) was 7.5 percent, rising to 8.4 percent during the period between the two living standards measurement surveys (in 1992-93 and 1997-98). Owing to rapid growth, significant gains in poverty reduction have been achieved. After ten years, the poverty incidence according to national poverty standards was reduced to only two thirds of the 1990 rate. By international poverty standards $^{(1)}$, Vietnam's poverty incidence was reduced to just half of the 1990 rate. Vietnam is considered by the international community to rank among the best-performing countries in terms of poverty reduction.

3. Nevertheless, Vietnam remains a poor country with low per capita income (per capita GDP is estimated at about US $\$ 400$ in the year 2000) and the poverty rate is still high. The Government of Vietnam recognizes this problem and believes that a strategy focused on achieving high and sustainable growth is key to narrowing the economic development gap between Vietnam and other countries in the region and the world, while at the same time generating sufficient resources to raise the welfare and living standards of the people, as well as reduce poverty and create social equity.

\footnotetext{
(1) Definitions are referred in Section 2.1 of Part I
} 
4. In order to maintain rapid and sustainable economic growth, and implement effectively the policy on poverty reduction, the Government of Vietnam developed the Ten-Year Socio-Economic Development Strategy for the 2001-2010 Period, strategies for sectoral and industrial development during the 2001-2010 period (Strategy for People's Health Care and Protection; National Strategy for Rural Clean Water Supply and Sanitation; National Strategy for Reproductive Health Care; Population Strategy for Vietnam; National Strategy for Nutrition; National Action Program for Vietnamese Children; Overall Program for Public Administrative Reform, National Strategy for the Advancement of Women in Vietnam to 2010, sectoral strategies 2001-2010 in education, technology, environmental protection, etc.), the Socio-Economic Development Plan for the 20012005 Period, National Targeted Poverty Reduction and Job Creation Program, Prime Minister's decisions on socio-economic development in the Central Highland, North Mountainous and Mekong river delta provinces, etc.

5. The Comprehensive Poverty Reduction and Growth Strategy (CPRGS) is an action program that translates the Government's Ten-Year Socio-economic Development Strategy, Five-Year Socio-economic Development Plan as well as other sectoral development plans into concrete measures with well-defined road maps for implementation. This is an action program to achieve economic growth and poverty reduction objectives. The Comprehensive Poverty Reduction and Growth Strategy is closely related to the national annual socio-economic development plans and the plans developed by different ministries, agencies and sectors. The national annual socio-economic development plan that is passed by the National Assembly serves a tool for bringing the policies and measures contained in the CPRGS into practice. The links between the Government's Ten-Year Strategy and socio-economic development plans and the CPRGS are shown below:

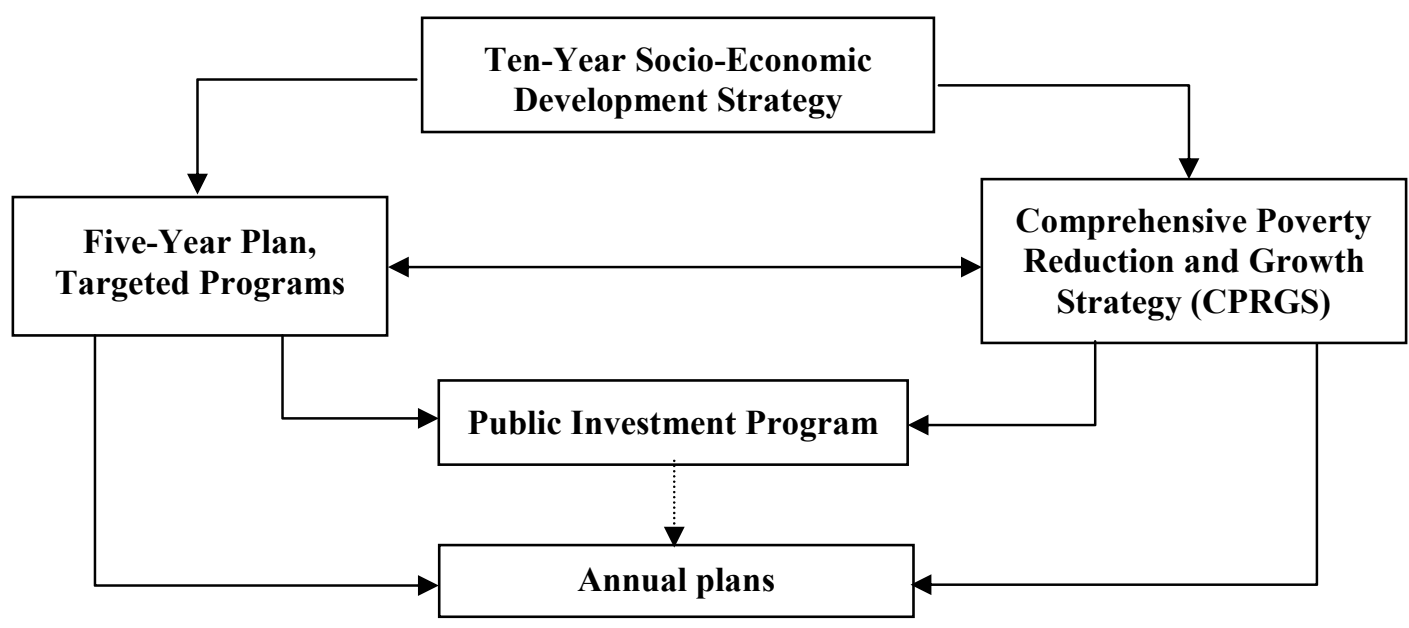

6. The CPRGS sees a harmony between economic growth and measures to solve social problems. The tasks and objectives contained in the poverty reduction and growth strategy not only calls for targeted measures to support specific poverty groups, but also sees linkages within the matrix of policies that range from macroeconomic policies, policies on structural adjustment, sectoral development policies and measures, to social welfare policies of all sectors and levels that must work in tandem to ensure sustainable development. The Comprehensive Poverty Reduction and Growth Strategy makes concrete the following major objectives:

- Promote rapid and sustainable economic growth coupled with attainment of social progress and equity, aimed at improving the material conditions and quality of life of all population strata; maintain rapid development of the dynamic areas and create favorable conditions for them to achieve high economic growth rates. At the same time, concentrate on developing agriculture and rural areas, ensure food security, create jobs, 
increase rural income; more attention will be given to investment and other support to disadvantaged areas; reduce the development gap between regions, pay attention to the living conditions of ethnic minority peoples.

- Create an equal business environment for all types of enterprises from all economic sectors, including enterprises with foreign direct investment (FDI), regarding their access to public services and business and investment opportunities, and encourage the development of small- and medium-sized enterprises.

- Continue with structural reforms to bring about a transformation of the nation's economic structure; reorganize, renovate and improve the efficiency of state-owned enterprises (SOEs); restructure the state budget; reform the commercial banking system, reorganize and strengthen the health of financial and credit organizations; continue with trade liberalization, honoring international commitments made under the framework of AFTA, make good preparations to meet conditions for WTO accession, implement bilateral trade agreements, and so on, in order to increase the efficiency and competitiveness of the economy and meet the requirements for rapid growth and sustainable development.

- Provide poor households with opportunities to raise their income by accelerating broad-based growth of agriculture, industry, and services; expand and develop markets to distribute consumer goods, improve socioeconomic infrastructure; ensure equal access to basic productive and social services.

- Encourage human development and reduce inequality, and give priority to health and education development, environmental protection, prevention of HIV/AIDS transmission and infection, gender equality and improving the lives of ethnic peoples.

- Solve the particular problems of urban poverty with regard to employment, income and housing. Ensure that urban poor have equal access to resources, public services and basic social services. Improve the access of migrants, especially their children, to these resources and services.

- Develop and expand social protection and safety nets for the poor, and for people suffering from natural calamities; and minimize the vulnerability of the people. Increase the participation of mass and social organizations in developing the social safety net.

- Undertake public administration reform in four areas: institutional reform, administrative apparatus reform, renovation and improvement of the quality of the contingent of civil servants; and public finance reform to enable civil servants and the administration to change their working styles and to heighten their sense of responsibility towards their work, to provide the people with better access to public services, and to ensure social equity. Implement fully the Decree on Democracy at the Grassroots Level to improve citizens' participation in the planning and implementation of decisions about community socio-economic development; enhance the transparency of the budget process and of the production of macroeconomic statistics.

Establish a system of qualitative and quantitative socio-economic development and poverty reduction indicators (with breakdown by gender and ethnicity) to monitor and supervise the progress of implementing the Comprehensive Poverty Reduction and Growth Strategy.

7. The preparation of the Comprehensive Poverty Reduction and Growth Strategy started in June 2001 based on the Interim Poverty Reduction and Growth Strategy Paper that was approved by the Prime Minister in March 2001. The Ministry of Planning and Investment takes the lead in this undertaking in collaboration with concerned ministries and agencies ${ }^{(2)}$ and is supported by a group of national and international consultants and broad consultation from concerned ministries and agencies, representatives of the donor community and other parties, such as the Poverty Working Group (composed of donors, government agencies and non-governmental organizations). The Comprehensive Poverty Reduction and Growth Strategy has received comments from

\footnotetext{
(2) The Strategy Drafting Team consists of 52 members from 16 Government's ministries and line agencies. Besides, the Ministry of Agriculture and Rural Development, Ministry of Health, Ministry of Science, Technology and Environment, etc. also established their Sectoral Poverty Task Forces to contribute to the preparation and implementation of the CPRGS. The donors, international organizations and NGOs also took part in the Strategy preparation.
} 
concerned ministries and agencies, scientists, mass organizations, non-governmental organizations and the donor community at various workshops organized at both central and regional levels in order to get the comments of 61 provinces and cities, and also comments at six commune and village consultations ${ }^{(3)}$. The widely consultative and consensus-building process of formulating the Comprehensive Poverty Reduction and Growth Strategy (CPRGS) reflects the government's commitment to strengthening participatory and democratic governance at all government levels, especially at the grassroots. At the same time, it raises awareness of the CPRGS and about the process of its implementation that is to follow.

\section{The Comprehensive Poverty Reduction and Growth Strategy formulated by the Government of Vietnam is composed of six parts:}

\section{Part I: Socio-Economic Setting, Current Poverty Situation, Achievements and Challenges}

During the 1990s, Vietnam continued to accelerate the process of institutional and legal reforms, and the transformation of the structure of the economy, rapidly opening up and integrating with the global economy and with regional economies. As a result, the country succeeded in quelling hyperinflation, maintaining macroeconomic stability and achieving a high economic growth rate of $7.5 \%$ per annum on average, while halving the poverty rate. Reforms in agriculture and rural areas helped to increase rapidly agricultural output. Per capita food production was boosted from $303 \mathrm{~kg}$ in 1990 to $444 \mathrm{~kg}$ in 2000, and revenues from agricultural exports more than quadrupled from US\$ 1 billion in 1990 to US\$ 4.3 billion in 2000. Remarkable improvements have been seen in the country's human development, community health and the living standards of the Vietnamese people. Vietnam's Human Development Index rose to 0.696 in 2000 (ranking 101st out of 162 countries) from 0.456 in 1990 (ranking 120th).

Despite these important achievements, poverty remains widespread, especially in rural, mountainous, remote and isolated areas. The income of a large segment of the population lies just above the poverty line and is highly vulnerable to negative shocks such as natural disasters, job loss, sickness, and volatile agricultural prices... Poor health, low level of education, and unsanitary hygienic conditions and environmental degradation make it difficult for the poor to improve their situation in order to escape from poverty. Moreover, the planned reform of state-owned enterprises (SOEs) in the coming period will lead to additional redundancies in the SOE work force, thus increasing pressure to generate more employment, but it is also a process to reallocate labor from one sector to another, creating opportunities for competitive development among economic sectors.

\section{Part II: Objectives and Tasks of Socio - Economic Development and Poverty Reduction for the Period up to 2005 and 2010}

The overall objective of Vietnam for the 2001-2010 period is to bring about a significant improvement in the people's material, cultural and spiritual life, lay the foundations for the country's industrialization and modernization, build a prosperous people, strong country and a just, equal, democratic and civilized society, and establish the institutions of a socialist-oriented market economy, protect and preserve the country's natural resources and national culture for future generations. To attain these objectives, the structure of the economy and labor force should be transformed along the lines of raising the efficiency and competitiveness of the economy. The country's international economic relations will be broadened and deepened, the social and

\footnotetext{
(3) Four regional workshops organized one in Northern mountainous region, one in the Central region, one in the Mekong River Delta, and one in Ho Chi Minh City for getting comments from the cities. In addition, ministries and line agencies organized a series of topical workshops to get additional comments. These included, for example, Workshop Gender, Workshop on Poor Women organized by Vietnam's Committee for Women's Advancement, Workshop on Environmental Issues held by Environment Department of the Ministry of Science, Technology and Environment.
}

Six village and commune consultations were organized by non-governmental organizations (e.g. Save the Children Fund UK, Oxfam UK, CRS, International Plan, Action Aids, and the World Bank) at Lao Cai for Northern mountainous region, Ha Tinh and Quang Tri provinces for the Central region, in Ho Chi Minh City, and in Vinh Long and Tra Vinh provinces for the Mekong River Delta. 
economic infrastructure will be strengthened; improve the education and training system so as to raise the quality of our human resources. Strengthen Vietnam's comparative advantages while implementing multilateral and bilateral trade commitments to enable our proactive integration into the world economy.

Economic growth must go hand in hand with social progress and equity and environmental protection in order to create more jobs for our growing labor force, improve the health of our people, eliminate hunger, reduce poverty, and reduce social problems in a timely and effective manner. Economic growth will generate resources for poverty reduction. At the same time, to make significant progress in poverty reduction, growth must be accompanied by additional targeted measures to create favorable conditions for the poor to access opportunities to improve their lives, recognizing that the poor themselves must make efforts to escape from poverty.

Poverty reduction is not simply about redistributing income in a passive manner, but also about creating a growth dynamic - a process in which the poor takes initiative to improve their situation in order to overcome poverty. At the same time, poverty reduction is not a one-way path with economic growth generating resources to support disadvantaged people, but is itself an important factor that creates the groundwork for a relatively level playing field for development, to generate more abundant resources, and to ensure stability during the period of economic "take-off".

\section{Part III: Create Environment for Rapid and Sustainable Growth, and for Poverty Reduction}

To promote rapid and sustainable growth, establish a legal environment to enforce a fair, level, and competitive playing field for all enterprises, state and private, domestic and foreign. Eliminate unnecessary business licenses and other administrative impediments; ensure that all types of enterprises have equal and non-discriminatory access to capital, credit, land, new technology, and information. Reorganize, renovate and improve the effectiveness of SOEs. Develop necessary policies and mechanisms to ensure that the investment plans of SOEs are in accordance with sectoral development strategies and a business environment informed by international economic integration. Complete the Law on Enterprise Bankruptcy. Implement the government's Decree on support to SMEs. Continue the process of reforming the public administration system aimed at building a transparent and efficient administration that is based on the rule of law. Strengthen the management capacity of local authorities, especially in economic and budget management.

To maintain macroeconomic stability, adopt a prudent monetary and fiscal stance, improve taxation policy, broaden the tax base, and closely link policy, planning and budgeting. Balance capital expenditures and current expenditures to ensure a pro-poor outcome. Maintain an appropriate rate of inflation and exchange rate and interest rate policies that are pro-poor. Continue the open-door trade policy, gradually remove non-tariff barriers, and implement our commitments under the ASEAN framework, the Vietnam - US bilateral trade agreement, and commitments made with international financial institutions. Improve the consistency of and linkages between trade policy, industrial policy and exchange rate policy, and strengthen coordination among the concerned ministries and agencies.

Implement the Grassroots Democracy Decree, strengthen dialogue between the authorities and local communities, and improve the legal support framework for the poor. Strengthen the accountability of public authorities, especially local government at all levels, towards the people though increased transparency and publication of local budgets.

\section{Part IV: Large-scale infrastructure development for growth and reduction of poverty.}

Large-scale infrastructure plays an important role in the economy through spillover effects such as private investment and FDI attraction, regional economic development stimulation, job creation, production cost reduction, product competitiveness enhancement etc, thus helping to create more resources for implementing development goals, accelerating growth and eradicating poverty. 
Beside the achievements recorded in infrastructure development over the recent years, Vietnam's infrastructure system remains poor and insufficient, failing to meet the demands of socio-economic development and economic restructuring process. Resources for infrastructure development are constrained, overlapping and not concentrated. Financial funding mechanism for infrastructure projects is not coherent and fails to keep up with reality. Shortcomings remain in project management, operation and maintenance.

Directing large-scale infrastructure development to poverty reduction and growth: A large-scale infrastructure network is needed in order to meet the demands of economic development towards industrialization and modernization, guaranteeing equal accessibility and use of infrastructure services by all economic sectors.

A large-scale infrastructure system must be developed in away that it is capable of receiving modern technologies and maintaining competitiveness in the process of regional and international integration. It is the target for Vietnam by 2020 to have a modern network of infrastructure services.

Policies and solutions for large-scale infrastructure development: It is necessary to enhance the work of planning and planning management with a view to develop large-scale infrastructure system under a suitable timetable and with long-term effectiveness and balanced with available economic resources.

To development large-scale infrastructure services in a way that guarantee the spill-over effects and create new opportunities for extending inter-region links.

To diversify resources for large-scale infrastructure investment; make new policies and mechanism to mobilize to the maximum resources for development, particularly from private sector and foreign investment.

To harmonize relations of partnership, diversifying ways and means of financial assistance; efficiently mobilize and use Official Development Assistance (ODA) for large-scale infrastructure development.

To pay due attention to environment protection and solutions for resettlement concerning large-scale infrastructure projects; to improve the work of maintenance; implement cost-reduction measures for infrastructure services; improve accessibility for the poor to infrastructure services.

Part IV: Major Policies and Measures for the Development of Sectors and Industries to Ensure Poverty Reduction and Sustainable Growth

Agriculture and rural development: ensure food security; diversify agricultural production; attach importance to market research and ensure timely provision of information; increase investments in agriculture; link the production of high value crops to developing storage and processing facilities; promote research and efficient use of natural resources; expand agricultural, forestry, fishery activities and extension activities in a manner that is suitable to production conditions in different areas and is responsive to the demand of poor people; develop fisheries and diversify aquaculture; develop a disaster prevention strategy to minimize losses and stabilize livelihoods and production in disaster-prone areas.

Industry and urban development: develop our comparative advantages in labor-intensive industries and industries that utilize domestically produced agricultural, fishery and forestry raw materials. Push up the development of the agricultural engineering sector to take advantage of the large domestic market and the markets in neighboring countries. Develop mechanisms to encourage spearhead and labour-intensive industries. Formulate policies to deal with the problems of urban poverty, provide legal support, create jobs, provide credit, develop basic infrastructure, improve the urban environment and landscape, strengthen vocational training and resolve effectively the problem of urban migration, etc.

Infrastructure development: based on the needs of the poor, develop policies and programs to provide electricity, small irrigation works, clean water, sanitation facilities, and develop and rehabilitate the transport system, especially in poor regions and areas. 
Focus investments on developing transportation in the Northern mountainous region and irrigation in the Central Highlands and Central region. Resolve effectively the problems related to housing for the poor, focusing on society's vulnerable groups.

Education and training: continue raising the quality of education and maintain the target of universalizing primary and lower secondary education; reduce and eliminate school fees and other contributions for children from poor families and poor areas. Ensure that the quantity and quality of schools, classrooms and teachers are adequate, and gradually consolidate the general and vocational training schools.

Health: Promote the grass-roots health system, maintain and develop community health services; give priority to combating diseases that affect most the poor (reproductive health, infectious diseases, HIV/AIDS, childhood illnesses and other social illnesses); improve the quality of health services; ensure that the poor have access to quality health services; provide support to the poor with health service subsidies.

Culture and information: preserve and restore our tangible and intangible cultural heritage; build commune cultural centers for gatherings; improve the quality of news and information; provide more information with the aim of helping people access and make use of information to widen their options and to make better decisions to improve their lives.

Environment and sustainable development: create a harmonious link between socio-economic development and protection and improvement of the environment, to ensure that every citizen can live in a clean and healthy environment.

Narrow the social development gap between different regions and population groups, reduce the vulnerabilities of the poor and disadvantaged groups; realize gender equity and the advancement of women; stabilize and raise the living standards of ethnic minorities; expand social protection and the social safety net, and develop an effective system of emergency relief; expand the participation and enhance the role of domestic social organizations and non-governmental organizations in the process of building and implementing the social safety net.

\section{Part V: Mobilization of Resources for Growth and Poverty Reduction}

During the 2001-2005 period, at least VND 840,000 billion (or about US\$ 60 billion) will be mobilized for development investment. This amount is 1.5 times larger than that of actually invested funds during the 1996-2000 period (of which one third will come from foreign sources and the remaining two thirds will come from domestic sources). The state sector is projected to account for $55.5 \%$ and the domestic private sector for approximately $26.2 \%$ of total development investment resources.

Resources from the state budget (public expenditures) have been mobilized to the highest level possible; the amount is estimated to total VND 630,000 billion (or US\$ 45 billion). Of this, VND 185,000 billion will be used for capital expenditures and VND 445,000 billion for current expenditures. The amount of funds to be used for national targeted programs and large projects is estimated to be about VND 60, 000 billion.

With this limited amount of capital, the targets we have laid out can be attained in terms of quantity, but quality will be constrained; for this reason, we must strive to mobilize more capital.

The State budget expenditure will be further restructured, and items of expenditure that do not fall under the functions and responsibilities of the State will be transferred to other economic sectors. The investment and business environment will be improved to better attract foreign resources.

Priority with respect to spending will be given to developing infrastructure, especially rural infrastructure, improving community health, increasing income-generating opportunities, and developing productive subsectors that have strong or potentially strong competitive advantage in order to promote growth.

Part VI: Organizational Arrangements for and Monitoring and Evaluation of the Poverty Reduction and Growth Strategy 
The implementation of the Comprehensive Poverty Reduction and Growth Strategy is organized in a centralized manner with close coordination among governmental agencies. A Steering Committee for the Comprehensive Poverty Reduction and Growth Strategy will be established in order to help the Prime Minister guide the implementation of the Strategy.

Establish criteria and procedures to appraise and select priority investment programs and projects, including an assessment of economic and social benefits (cost/benefit analysis). Analyze and evaluate possible risks to successful implementation of the Strategy and take effective measures to minimize them.

Organize the monitoring and evaluation of the progress in the Comprehensive Poverty Reduction and Growth Strategy implementation in order to have an overall assessment and to uncover in order to correct irrationalities in the current system of mechanisms, policies, industrial and sectoral development measures. On that basis, adjust and amend policies to implement the Strategy effectively, consistently, on schedule, and according to the objectives we have laid out. Research, analyze and evaluate the impact of structural, financial and macroeconomic reforms on the poor.

The system of CPRGS monitoring and evaluation indicators includes: indicators to monitor and evaluate inputs; indicators to monitor and evaluate the efficiency and effectiveness of resources invested in the Strategy; indicators to evaluate the impact of each program or strategy on the poor and the whole society. The indicators will be further disaggregated as follows: urban or rural, region, locality, gender, ethnicity, and so on.

Line ministries, agencies and local authorities take responsibility for collecting on a regular basis qualitative and quantitative information for monitoring and evaluation at their respective administrative level. Independent research organizations (NGOs, institutes, universities, etc.) shall organize the collection of comments from the people, and collect and analyze data to assess the present condition and growth and poverty reduction trends. 


\section{PART I}

\section{Socio-Economic Setting, Current Poverty Situation, Achievements and Challenges}

\section{SOCIO-ECONOMIC SETTING}

1. During the period of carrying out the Ten-Year Socio-economic Stabilization and Development Strategy (1991-2000), the economy of Vietnam, despite great difficulties and challenges, especially during the five-year period from 1996 to 2000, managed to maintain a favorable development trend, due to successful implementation of appropriate policies and methods that unleashed the nation's productive potential combined with effective support from the international community; the annual GDP growth rate averaged 7.5 percent, accompanied by a continuous rise in domestic saving and per capita income. The ratio of domestic savings to GDP in the year 2000 was 2.5 times larger than that in 1990, and per capita GDP was 1.8 times larger. The nation's capital stock also grew swiftly as gross fixed capital formation rose to 29 percent of GDP by the year 2000 from 14.4 percent in 1990.

Table 1.1: Selected Economic Indicators, 1990-2000

\begin{tabular}{lccc}
\hline & $\mathbf{1 9 9 0}$ & $\mathbf{1 9 9 5}$ & $\mathbf{2 0 0 0}$ \\
\hline $\begin{array}{l}\text { Five-year average growth rate of GDP } \\
\text { (1986-1990; 1991-1995; 1996-2000) \% }\end{array}$ & 4.4 & 8.2 & 6.9 \\
$\quad$ Of which: & & & \\
$\quad$ Agriculture, Forestry, Fishery, \% & 3.1 & 4.1 & 4.3 \\
$\quad$ Construction and Industry, \% & 4.7 & 12.0 & 10.6 \\
$\quad$ Services, \% & 5.7 & 8.6 & 5.75 \\
Exports, billion US\$ & 2.4 & 5.4 & 14.5 \\
Imports, billion US\$ & 2.7 & 8.1 & 15.2 \\
Domestic savings as percentage of GDP, \% & 8.5 & 22.8 & 27.0 \\
Consumer Price Index, \% & 67.1 & 12.7 & -0.6 \\
\hline
\end{tabular}

(Source: General Statistical Office and Ministry of Planning and Investment)

2. Agriculture - the foundation for Vietnam's socio-economic stability - maintained a relatively high growth rate and had a decisive impact on poverty reduction by ensuring food security, generating employment and income for the rural population. The growth of agricultural production was relatively high and broad based at 5.6 percent per annum during the 1991-2000 period. Per capita food production increased from $303 \mathrm{~kg}$ in 1990 to $444 \mathrm{~kg}$ in 2000 . Vietnam became self-sufficient in food with satisfactory food reserves, and now exports over three million tons of food each year. Revenues from agricultural exports nearly quadrupled from around US\$1 billion in 1990 to over US\$4.3 billion in 2000 .

The structure of agricultural production in many regions has transformed in the direction of greater efficiency per unit of area used; the rapid growth of fishery and aquaculture is especially noteworthy. The rural economy is more diversified. Many large-scale agricultural production areas with close links to agro-processing have been established; the tradition of craft villages has been restored, and farm-based production has seen rapid expansion. 
3. Industry continues to grow at a rapid rate, contributing importantly to socio-economic stability and poverty reduction. Production capacity of many industrial products has risen considerably; this not only ensures that domestic demand for food, clothing, housing, means of transportation, education and many other essential goods, is met, but it also provides for a gradual expansion of export capacity. The considerably transformed structure of a number of industries has lead to the development of certain key products; also, a number of industrial and export processing zones with many production establishments using modern technologies have been established. Along with the development of large-scale industrial establishments, the Government attaches great importance to the development of small and medium-sized enterprises and of craft villages, with a view to creating more employment and raising producers' incomes, etc.

4. The services sector managed to perform well under difficult conditions and the quality of services has improved, meeting the demand of economic growth and the needs of the people. The domestic market has become more open with the participation of many economic sectors.

From 1991 to 2000, the value of financial services increased 3.2 times, education and training services increased 2.2 times, and health and related social services increased 1.7 times.

Despite its initial dilapidated condition, the transportation services sector has responded relatively well to the nation's economic growth requirements. The output value of the transport, storage and communications sector increased 1.8 times. The physical infrastructure of the transport industry has improved considerably and many modern bridges have been built replacing old, weak ones; many ferry landings and wharves have been upgraded and expanded to meet transportation demand in the last few years. Post and telecommunication services also have expanded rapidly and the domestic telecommunications network has been modernized. Many modern modes of communication that meet international standards have been established to meet growing domestic demand for information and trading services. Markets for insurance services have been established with the participation of enterprises from various domestic and foreign economic sectors. Important renovations have been made in financial and banking services. Other high value-added services that should grow quickly over time such as legal, scientific and technological consulting services, and so on, have begun to develop.

5. Trade liberalization and the expansion of export markets have resulted in the rapid growth of both exports and imports. The speed of the opening of the Vietnamese economy is seen in the dramatic rise in the trade to output ratio (defined as external trade turnover on GDP ratio) from 58.2 percent in 1998 to 111 percent by the year 2000. From 1991 to 2000, exports of goods and services increased by 3.6 times, while imports of goods and services rose by 3.2 times. The trade liberalization policy has encouraged a significant rise in the number of domestic enterprises from all economic sectors involved in export and import activities.

6. Many polices and mechanisms regarding socio-economic renovation have been adopted; many economic laws have been promulgated and revised to keep up with the requirements of the market economy, such as the Civil Law, Land Law, Labor Code, Trade Law, Law on Foreign Direct Investment, Enterprise Law, Law to Encourage Domestic Investment, Customs Law, Insurance Law, State Banking Law, Law on Credit Organizations, State Budget Law, Taxation Laws and so on, to gradually create a relatively complete, comprehensive, safe, favorable and egalitarian legal environment for production and business activities. Market institutions for goods and services, capital, labor, real estate, science and technology, etc. are being established and gradually improved, thereby encouraging domestic residents, and domestic and foreign enterprises, to invest in developing and expanding production.

7. Total investment, including foreign investment, has risen considerably, and has been the most important effective demand stimulus and the most important factor for strengthening the economy's potential during the 1990s. Domestic resources have been more effectively mobilized, especially from the private and household sectors, and now account for over $60 \%$ of total investment.

8. Living standards of the people have improved greatly. Clear gains have been recorded with respect to social development targets and targets for improving the lives of various population strata in urban and rural areas, especially poverty reduction targets. During the last ten years, average life expectancy rose to 68 years in 
2000 from 64 years in 1990. The child malnutrition rate fell from $51.5 \%$ to $33.1 \%$; the under-five child mortality rate from $81 / 1,000$ to $42 / 1,000$ live births and the maternal mortality rate have fallen from $110 / 100,000$ to $100 / 100,000$ live births in the last ten years.

The percentage of the rural population with access to safe water has doubled. The net enrollment rate at the primary education level increased to $95 \%$. The percentage of communes where basic infrastructure is unavailable or inadequate decreased greatly (in 2000, $88 \%$ of communes had access to electricity, $95 \%$ of communes were accessible by car). The living standards of people in many areas, especially rural and especially disadvantaged areas, have improved significantly. Vietnam's Human Development Index (HDI) and access to social services have shown remarkable progress. In 1999, although Vietnam's per capita GDP country ranking was only 167, its HDI country ranking was much higher at 101, which places Vietnam, with an HDI index of 0.682, in the average category (in 1990 Vietnam's HDI ranking was 121 with an HDI index of 0.456). According to the UNDP Human Development Report, Vietnam ranks 89 out of 162 countries in the Gender Development Index (GDI). Women account for 26\% of the National Assembly, placing Vietnam in the group of 15 countries that have the highest female participation in Government bodies of power.

9. Nevertheless, despite significant gains of the past decade, Vietnam's economic growth path is not yet on a securely sustainable footing. Since 1997, the regional economic crisis has hurt the Vietnamese economy, and contributed to a slowing of output growth. Although a revival of economic growth is anticipated, with GDP reversing the previous declining trend by growing at approximately 6.8 percent in 2001, it may not be possible to repeat the high economic growth rates of the mid-1990s. The Vietnamese economy still faces great difficulties due to adverse external impacts, and consecutive years of natural calamities...

10. The quality of development is still low; economic efficiency is not high, and many sectors and products are not competitive. In agriculture, advanced cultivation methods have been introduced in rural areas at too slow a pace and their introduction has not been widespread; there are too many job seekers while the ratio of unskilled labor remains high; aggregate labor productivity is low and the manufacturing sector's record of creating new jobs has been disappointing; product distribution has been difficult; the environment has been degraded, natural resources have been overexploited and risk becoming exhausted.

In industry, production has been unstable with low efficiency. A number of industrial branches have encountered difficulties in production and product distribution; the low level of technology, obsolete machinery and equipment, and the slow rate of upgrading have lead to high production costs. The pace of reorganization of production and reform and equitization of enterprises has been slow. The development of services industries also has been slow. Moreover, trading networks and markets in rural, mountainous, remote and isolated areas are underdeveloped.

11. Implementation of international trade commitments in the course of international economic integration, while offering many important advantages, will expose domestic enterprises to challenges and fierce competition with foreign enterprises right in the domestic market.

12. Macroeconomic balances are fragile and seriously constrained. National assets, public finance and SOEs finances have not been closely managed. The system of policies and legal regulations on taxation is incomplete; the trend of exempting or allowing tax reductions on certain components of government revenue remains widespread. Many revenue items have not been adequately collected (e.g. property tax, personal income tax, etc.) while the major sources of revenues are still crude oil exports and import taxes, etc. The tax collection system should be renovated. The amount of funds mobilized from the private sector remains small. The credit analysis capability of commercial banks remains weak and consequently the supply of credit has not been directed towards efficient enterprises. Credit quality has not been high and the percentage of bad debts is still large. The ratios of saving and investment to GDP lag behind requirements for sustainable economic growth. Because of these drawbacks, the mobilization, utilization and management of economic resources have been inefficient. Consequently, our people's resources have not been adequately mobilized, and the economy's productive potential has neither been released nor brought into full play. 
13. The system of economic laws is inadequate and lacks consistency. Some important laws (e.g. Competition Law) are not in place yet. A large number of by-laws have not been promulgated in a timely manner and conflict with each other; this has created considerable difficulties in law implementation. The quality of some economic laws and by-law documents remains low.

14. Public administration reform is slow and lacks decisiveness. The administrative apparatus is slow to reform, ineffective and inefficient. There are more than a few public servants who are neither capable nor qualified; they cannot meet the requirements of their assigned work and responsibilities, which lead to large bottlenecks in implementing policies and mechanisms. Embezzlement and wasteful use of public funds remains a serious problem that is slow to resolve.

15. There are many urgent social and environmental problems. Labor and employment have become the most acute and pressing issues. The level of income and labor productivity, especially in agriculture, is extremely low, the rural and urban income gap is widening, a large proportion of workers have a low level of skills, and the percentage of untrained workers is still high. Science and technology has not been able to serve as a foundation and source of dynamism for production and trade. The slow growth of industrialization and urbanization makes it difficult to absorb labor that has been made redundant.

Natural resources have not been exploited effectively, economically, and sustainably. There is a trend decline in the quality of the environment. The area of natural forests continues to decline; in certain areas, mineral resources are exploited in haphazard fashion; in other areas, land is eroded and degraded. Bio-diversity on land and sea is gradually declining. The coastal sea area has begun to see pollution. Environmental and sanitation conditions in rural, remote, isolated, mountainous areas and areas where ethnic minorities live remain poor.

There remain many urgent social problems, and social ills continue to rise. Trade fraud has not been reduced. Transport accidents are serious and on the rise. The child malnutrition rate is still high; over $60 \%$ of disabled children have not been treated; child labor is now a burning issue; trafficking and abuse of children and the number of street children are on the rise. The spread of HIV/AIDS has not yet slowed down. Complaints and lawsuits take a long time to resolve, etc. People living in remote, isolated and disaster-prone areas remain in difficulty.

\section{CURRENT POVERTY SITUATION AND CAUSES OF POVERTY IN VIETNAM}

\section{Definition and Approach to Poverty Line}

\subsection{Definition}

Vietnam accepts the general definition of poverty agreed to at the Asian - Pacific Conference on poverty reduction organized by ESCAP in Bangkok, Thailand in September 1993: "Poverty is a situation in which a proportion of the population does not enjoy the satisfaction of basic human needs that have been recognized by the society depending on the level of economic and social development and local customs and practices."

\subsection{International Poverty Line Measurement Method}

The method to define the poverty line based on international standards was jointly developed by the Vietnamese General Statistical Office and the World Bank and was applied in the Living Standards Measurement Surveys in Vietnam (in 1992-93 and 1997-98). The lower line is the food poverty line; the higher line is the total poverty line and includes both food and non-food commodities.

The definition of the food poverty line is based on the standard used by most developing countries and WHO and as well as international organizations at present, i.e. average 2,100 Kcal daily calorie intake per capita. People whose expenditures are lower than this minimum level are considered poor in terms of food. 
The method to define the total poverty line is to add the costs of non-food to the minimum expenditures. By adding this amount to the amount for the food poverty line, we have the total poverty line.

The 1993 expenditure-based total poverty line was VND 1.16 million per annum per person (55\% higher than the food poverty line) and the 1998 one was VND 1.79 million (39\% higher than the food poverty line). Based on these poverty lines, the total poverty incidence in Vietnam in 1993 and 1998 was 58\% and 37.4\% respectively while that of food poverty was $25 \%$ and $15 \%$ respectively.

\subsection{National Poverty Line Measurement Method}

Based on the level of the economy and the rate of economic growth, the financial resources for the 20012005 period, and actual living standards of Vietnamese in specific regions, the Ministry of Labor, Invalids and Social Affairs (MOLISA) of Vietnam developed a national poverty line ${ }^{(4)}$ for the following purposes: identify who are the poor and which communes are poor with specific numbers and addresses in order to develop a list of poor households from the hamlet and commune level, and that of poor communes from the district level upwards, who are eligible for support from the National Targeted Poverty Reduction Program and other support policies...

In view of the country's achievements in poverty reduction and economic growth and improvement in living standards, a new poverty line) was published in 2001 to be applied to poverty measurement in the 2001-2005 period in which the new national poverty line developed by the National Poverty Reduction Program is defined at different levels depending on specific areas/regions, based on per capita income: VND 80,000 per month for island areas and rural mountainous areas, VND 100,000 per month for rural plain areas, and VND 150,000 per month in urban areas.

In the future, Vietnam will move towards using one common poverty line for estimating poverty incidence in the country, taking into consideration international poverty standards for comparison purposes.

\section{Poverty Situation in Vietnam}

\subsection{Vietnam ranks among the world's poorest countries}

The percentage of poor and hungry households in Vietnam remains relatively high ${ }^{(5)}$. According to the Living Standards Measurement Survey (using the international poverty line), Vietnam's poverty incidence was over $37 \%$ in 1998, and is estimated at about 32\% in 2000 (equal to a halving of the number of poor households from 1990). Applying Vietnam's food poverty standard (2100 calorie intake per day), the poverty rate was 15\% in 1998 and was estimated at $13 \%$ in 2000 .

Using the new poverty line developed by the National Poverty Reduction Program, it is estimated that there are 2.8 million poor households by the beginning of the year 2000 , or $17.2 \%$ of the total number of households in the whole country.

\subsection{Poverty is widespread among households with low and unstable income}

\footnotetext{
(4) In 1997, Vietnam set a poverty line under the national program (the old poverty line) to apply to poverty measurement in the 1996-2000 periods as follows: Poor households: different income levels are set for different areas/regions: rural mountainous and island areas: less than $15 \mathrm{~kg}$ per person per month (equivalent to VND 55,000); rural plain and midland areas: less than $20 \mathrm{~kg}$ per person per month (equivalent to VND 70,000); and urban areas: less than $25 \mathrm{~kg}$ per person per month (equivalent to VND 90,000); Poor communes: communes with poverty incidence of $40 \%$ and above that lack infrastructure (roads, schools, clinics, electricity and water for livelihood needs, small irrigation works and markets).

(5) The existing body of information on poverty in Vietnam is extremely rich compared to many other developing countries. The most detailed and large, nationally representative, data were gathered from the 1992-93 and the 1997-98 Vietnam Living Standards Survey (VLSS) conducted by the General Statistical Office with assistance from the UNDP, SIDA and the World Bank. The surveys covered 4800 and 6000 households respectively with a detailed and comprehensive survey questionnaire in both surveys. This body of information is further augmented by in-depth participatory poverty assessments (PPAs) conducted by the Vietnam-Sweden Mountain Rural Development Program (MRDP), Action Aid Vietnam, Oxfam GB and Save the Children Fund UK.
} 
Although Vietnam recorded great achievements in bringing down the incidence of poverty, it is not yet on solid ground in the struggle against hunger and poverty.

The income of a large proportion of the population lies just above the poverty line, and even a small adjustment in the position of the line will put them below the poverty line.

Most of the income of the poor comes from agricultural work. Given their very limited resources (land, labor and capital), their income is highly unstable and they are vulnerable to unexpected shocks at the family and community levels. The income level of many households is barely above the poverty line, so that a small downward shift in income can easily push them below the poverty line. Seasonal factors affecting agricultural production also create difficulties for the poor.

The rate of increase in income among the poor is low compared to that of the middle-income group, and much lower compared to the high-income group. The widening gap between the richest and poorest quintiles (from 7.3 times in 1996 to 8.9 times in 1999) shows the extent to which the poor are lagging behind the rich. Thus, although the poverty situation in Vietnam has improved, the rate of improvement among the poor is slower compared to the average rate and much slower compared to the rich. In addition, the gap in living standards between urban and rural areas remains very large.

The poorest provinces also rank lowest in the countrywide Human Development Index (HDI) and the Gender Development Index (GDI).

\subsection{Poverty is concentrated in areas with unfavorable conditions for making a living}

A majority of the poor live in areas that have very poor natural resources and harsh natural conditions such as mountainous, remote and isolated areas, or in the Mekong River Delta region and the Central region where sudden weather changes (typhoons, floods, drought) make conditions for living and producing even more difficult. In particular, the underdeveloped infrastructure of poor regions causes the gap between them and other regions in the country to widen. In the year 2000, the status of infrastructure of 1,870 especially disadvantaged communes is as follows: $20-30 \%$ of them do not yet have roads leading to commune centers; $40 \%$ do not yet have enough classrooms; $5 \%$ do not yet have health stations; $55 \%$ do not yet have access to safe water; $40 \%$ of them do not yet have electricity lines to commune centers, $50 \%$ do not yet have enough small-scale irrigation works; and $20 \%$ of them do not yet have markets at the commune or commune cluster level.

In addition, due to unfavorable natural conditions, each year the number of people qualified to receive emergency relief is relatively high, between 1 and 1.5 million. On average, the number of households that fall below the poverty line again each year remains large relative to the number of households that manage to escape from poverty.

\subsection{Poverty is concentrated in rural areas}

Poverty is a widespread phenomenon in rural areas; over $90 \%$ of the poor live in rural areas. In 1999, the food poverty incidence in urban and rural areas was $4.6 \%$ and $15.9 \%$ respectively. Over $80 \%$ of the poor are farmers with low professional and business skills, and too little access to productive resources (capital, knowhow, technology...). They encounter many difficulties in selling their products due to unfavorable geographical conditions, low product quality, and poor product mix. Poor farmers have little access to information and limited possibility for shifting to non-farm employment. Female farmers in remote and isolated areas, especially unmarried female householders, and elderly females, are among the most vulnerable of the poor. The working time of poor women is longer but their income is lower; they have a lesser voice in making decisions in their homes and communities; as a result, they have less opportunity to access the resources and benefits made available through government policies.

Table 1.2: Estimated Magnitude and Incidence of Poverty between Rural and Urban Areas According to the New Poverty Line in 2000 


\begin{tabular}{lccc}
\hline & $\begin{array}{c}\text { Number of } \\
\text { poor } \\
\text { households, } \\
\text { (thousand) }\end{array}$ & $\begin{array}{c}\text { As percentage } \\
\text { of total } \\
\text { households in } \\
\text { the region } \\
\mathbf{( \% )}\end{array}$ & $\begin{array}{c}\text { As percentage } \\
\text { of total poor } \\
\text { households } \\
\text { nationwide } \\
\mathbf{( \% )}\end{array}$ \\
\hline Total & $\mathbf{2 , 8 0 0}$ & $\mathbf{1 7 . 2}$ & $\mathbf{1 0 0}$ \\
Rural & 2,535 & 19.7 & 90.5 \\
Of which: & & & \\
$\quad$ - Rural mountainous areas & 785 & 31.3 & 28.0 \\
$\quad$ - Rural plain areas & 1,750 & 16.9 & 62.5 \\
Urban & 265 & 7.8 & 9.5 \\
\hline
\end{tabular}

(Source: National Program on Poverty Reduction)

\subsection{Poverty in Urban Areas}

Although the poverty rate in urban areas is lower and living standards are higher than the national average, the rate of improvement in living standards is unequal. A majority of the urban poor work in the informal economic sector with unstable jobs and low and unstable incomes.

The transformation of the economic and ownership structure in the state sector has led to labor shedding, making the living conditions of redundant state employees more difficult. These people have been forced to shift to the non-state sector and have had to accept a lower salary or wage level. Those unable to find a job have joined the ranks of the unemployed.

A majority of the urban poor live in areas where the infrastructure is poor and access to basic services (safe water, hygienic and sanitary environment, adequate water drainage, lighting and garbage collection, etc.) is very limited.

The urban poor are vulnerable because of their great dependence on cash income. They usually have no or limited ability to save, and meet with many difficulties in accessing loans to create income-generating employment.

The process of industrialization and urbanization has increased the inflow of unregistered migrants from rural areas, mainly those of working age and children. At present, no statistics on the number of these unregistered migrants are available in reports on urban poverty. These migrants usually find it very difficult to secure permanent registration or registration of long-term temporary residence and, consequently, they encounter many difficulties in getting a stable job with stable income. They have very limited access to social services and must pay more for them because they are not given access to basic public social services (health care, education...) that are enjoyed by registered residents.

In addition, the poverty rate is high among other socially targeted groups such as the unemployed, homeless, and those who fall prey to social evils.

\subsection{Poverty is concentrated in remote, isolated and mountainous areas}

Poverty has marked regional characteristics. The poverty rate is relatively high in the upland, remote and isolated areas and ethnic minority areas. As many as 64 percent of the poor live in the Northern mountainous 
region, North Central region, Central Highlands, and Central coastal region. These areas are characterized by difficult living conditions, geographical isolation, very limited access to productive resources and services, underdeveloped infrastructure, harsh natural conditions and high frequency of natural disasters.

\section{Table 1.3: Estimated Poverty Magnitude and Incidence According to the New Poverty Line (2001-2005) Developed by Regional \\ Poverty Reduction Program in Early 2001}

\begin{tabular}{|l|c|c|c|}
\hline & $\begin{array}{c}\text { Number of } \\
\text { poor } \\
\text { households, } \\
\text { (thousand) }\end{array}$ & $\begin{array}{c}\text { As percentage } \\
\text { of total } \\
\text { households in } \\
\text { the region } \\
\text { (\%) }\end{array}$ & $\begin{array}{c}\text { As percentage } \\
\text { of total poor } \\
\text { households } \\
\text { nationwide } \\
\text { (\%) }\end{array}$ \\
\hline Total & $\mathbf{2 , 8 0 0}$ & $\mathbf{1 7 . 2}$ & $\mathbf{1 0 0}$ \\
Northwest region & 146 & 33.9 & 5.2 \\
Northeast region & 511 & 22.3 & 18.2 \\
Red River Delta & 337 & 9.8 & 12.0 \\
North Central region & 554 & 25.6 & 19.8 \\
Central Coastal region & 389 & 22.4 & 13.9 \\
Central Highlands & 190 & 24.9 & 6.8 \\
Southeast region & 183 & 8.9 & 6.6 \\
\hline Mekong River Delta & 490 & 14.4 & 17.5 \\
\hline
\end{tabular}

(Source: National Program on Poverty Reduction)

\subsection{The poverty rate is extremely high among ethnic minority groups}

In past years, although the Government has actively invested in and supported ethnic minority communities, they continue to experience many difficulties and disadvantages. While accounting for roughly 14 percent of the total national population, the representation of ethnic minority groups among the poor is disproportionately high at approximately 29 percent.

The majority of ethnic minority people live in remote and isolated areas. They are geographically and culturally isolated, and lack favorable conditions for developing infrastructure and basic social services.

\section{Causes of Poverty and Major Factors Contributing to Poverty}

\subsection{Limited and Poor Resources}

Poor people tend to lack many resources and fall into a vicious cycle of poverty and lack of resources. Poor people are likely to remain poor because they are unable to invest in their own human capital. At the same time, limited human capital prevents the poor from escaping from poverty.

Poor households have very little land, and this condition of lacking land tends to perpetuate. This is especially the case in the Mekong River Delta. Their lack of land affects their capacity to ensure food security and prevents them from diversifying their production and shifting to higher value crops. A majority of the poor choose the strategy of self-sufficiency, and stick to traditional modes of production that generate low value, because they lack 
opportunities to employ more profitable production strategies. Because of their pursuit of traditional modes of production, their productivity is low, their products are not competitive and are of low value; this in turn keeps them trapped in a vicious cycle of poverty.

In addition, most of the poor do not have many opportunities to access production enhancing services like agricultural and fishery extension and animal and plant protection from disease. Many production inputs such as electricity, water, crop seeds and animal varieties, fertilizers, etc. drive up their production costs, and cut into their per unit net revenues.

Poor people also have limited access to various sources of credit. Without enough capital, the poor cannot easily renovate production, introduce new technologies and new varieties, etc. Although the access of the poor to credit has improved greatly thanks to the Project on Providing Credit to the Poor under the National Program on Poverty Reduction, a considerable number of poor people, especially very poor people, still have no access to credit. On the one hand, poor people, because they have no collateral, are forced to rely on small and inefficient loans that limit their repayment capacity. On the other hand, most poor people do not have concrete plans for production and may use these loans for purposes other than the one they have committed to with their lenders; this limits their opportunity to access future loans and in the end they become even poorer.

In addition, lack of information, especially information on laws, policies and markets, makes the poor become even poorer.

\subsection{Low levels of educational attainment, insufficient and unstable employment}

Poor people tend to be less educated and have few opportunities to find good and stable jobs. Their level of income is barely enough to meet their minimum nutrition requirements; consequently they cannot afford to improve their education level even though that would enable them to eventually escape from poverty. In addition, their low level of education hurts their ability to make wise decisions about education, child delivery and child rearing, and so on with adverse effects not only on the present generation but also future generations. Child and infant malnutrition have a negative impact on the school enrollment of children from the poorest families, making it even more difficult for the poor to escape from poverty through education.

Statistics on the educational level of the poor show that about 90 percent have reached at most lower secondary level or below. The results of the Living Standards Measurement Survey show that among the poor, the rate of those who have never attended school is 12 percent; the rate of those completing primary education and lower secondary education are 39 percent and 37 percent respectively. The fact that education expenditure is high for the poor, and the quality of education that they are able to access is limited, prevents them from improving their situation in order to overcome poverty. The poverty rate declines as the level of education rises. 80 percent of the poor are involved in agricultural activities that generate very low levels of income. A low level of education prevents the poor from finding better jobs in other sectors, for example in non-farm sectors that provide more remunerative and stable employment.

3.3. The poor are not given sufficient conditions to access the law and their legitimate rights and interests are not protected

Poor people, ethnic minority peoples, and people living under special circumstances tend to have a low level of education and therefore are unable to resolve legal problems on their own. Enforcement mechanisms are complicated for many of the laws and legal documents, making it difficult for the poor to grasp. In addition, the network of legal services is limited and the number of lawyers is small; they are unevenly distributed and mainly found in cities and towns, and fees for legal services remain high.

\subsection{Demography-driven Causes}

Household size is an important "denominator" affecting the average income level of household members. Large numbers of children are both cause and effect of poverty. The birth rate among poor households remains very high. One of the characteristics of poor households is the large number of children. In 1998, the average 
number of children per woman in the poorest quintile was 3.5 compared to 2.1 in the richest quintile. Large household size leads to a high dependency level (the dependency level among the poorest quintile is 0.95 compared to 0.37 among the richest quintile).

One of the causes of the high birth rate among poor households is their poor knowledge of and very limited access to birth control and reproductive health protection measures. The percentage of poor woman using IUDs is low, and so is the percentage of men whose awareness of their responsibility in family planning and in using contraceptive method. Poor husbands and wives tend to know very little about safe sexual practices. They also have a limited understanding of the link between poverty, reproductive health, and population growth.

The high dependency level among poor households also means that labor resources are inadequate; this also contributes to household poverty.

\subsection{Risk of high vulnerability to natural disasters and other risks}

Poor households are highly vulnerable to the daily difficulties and occasional shocks that may strike an individual, a family or a community. Because their income level is very low and unstable, they have low savings capacity and are unlikely to be able to resist unexpected shocks (such as loss of harvest, job loss, natural disaster, loss of labor resources, loss of health, and so on). Given the fragile economic conditions of poor households in rural areas, these shocks will create great instability in their lives.

Production and business risks are also very high for the poor because they have little or no skills and lack business experience. Their ability to respond to and overcome these risks is very weak; their limited sources of income limit their capacity to overcome risks and may even expose them to additional risks.

The number of people who need emergency relief every year due to natural calamities ranges from 1 to 1.2 million. On average, the number of households that fall below the poverty line again is large compared to the number of households that manage to escape from poverty. This is because a very large number of households live just above the poverty line and therefore are highly vulnerable to negative shocks such as natural disasters, job loss, sickness, and so on.

Analysis of the Household Living Standards Measurement Surveys in 1992/93 and 1997/98 indicate that households that suffer from frequent natural disasters are likely to fall into deep poverty. Consequently, efforts to identify effective measures to mitigate the consequences of natural calamities are an important component of poverty reduction.

\subsection{Gender inequality negatively impacts the lives of women and children}

Gender inequality aggravates the condition of the poor in all aspects. In addition to placing an oppressive burden on women and girls, it also has an adverse impact on their families.

Women account for nearly 50 percent of the total agricultural workforce and for a large share of total new jobs created annually in agriculture. However, only 25 percent of the participants in animal breeding extension training courses and 10 percent of the participants in cultivation extension training courses are women.

Women have fewer opportunities to access technology, credit and training, while having to bear the greater burden of housework, having fewer rights in family decision-making and being paid less than men for the same work. Less educated women experience a higher rate of infant and maternal mortality, their families tend to suffer from poorer health and their children have a higher drop-out rate from school.

Gender inequality also contributes to a higher birth rate and a higher HIV transmission rate because women have less power to protect themselves in sexual relations.

\subsection{Disease/morbidity and poor health: another factor pushing people into deep poverty}


Morbidity and poor health directly impacts the income and expenditure of the poor, and traps them in a vicious cycle of poverty. They suffer a double blow: first from the loss of labor income, second from the very high cost (relative to family income and assets), both direct and indirect, of diagnosis and medical treatment. The cost of medical care is a heavy burden for the poor, forcing them to borrow money or to mortgage assets to cover those costs, making their escape from poverty even less likely. Meanwhile, limited capacity to access preventive health care services (clean water, health programs...) increases the exposure of the poor to communicable diseases.

Despite Vietnam's remarkable achievements in health over the past decade, the percentage of the poor who are afflicted with common illnesses is quite high. According to findings from the 1998 Household Living Standards Measurement Survey, the annual average number of sick days of the poorest quintile is 3.1 compared to about 2.4 for the richest quintile. It is noteworthy that during the 1993-1997 period, the sickness status of the richest quintile improved considerably (reduced by 30 percent) while that of the poor remained unchanged. The improvement in the health status of the poor is a key factor that will enable them to escape from poverty on their own.

3.8. The Impact of Macroeconomic Policies and Reform Policies (Trade Liberalization, State-owned enterprises Reform, etc.) on Poverty

High and stable economic growth in the past period has been a major contributor to poverty reduction, allowing Vietnam to record an impressively broad and diverse range of achievements in poverty reduction. Nevertheless, the process of development and opening of the economy has had a negative impact on the poor in certain areas.

Inappropriate investment structure: the share of investment in agriculture and rural areas is still low, and focused on irrigation. The bulk of investment spending has concentrated on key capital-intensive importsubstitution industries, with little attention paid to investments in labour-intensive industries. Small and medium enterprises have not been encouraged in a timely manner; many subsidy policies (subsidized interest rates, price subsidies and subsidies for assorted charges, etc.) have missed their intended targets, with negative effects on markets in rural, isolated and remote areas.

The reform of SOEs and the financial difficulties of SOEs led to the elimination of nearly 800,000 jobs during the early years of reform. Many laid-off workers experienced great difficulties finding new employment and fell into poverty. A high proportion of these are women, people with low levels of educational attainment, and older people.

The policy to reform the economy, create a healthy environment for competition, and liberalize trade has made the economy more dynamic and provided good incentives for enterprises and individuals. At the same time, not enough attention has been paid to labor-intensive industries, nor to small and medium-sized enterprises that can create jobs; they have not been provided with adequate opportunities to develop. Lack of information, obsolete production equipment, low level of competitiveness, and limited production capacity have been important factors that have caused a considerable number of small-and medium-sized enterprises to go bankrupt and to lay off their workers, who are then forced to join the ranks of the poor.

While economic growth broadly contributes to poverty reduction, our ability to improve the status of the poor (in terms of income level, access to development resources) depends on the type of economic growth that takes place. In other words, the distribution of the benefits of growth among different population groups, including income groups, depends on the character of growth. An analysis of changes in the income level of different population groups shows that rich people have benefited more from economic growth, and this has widened the gap between rich and poor.

Transport infrastructure to remote, isolated and poor areas is insufficient and weak. It is still extremely difficult to access to these areas. Investment from the State is still not enough to meet the demand, and contributions from the people, mostly in the form of labour, are limited. 


\section{ACHIEVEMENTS AND CHALLENGES}

\section{Achievements}

1.1. High and stable economic growth has been one of the major factors in reducing the incidence of poverty, of which development of agricultural production and aquaculture and rural economy play an especially important role.

It is estimated that during the mid-1980s, seven out of ten Vietnamese lived in poverty.

After 15 years of renovation and transformation, the economy of Vietnam has seen fundamental changes in social and economic relationships that have led to an unprecedented stage of economic development and poverty reduction after more than four decades of war and difficulties in economic development. In this regard, Vietnam is seen to be an excellent example of a successful transition from a centrally planned to a marketoriented economy. The new economic mechanism has unleashed the inherent dynamism of the economy with impressive results. The economy grew by an annual average rate of about 7.5 percent during the 1991-2000 period. Export turnover has grown rapidly; inflation has been gradually brought under control and the price level has stabilized.

Along with economic growth, Vietnam's significant gains in poverty reduction already have been noted. The Government policy to give priority to agricultural and rural development, and development of remote and isolated areas, succeeded in unlocking the productive capacity of the rural population and has stimulated the people to act on their own behalf and take steps to improve their situation. The resulting achievements in this area, especially in increasing per capita food production, has contributed importantly to poverty reduction, and has helped to improve the income level and living standards of the people.

Using international poverty standards, the overall poverty incidence declined from over $70 \%$ in 1990 to approximately $32 \%$ in the year 2000 (or the percentage of poor households declined by more than half compared to that in 1990). By these measures, Vietnam has achieved the development objective of the Millennium set by the international community, which is to reduce the poverty incidence by half during the 1995-2015 period.

\subsection{Resources for poverty reduction and employment generation have increased}

Despite budget constraints, the State has financed national programs for poverty reduction through a program on infrastructure development in poor communes (Programs 133 and 135). Between 1992, when the program on hunger eradication and poverty reduction was developed, and the year 2000, the State has made a total investment of approximately VND 21,000 billion through national programs directly related to the objective of hunger elimination and poverty reduction. The figure for the two years 1999 and 2000 alone was nearly VND 9,600 billion (of which VND 3,000 billion came from the State budget; over VND 800 billion from joint financing with other programs and projects; more than VND300 billion were mobilized from the community; and over VND 5,500 billion came from concessional credits to poor households).

The Bank for the Poor was established to provide concessional credit to the poor. The amount of funds mobilized from the population, domestic organizations and individuals has also increased considerably.

The total amount of funds lent to the poor reached VND 5,500 billion. In addition, the State provided considerable support to ethnic minority people living in especially disadvantaged areas. This includes a total grant of VND 70 billion and zero interest rate loans provided to nearly 90,000 households for production purposes.

The State has also given attention to investing in and providing financial support to fixed cultivation and fixed settlement and relocating people to new economic zones. In recent years, more than VND 500 billion of the central budget has been earmarked to support the settlement of households who practiced fixed cultivation and fixed settlement and moved to new economic zones. 
Over the past years, Vietnam's poverty reduction campaign has received support from many nations, international organizations and non-governmental organizations through various means (experience sharing, technical assistance, funds) under the framework of grant aid and concessional credit. This is a very important factor contributing to faster progress in eradicating hunger and alleviating poverty.

\subsection{The percentage of communes with inadequate or nonexistent basic infrastructure has declined}

During 1999 and 2000, the Government invested in the development of 6,500 infrastructure projects in poor communes (during which funds from the State budget was directly transferred to 1,200 communes in 1999 and 1,870 communes in 2000). The local budget was used to finance infrastructure development in 650 other poor communes. On average, 2.5 projects were developed per commune. In addition, more than 17 million workdays were mobilized from the local population to contribute to infrastructure development projects, and cash and in-kind contributions from the population valued at tens of billion dongs were mobilized. As of April 2001 , over 5,000 projects were completed and put into operation.

\subsection{The capacity of poverty reduction workers has been improved}

As of the end of 2000, on-site specialized poverty reduction workers have been made available to 1,798 communes from 22 provinces and cities. These are core staff, equipped with basic knowledge and qualified to instruct people to implement poverty reduction programs in their specific areas, thus contributing to the attainment of hunger eradication and poverty reduction objectives.

1.5. The Government has adopted many mechanisms and policies to create jobs and opportunities to allow people to take the initiative in finding jobs or to be self-employed with help from the State and the community

The National Employment Generation Program has been implemented with many good results. Employment promotion centers and vocational training, career advising, and training centers established by different sectors and levels and mass associations have been in active operation. Broad-based support for poverty reduction policies has come from diverse sectors, population strata, mass associations, social organizations and the working people themselves. A broad range of activities have been undertaken to help poor households overcome their difficulties and develop their capacity to gradually improve their situation to escape from poverty and stabilize their lives.

Agriculture and the rural sector has been the main absorber of labor. On average, employment has been created for 1.2 to 1.3 million people per annum. The private, collective and co-operative economic sectors absorb about 90 percent of these new entrants into the labor force. Under considerably difficult economic conditions, and even during the years of slower economic growth, Vietnam adopted stronger social protection policies, especially with respect to poverty reduction, employment creation, education and training, public health care, and care for disabled and homeless children, including policies to stabilize the lives of people in targeted groups.

\subsection{There has been a marked improvement in living standards in many regions}

Poverty reduction is clearly observed in both rural and urban areas, among both Kinh and ethnic minority people, especially in the periphery of cities and towns, and areas endowed with favorable natural conditions such as fertile land. Per capita consumption in current prices increased from VND 2.6 million in 1995 to VND 4.3 million in the year 2000 .

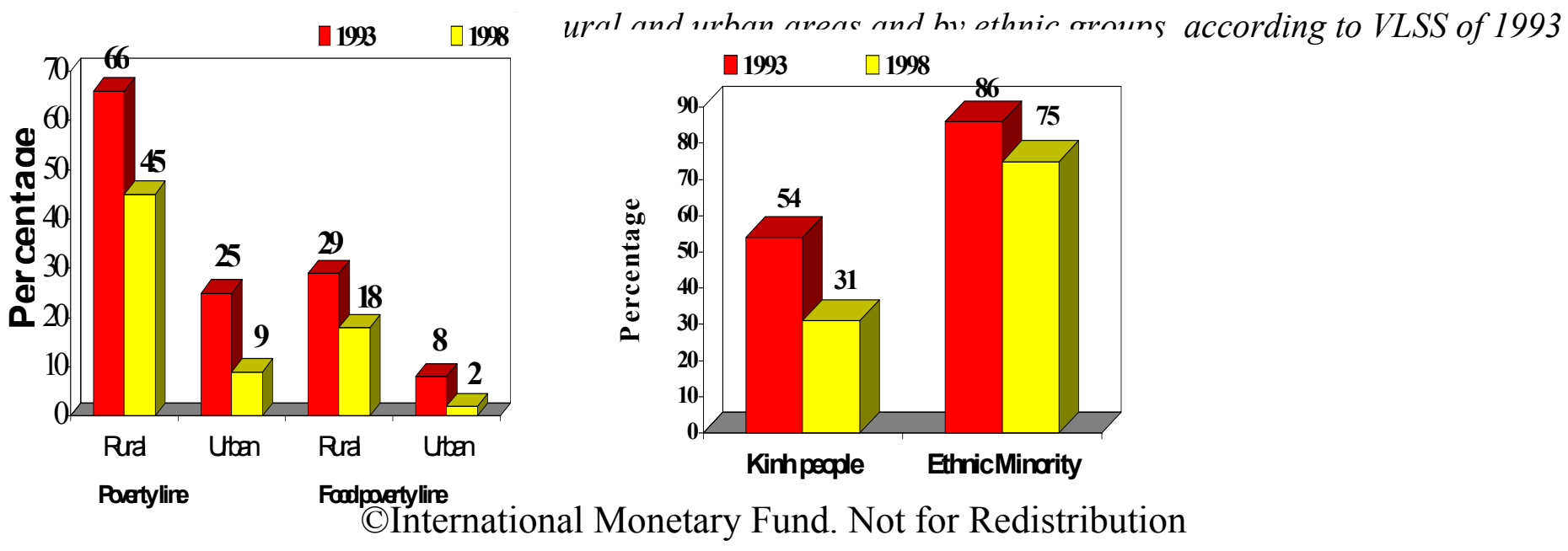




\section{Causes of Success and Lessons Learned}

2.1. Continuous and stable economic growth and development, especially agricultural and rural development - to which investment priority is given by the State (irrigation, transformation of economic structure, introduction of scientific and technical advances to production, etc.) - combined with agricultural and rural reform policies, especially with regard to the transfer of land use right to the people, has created a new dynamism and resources that allow broad-based hunger eradication and poverty reduction to take place. Consequently, the living standards of the rural population, where most of the poor live, have improved markedly.

Rapid and stable economic growth is the precondition for rapid and comprehensive poverty reduction. However, sustainable poverty reduction can only be achieved if conditions for the poor to benefit from the fruits of development are provided.

2.2. Poverty reduction programs have received close guidance from various levels of Party committees, the government and mass organizations, from central to local, and have been actively implemented. They have received sympathy and support from the people. Those programs have been concretized into specific policies, mechanisms, projects and annual plans so as to concentrate efforts on agricultural and rural development, establish irrigation works to serve livelihood and production needs, support the structural transformation of the economy and of crops and livestock, ensure food security, etc. This has helped the poor to properly assess their poverty situation and its causes in order to develop their own capacities to escape from poverty, and to take advantage of available opportunities for poverty reduction and make effective use of support from the Government and community.

A lesson drawn from these poverty reduction programs is that all national levels, sectors and mass organizations, from central to the grassroots level, and the people, must have a clear perception of their responsibility for poverty reduction in order to effectively join forces to reduce poverty; at the same time, the poor have started to have a correct understanding of the problem and to see the need to take the initiative themselves to improve their situation; consequently they will be motivated to develop their own capacities in order to escape from poverty.

2.3. The set of policies, mechanisms and measures for poverty reduction has begun to be implemented and the impact of this is starting to be felt in the lives of the poor. It includes: the provision of concessional credit, guidance in how to make a living, health care and education support, support for ethnic minorities in especially disadvantaged areas, investment support for infrastructure development, support for sedentarization, fixed settlement and relocating people to new economic zones, legal support, etc. This has created a favorable legal foundation for poverty reduction, and increased investment in physical infrastructure to enable poor communes to develop and expand production and improve their living standards, especially poor communes in mountainous, border, island, remote, isolated and ethnic minority areas.

Poverty reduction objectives should be consistent and visionary: the goal should be to not only improve the living standards of the people, but also to create opportunities and the legal foundations to raise the social intelligence of the poor and to strengthen their awareness of the law in order to enable their participation in the economic, political and social life of the nation. State policies and mechanisms should not only focus on combating poverty but also on poverty prevention.

Strategies to address poverty must be multi-dimensional and targeted to the needs of a diverse population. Policies and mechanisms should be flexible enough to respond to particular conditions in each area and locality. To effectively implement those policies and mechanisms, close coordination among different sectors and levels, and the launching of a strong and far-reaching nationwide drive for poverty reduction, are needed.

2.4. A system of organizations and cadres has been established in different provinces and cities, and is beginning to work well in some localities. The contingent of young volunteers, provincial and district officers 
sent as supplementary staff to poor communes on a time-bound basis (about 2,000 people in 1999 and 2000) have been active in helping those communes develop poverty reduction plans and projects and in organizing the implementation of poverty reduction programs in these localities.

Many effective poverty reduction models at the household, village, commune and district level have been established and widely replicated. These include women's savings - credit models, self-help poverty reduction models, poverty reduction models for ethnic minorities, combined community development and poverty reduction models, and models linking the activities of general corporation state-owned enterprises with poverty reduction objectives.

2.5. Diversification of resources mobilized for poverty reduction. First, local resources are brought into full play; resources from the community (general corporations, localities with good sources of revenue, various population strata, etc.) are mobilized in combination with State investment support; expand to include international cooperation in the form of experience sharing, technical assistance and financial support.

\section{Challenges}

While acknowledging the above-mentioned achievements on poverty reduction in recent years, many new difficulties and challenges confront us.

3.1. The incidence of poverty remains high. Using the new poverty standards, although lower than those of other countries in the region, there are still about 2.8 million poor households, accounting for 17 percent of households in Vietnam, in early 2001. A majority of these households experience great difficulties in reducing poverty.

Poverty is not evenly distributed throughout Vietnam. A relatively high poverty incidence is found in mountainous, remote, isolated, island and disaster-prone and ethnic minority areas. Progress has been slow in improving infrastructure in poor communes. A majority of the poor have no access to basic social services.

3.2. The process of opening up the economy and integrating with the global economy creates many difficulties and challenges for Vietnam. The economy of Vietnam must deal with fierce competition in international markets while the quality of its development is low, productivity is still not high, and its ability to compete is weak. Moreover, the price of agricultural products is unstable and appears to have a downward trend.

3.3. Poverty reduction objectives should further broaden in substance and encompass qualitative changes; they should include not only food sufficiency, but also the satisfaction of other needs such as clothing, shelter that is not dilapidated, treatment when sick, and schooling for children, etc. To meet this requirement, in addition to ensuring food sufficiency, supporting commodities production and infrastructure development in poor communes, favorable conditions should be created for the poor to access basic social services, improve their social intelligence, and be provided with legal support, while mechanisms for protecting the interests of the poor should be made available, and grassroots democracy should be practiced, in order to minimize the risks that the poor are exposed to.

3.4. The widening income and living standards gap between urban and rural areas, between mountainous and plain areas, among different population strata, and between rich and poor regions in the country, is on a rising trend. The gap also is increasing within the same region/area, especially in urban areas where urban poverty is spreading and has become severe. Moreover, poor areas are low-income areas; thus, policies to attract foreign and domestic investment to rural areas in general, and to poor areas in particular, are needed.

Poor people still encounter many difficulties in accessing basic social services. That all citizens can access services and benefit from economic growth and share the fruits of development on an equal and impartial basis remains a fragile possibility. 
3.5. Poverty reduction gains may not be sustainable; the risk of falling back into poverty remains high. Poor people remain highly vulnerable to risks and unexpected shocks (such as sickness, natural disasters, harvest losses, market fluctuations, environmental pollution, loss of the family breadwinner, unemployment, and so on). The social safety net has not been extended to rural, remote, and isolated areas. In particular, the fact that our country is situated in a natural disaster - prone area and that 80 percent of the poor work in the agricultural sector increases the risk that people will fall back into poverty. That a very large number of households live barely above the poverty line and have unstable incomes also increases the risk that they will fall back into poverty.

In addition, poverty is closely related to environmental degradation. Poverty can lead to overexploitation by farmers of already limited natural resources and consequently can make poverty more severe.

Mountainous, remote, isolated areas are often threatened by natural disaster. Indeed, a severe natural disaster can jeopardize the flow of services from infrastructure works. Moreover, those areas are negatively affected by backward customs and practices, social evils, such as drug trafficking, haphazard exploitation of mineral resources, migration, etc.

Figure 1.2: Poverty reduction gains remain fragile

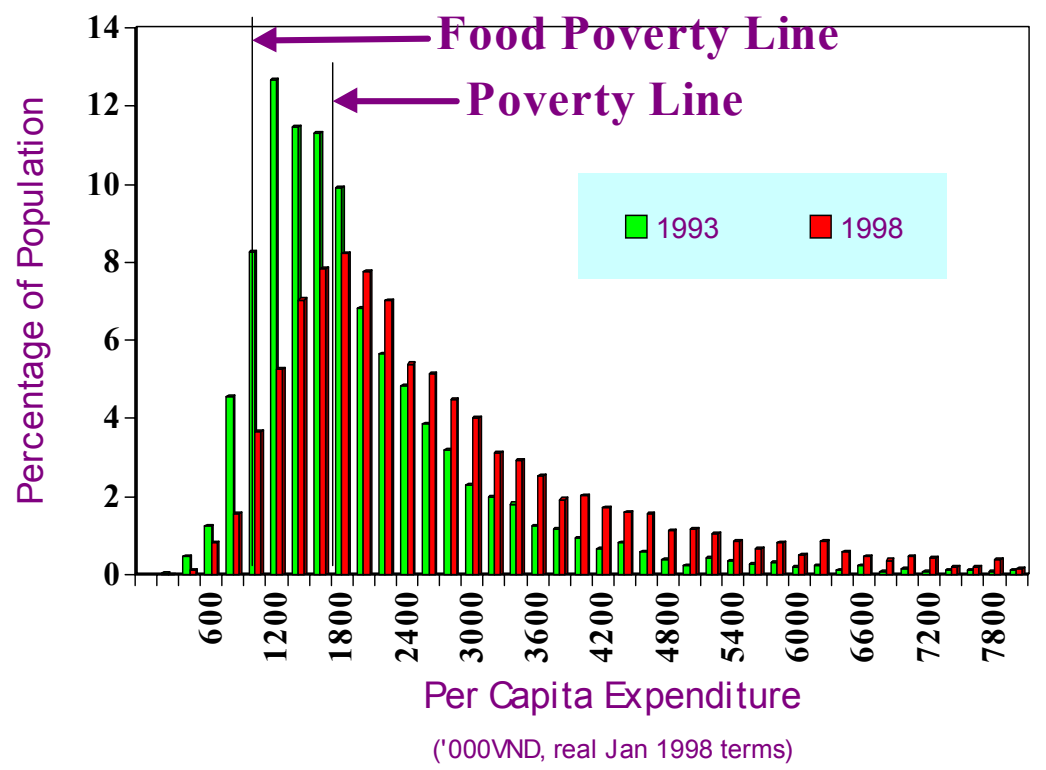

3.6. Domestic resources remain extremely limited; substantial investment is needed both for the overall development of the country and for poverty reduction. At the same time, resource mobilization has been limited and inefficient. The orientation of certain investments is in the process of being readjusted, the capacity for reinvestment is inconsequential, and the banking and financial system is inefficient. Furthermore, the financial market is in an embryonic stage so that its capacity to mobilize investment capital is still weak. Although resources for poverty reduction programs have been increasing over time, they are still not enough to meet the needs of poor localities. At present, the focal areas for poverty reduction are upland and isolated regions, which experience great difficulties and suffer from inadequate and obsolete infrastructure. These problems and the higher investment costs make it difficult for these areas to attract private sector investment. This presents a very great challenge to the task of poverty reduction in the coming period.

3.7. Redundant workers are numerous. The proportion of trained workers in the labor force is low. The continued high rate of population and labor force growth, while Vietnam's ability to create new jobs and increase labor productivity remains limited, intensifies pressure to solve the employment problem. The number 
of unemployed and underemployed people in the country remains large. The underemployment rate in rural areas is high, about 26 percent (the rate of working time utilization is low, just a little above 74 percent). In urban areas, there appears to be a trend rise in the unemployment rate, especially in big cities (about 6,4 percent) due to the adverse impacts of migration, loss of land for production purposes, urbanization, etc.

Continuation and intensification of the process of reforming the economy and state-owned enterprises and trade liberalization on a larger and wider scale is expected to unleash new sources of economic dynamism that should generate additional resources for poverty reduction. However, if the poor are not given opportunities or are unable to participate in this process, unemployment will increase and so will poverty. The renovation and reorganization of state-owned enterprises in the 2001-2010 period will lead to the shedding of tens of thousands of workers who will then need new jobs.

3.8. Although poverty reduction and pro-poor policies and mechanisms are being implemented, they are still not sufficient, well-integrated, clear and transparent in some areas and localities, and are inappropriate to the particular conditions of each region and each group of poor people; consequently, their actual implementation is less effective and their impact on poor communities is still not strong enough. There are many weaknesses in the organizational arrangements for and implementation of poverty reduction policies. Among the changes in economic relations, shifts in the terms of trade between agricultural and industrial products directly affects the income of farmers, especially low-income farmers. Although poverty reduction programs and the program on socio-economic development in especially disadvantaged communes, etc. have been effectively implemented in certain localities, the benefits of these programs have not been widespread because of the lack of appropriate supervision mechanisms.

3.9. Policies on gender equality are adequate but not strictly implemented. Poor women and young girls in remote and isolated areas and ethnic minority women benefit less from those policies. They are negatively affected by backward beliefs, customs and practices. In many areas, they are victims of female trafficking and family violence. The socialization of education and health increases the burden on poor families, and especially women. 


\section{PART II \\ Objectives and tasks of Socio-economic \\ Development and Poverty Reduction \\ For the Period up to 2005 and 2010}

\section{OVERALL OBJECTIVES AND TASKS OF SOCIO-ECONOMIC DEVELOPMENT AND POVERTY REDUCTION}

\section{Overall Objectives}

\subsection{Overall Objectives of Socio-Economic Development for the 2001-2010 Period}

To bring Vietnam out of the state of underdevelopment, significantly improve the people's material, cultural and spiritual life; and lay the foundations for transforming the country into a modern industrialized country by 2020. To enhance our human resources, scientific and technological capacity, infrastructure, and economic, defense, and security potential; to establish the institutions of a socialist-oriented market economy; to advance Vietnam's position in the international arena ${ }^{(6)}$.

\subsection{Overall Objectives of the Five-Year 2001-2005 Plan}

Achieve rapid and sustainable economic growth. Stabilize and improve the living standards of the people. Transform the structure of the economy and labor force to increase the productivity of the economy. Improve significantly the efficiency and competitiveness of the economy. Broaden the country's international economic relations. Create fundamental changes in education and training, science and technology, and bring into full play our human resources. Create many jobs; basically eliminate hunger and reduce the number of poor households, reduce social problems. Continue to strengthen our social and economic infrastructure. Achieve significant progress in establishing the institutions of a socialist-oriented market economy. Maintain political stability, social order and security; protect the nation's independence, national sovereignty, territorial integrity, and national security.

\section{Specific Tasks of Socio-Economic Development}

2.1. Strive for a higher economic growth rate than that of the past five years; lay the groundwork for growth in the next five years.

2.2. Continue to transform the structure of the economy and the structure of production in the direction of bringing into full play the country's comparative advantage, especially in agricultural, fishery and industry production and in the services sector; vigorously push up exports; meet the demand for domestic production and consumption on the basis of high quality and strong competitiveness.

2.3. Rapidly increase and improve the efficiency of capital for socio-economic development investment. Mobilize fully domestic resources for investment development, especially resources from the people. Encourage investment from the population, stimulate sensible consumption spending, and mobilize to the maximum level possible domestic savings for development investment. Continue to implement the policy to stimulate investment and consumption demand.

Improve the basic infrastructure system. Develop an integrated and sustainable national transport network and establish a transport infrastructure system that is at the right level to support the nation's industrialization, modernization, and international economic integration. Invest adequately in focal economic areas and provide more investment to disadvantaged areas.

\footnotetext{
${ }^{(6)}$ For more details, see the Ten -Year Socio-Economic Development Strategy (2001-2010) - National Political Publishing House, Hanoi 2001.
} 
2.4. Broaden and increase the efficiency of external economic relations. Firm up existing markets and expand into new markets. Take necessary and coordinated measures to rapidly increase total exports. Create stable markets for agricultural and industrial products that have competitive potential. Speed up the search for new markets for new export products; improve the quality and prestige of export products.

2.5. Continue to renovate and safeguard the healthy operation of our financial and monetary system, and strengthen the potential and capacity of national finance. Promote the propensity to save; increase the share of spending on development investment in the state budget; expand the capital market to meet the requirements of socio-economic development.

Continue to restructure the state budget, reform the commercial banking system; vigorously push the restructuring, renovation, development and improvement of the efficiency of SOEs to meet the need to transform the structure of the economy and to achieve sustainable development.

2.6. Renovate and create fundamental and comprehensive changes in the development of education and training and science and technology; improve the quality of human resources with appropriate structures; achieve universalization of lower secondary education; rapidly apply advanced modern technologies; gradually develop the knowledge-based economy; reduce environmental pollution and improve the efficiency of environmental protection.

2.7. Effectively address pressing social problems arising from the process of urbanization and industrialization, create jobs and reduce unemployment in urban areas as well as underemployment in rural areas; develop integrated and coordinated policies and guidance that is appropriate to specific regional circumstances to eradicate hunger and rapidly reduce the number of poor households; resolve social problems; ensure sustainable development. Vigorously develop culture, communications, health care and sports; raise the material and spiritual living standards of the people; meet part of the people's requirement for curative medicines; reduce the child malnutrition rate; and increase the percentage of rural people having access to clean water. Reduce social ills such as: HIV/AIDS, drug addiction, and traffic accidents.

Promote gender equality, integrating it into various development policies, programs and projects. Ensure that necessary resources are given to ministries, agencies and provinces to construct and implement policies and programs that support gender equality.

2.8. Accelerate the reform of public administration in four areas: administrative institutions, organization of the administrative apparatus, developing the contingent of civil servants; and public finance reform with the aim of enhancing the efficiency and transparency of state policies and service delivery instruments; promote the application of information technology to improve services, and ensure an open, transparent and stable relationship between the State, citizens, and enterprises. Minimize bureaucracy, push back corruption and implement participatory and democratic governance at all levels, especially at the grassroots level.

Ensure order and respect for the law in all social and economic activities and implement the grass-roots democracy, strengthen the people's supervision over public services, administrative activities, and public financial resources...

\section{MAJOR SOCIO-ECONOMIC DEVELOPMENT AND POVERTY REDUCTION TARGETS FOR THE PERIOD UP TO 2005 AND 2010}

Based on the Ten-Year Socio-economic Development Strategy for the 2001-2010 period, sectoral and industrial development strategies and the Five-Year Socio-economic Development Plan for the 2001-2005 period, and taking into consideration the Millennium Development Goals (MDGs) set by the United Nations, the Government of Vietnam has identified socio-economic development and poverty reduction targets for the period up to 2005 and 2010 as follows:

\section{Economic Targets}


1.1. GDP in 2005 is double that in 1995 and GDP in 2010 is at least double that in 2000, of which the value added of agriculture, forestry and fishery grows at 4.0-4.5\% on average during the 2001-2010 period, and 4\% during the five-year 2001-2005 period; industry and construction at 10.0-10.5\% on average during the 20012010 period, $10.4 \%$ during the five-year $2001-2005$ period; services at $7.0-8.0 \%$ on average during the 2001 2010 period, $6.8 \%$ during the five-year 2001-2005 period.

1.2. Ensure the ratio of domestic saving rises over $30 \%$ of GDP, mobilize VND 840 thousand billion (US\$60 billion) to finance development investment for the period 2001-2005.

1.3. The share of agriculture in GDP is $20-21 \%$ in 2005 and $16-17 \%$ in 2010 ; industry is $38-39 \%$ in 2005 and $40-41 \%$ in 2010; and services is $41-42 \%$ and $42-43 \%$ respectively.

1.4. The share of industrial labor in total labor force rises to $20-21 \%$ in 2005 and $23-24 \%$ in 2010 . The share of labor in agriculture, forestry and fishery decreases to $56-57 \%$ in 2005 and $50 \%$ in 2010 . The share of labor in services rises to $22-23 \%$ in 2005 and $26-27 \%$ in 2010.

\section{Social and Poverty Reduction Targets}

\subsection{Reduce the percentage of poor households}

Reduce the international standards-based ${ }^{(7)}$ poverty incidence by two fifths by 2010 and the food poverty incidence by three fourths by 2010 relative to the year 2000 .

Reduce the proportion of poor households by two fifths by 2005 and by three fifths by 2010 relative to the year 2000 (based on the criteria of the National Targeted Poverty Reduction and Employment Generation Program).

2.2. Ensure the provision of basic infrastructure facilities to poor people, poor communities and poor communes

Continue to reform, upgrade and expand existing basic infrastructure facilities and develop new ones (small irrigation schemes, schools, commune health clinics, rural roads, electricity for lighting, clean water, markets, commune cultural and postal offices, meeting rooms, etc.) to ensure that $80 \%$ of poor communes are provided with adequate essential infrastructure by 2005 and $100 \%$ by 2010 ;

Expand the national transmission grid to reach centers of 900 poor communes by 2005 and ensure that $90 \%$ of communes are provided with electricity.

Ensure that roads to commune centers are accessible by car. Strive to ensure that $80 \%$ of commune roads have the appropriate road surface structure, of which $30 \%$ should be paved with asphalt or cement.

Ensure that by $2005,80 \%$ of the urban population, especially those living far from major transport roads, and $60 \%$ of the rural population, have access to clean water with an average daily supply of 50 liters per person, and that $50 \%$ of households have toilets that meet basic sanitation standards. Attach importance to ensuring that nursery schools, kindergartens, schools, health clinics in rural areas have clean water facilities and hygienic sanitation. Ensure that by $2010,85 \%$ of the rural population have access to clean water with an average daily supply of 60 liters per person and $75 \%$ of households have toilets that meet basic sanitation standards. Pay special attention to enabling poor households to access clean water supply facilities, especially households located far from commune centers and main roads.

\subsection{Job Creation}

Provide new jobs for approximately 1.4-1.5 million people per annum on average; Increase the proportion of women hired in newly created jobs to $40 \%$ by 2005 and $50 \%$ by 2010 .

\footnotetext{
(7) The definition is described in Section I.1.2
} 
Increase the proportion of trained workers in the total workforce to $30 \%$ by 2005 and $40 \%$ by 2010 ; increase the rate of rural working time utilization to $80 \%$ by 2005 and $85 \%$ by 2010 , of which the rate of working time utilization for women is $75 \%$ by 2005 and $80 \%$ by 2010 .

Reduce the proportion of urban unemployed people in the total number of people of working age to about $5.4 \%$ by 2005 and to under $5 \%$ by 2010 .

\subsection{Universalizing Education and Improving the Quality of Education}

Consolidate, maintain and bring to fruition the gains from universalizing primary education and eliminating illiteracy, especially in mountainous provinces and in remote and isolated areas; implement universalization of lower secondary education nationwide. Increase the rate of children under 3 years old attending nursery school from $12 \%$ in 2000 to $15 \%$ in 2005 and $18 \%$ in 2010 . Increase the rate of 3 to 5 year old children attending kindergarten from 50\% in 2000 to $58 \%$ in 2005 and $67 \%$ in 2010 .

Increase the rate of children going to schools at the appropriate age to $97 \%$ by 2005 and $99 \%$ by 2010 . Increase the rate of pupils completing the primary education program to $85-95 \%$ by 2010 .

Implement lower secondary education universalization in cities, towns and other areas by 2005 and in the whole country by 2010 . Increase the rate of age appropriate lower secondary school enrollment to $80 \%$ by 2005 and $90 \%$ by 2010 .

Increase the rate of children going to upper secondary schools at the appropriate age to $45 \%$ by 2005 and $50 \%$ by 2010 .

Ensure that by 2010, most primary and secondary schools will meet basic conditions to offer two daytime sessions when pupils can "study through play, play through study".

Eliminate illiteracy for $95 \%$ of illiterate women under 40 years old by 2005 and $100 \%$ by 2010 .

Increase the net enrollment rate of pupils in vocational schools to $10 \%$ in $2005,15 \%$ in 2010 ; increase the net enrollment rate of secondary school graduates in skills training schools from $6 \%$ in 2000 to $10 \%$ in 2005 and $15 \%$ in 2010 .

Improve the quality of education at all levels and for all, especially for the poor.

\subsection{Reduce the Birth Rate, the Child Mortality Rate and the Child Malnutrition Rate}

Maintain the trend reduction in the birth rate in order to reach the average replacement rate in the whole country by 2005 at the latest and in remote and poor areas by 2010 at the latest.

Reduce the mortality rate of children under 1 to $30 \%$ by 2005 and to $25 \%$ by 2010 and that of children under 5 to $36 \%$ and $32 \%$ by 2005 and 2010 respectively.

Reduce the malnutrition rate of children under 5 to less than $25 \%$ by 2005 and to less than $20 \%$ by 2010 .

Reduce the rate of children of low birth weight (less than 2,500 grams) to 7\% by 2005 and to 5\% by 2010 .

\subsection{Reproductive health, epidemics, HIV/AIDS and other social diseases}

Reduce the maternal mortality rate to $80 / 100,000$ live births by 2005 and to 70/100,000 live births in the whole country by 2010 (the rate for mountainous areas is 100/100,000). Improve post-delivery health status of mothers.

Maintain the achievement of polio eradication; reduce to the minimum the morbidity and mortality rates for cholera, typhoid, petechial fever, malaria, and plague...

Hold down the rate of HIV/AIDS transmission and minimize the effects of HIV/AIDS. Take preventive measures to minimize the number of children infected by HIV/AIDS. By 2005, slow down the growth rate of 
HIV/AIDS transmission and halve this rate by 2010. Control and move towards eliminating social diseases. Prevent and struggle against accidents, traumas and the harmful effects of cigarettes.

\subsection{Develop culture and information and elevate the spiritual life of the people}

By 2005 , strive to raise the proportion of "cultured families" to $80 \% ; 50 \%$ of villages and urban neighborhoods will be up to "national culture" standards; $78 \%$ of all communes will have a cultural center, and on average each person will have four new books a year.

Continue to improve the system to broadcast radio and television nationwide, ensuring that $95 \%$ of all households can hear the Voice of Vietnam and over $90 \%$ can see Vietnam Television programs by 2005, and universalize basic mass communication equipment to reach each household by 2010.

Increase the amount of programming and broadcasting hours in the languages of ethnic minority peoples.

\subsection{Improve the cultural life and preserve the culture of ethnic minority peoples}

Raise the social consciousness, preserve and bring into play the traditional cultural values of ethnic minority peoples. Sustain and develop the reading and writing ability of ethnic languages in areas with high ethnic populations. Provide access to kindergarten education to every child from ethnic minority groups and opportunities for children from ethnic minority groups to complete the primary education program partly in Vietnamese and partly in their own language by 2010. Provide support to ethnic minority people to increase their representation in the total staff of public agencies. Increase the proportion of trained staff, workers and public servants who are from ethnic minorities in the total staff of public agencies.

Ensure the entitlement of individual and collective land use rights to ethnic minorities and mountainous people; prevent buying and selling agricultural land that belongs to ethnic minorities. Localities are required to have a land and house fund to use for children's playing and entertainment areas.

Continue to consolidate and expand health care, culture, information and related activities to reach ethnic minority peoples. By 2010, each village or hamlet in upland, remote and isolated areas should have a "community house" for meeting and playing.

\subsection{Ensure a sustainable environment}

Focus on addressing the problems of environmental degradation and preserve natural resources; ensure that by 2010 there are no slums in cities and no temporary houses in rural areas, especially in the Mekong River Delta.

Strive to ensure that by 2010 waste water will be treated and solid waste matter and waste from toilets will be collected at $100 \%$ of the industrial zones, cities, towns and rural craft villages; plan to fix environmental damage to rivers, lakes, ponds, canals, etc.

Raise the quality of forest protection work, forestation, reclamation of barren land and hills; and increase forest coverage from the current level of 33\% of total country area to $38 \%$ by 2005 and to $43 \%$ by 2010 .

Manage and sustainably use natural and energy resources; and minimize raw materials and waste in production.

2.10. Reduce the vulnerability of the poor and disadvantaged groups and strengthen the social safety net to support them

Ameliorate significantly the income of the poor, especially of households headed by women; improve the quality and access of the poor to basic social and production services as well as other resources, especially for poor women.

Ensure that by 2010 households in urban areas are granted land use right certificates and certificates on the right to own their houses situated on a legal land area. 
Expand the formal social safety net to all people. Reform social insurance policies and mechanisms. Encourage household and community participation in various forms of voluntary insurance.

Improve the access of poor workers and disadvantaged groups to the labor market, and especially improve their access to job training. Increase the quality and quantity of employment. Assure job security.

Strengthen child and juvenile security; resolve the problem of child labor, homeless children, children in special circumstances, and especially children from households headed by women. Protect people living under special circumstances (disabled people, people affected by dioxin, the dependent elderly who live alone, people targeted by policy and other groups of people). Take care of and provide treatment to HIV/AIDS infected patients, drug addicts, etc.

Develop strategies to prevent and alleviate natural disaster. Halve the number of people falling back into poverty due to calamities and other risks by 2010 .

\subsection{Gender equality, empowering women and ensuring children's rights}

Improve the quality of women's spiritual and material lives; improve their professional skills. Create conditions for women to participate in and benefit fully and equally in all aspects of life: political, economic, cultural and social. Increase the participation of women in agencies, sectors and enterprises at all levels by more than $3-5 \%$ in the next 10 years.

Ensure the rights of women to benefit from household assets by allowing them to register as co-owner of assets (same as for their husbands); ensure that the names of both husband and wife appear on land use right certificates before 2005 .

Encourage the building of cultured families based on enhancing the role of women as an authority figure in the family; adopt necessary measures to help women alleviate their burden in domestic work (preparation of food/meals for families, transport, child care, etc.). Reduce violence against women and female children in the family as well as in society.

Create favorable conditions to implement policies on child care and child protection, enforce the rights of children to ensure that they are able to live in a safe and healthy environment, to develop their physical strength, intellect and ethics, and to ensure that orphans and disabled children who live in difficult circumstances are provided with opportunities to study and play.

\subsection{Accelerate public administration reform, provide the poor with knowledge of the law}

Increase the efficiency of the State management; implement the overall public administration reform program for the 2001-2010 period.

Continue to improve the institutions and polices that affect poor people; and improve the targeting of the poor and improve the allocation of resources for pro-poor programs

Improve the access of poor people to a transparent, accountable and participatory government; ensure that all citizens, especially poor women, have better access to the judicial system and information about the law.

Complete the development of reform strategies regarding the public sector, jurisdiction and financial management in order to provide better support to the poor. Develop a master plan for public administration reform and ensure that it is thoroughly implemented in urban areas in 2010.

Minimize bureaucracy and drive back corruption; practice a democratic and participatory state management. Implement effectively the Decree on Grassroots Democracy.

Expand legal support for the poor, consolidate and continue to diversify forms of support, improve the flexibility and efficiency of the forms of support, and create favorable conditions for the poor to have easy access to free legal services. 


\section{THE RELATIONSHIP BETWEEN GROWTH AND POVERTY REDUCTION}

\section{Poverty reduction serves as a fundamental factor for ensuring social equality and sustainable growth}

Poverty reduction is not only a mission confronting us today but also in the long term. Our initial task is hunger elimination and poverty reduction; our long-term mission is to reduce the gap between rich and poor, and to build a prosperous, strong, just, democratic and civilized society.

Poverty reduction is not simply about a passive redistribution of income, but about creating a growth dynamic - a process that enables the poor to take initiative in improving their situation in order to overcome poverty. At the same time, poverty reduction is not just a one-way path with resources from economic growth providing support to disadvantaged people, but is itself an important factor that creates the groundwork for a relatively level playing field for development, to generate abundant resources, and to ensure stability during the period of economic "take-off".

Thus poverty reduction is one of the objectives of growth (from the economic and social point of view); at the same time, it is a precondition for rapid and sustainable growth. The considerable amount of social resources allocated to poverty reduction may be seen in the short run as a diversion of resources away from growth, but from the long run big picture perspective, poverty reduction is the foundation for generating even more resources for economic growth. The situationis analogous to "land to the tiller" programs in many countries that produced giant strides in agriculture. It enabled many farmers to escape from poverty and gave them opportunities to carry out the "green revolution" which created new factors for agricultural development

2. Progress in poverty reduction must rest on broad-based, high quality and sustainable economic growth and must create favorable conditions for poor people and poor communities to access opportunities to develop and expand their production and businesses, and to enjoy the fruits of growth.

High quality growth enables a rapid reduction of the poverty rate. Our own recent experience shows that high economic growth rates made it possible for the State to generate the material resources for developing and implementing programs to provide financial and material support to disadvantaged communes to develop their basic socio-economic infrastructure. As a result, poor people and poor communes were provided with opportunities to develop their capacity to escape from poverty. Economic growth is an important condition for eliminating widespread poverty. Without economic growth, traditional poverty reduction methods such as redistribution programs, would be less effective.

Broad-based, high quality and sustainable economic growth, focusing first on structural transformation, diversification of agricultural production, and the development of professions and trades, creates more opportunities for small and medium enterprises to develop and to generate the non-farm employment needed to raise the income of the poor, etc.

3. Poverty reduction is structured as a component of the Ten-Year Socio-Economic Development Strategy and Five-Year and Annual Socio-Economic Development Plans from the central to the grassroots level.

Attention must be given to poverty reduction right when the orientation of the long-term, medium-term and annual socio-economic development plans is being developed; poverty reduction should be seen as one of the central tasks of the Government's socio-economic development plans. Through these plans, the State takes the initiative in adjusting properly diverse resources available from society for national poverty reduction objectives and activities. The State is responsible for developing basic measures such as provision of investment to support production, development of infrastructure, establishment of social relief funds, and so on, to help and protect the 
poor. A market-oriented exchange and distribution mechanism should be maintained while ensuring that the poor are not excluded from accessing resources and benefiting from the nation's economic prosperity. International experience shows that the absence of the State's role in this undertaking would be especially harmful to poor people and poor communities, because the poor cannot safeguard their rights on their own; moreover, the common fruits of economic growth are closely related to the core role of the State, which is responsible for attracting the active participation of the community, and of political, economic and social organizations.

\section{Poverty reduction is not only the task of the Government and the whole society, but it is first and} foremost the responsibility the poor themselves to develop the capacity to escape from poverty.

Although it is the responsibility of government to help eliminate social and economic constraints and barriers in order to eliminate hunger and reduce poverty, the outcome will be weak if the poor themselves do not actively strive to improve their living conditions.

Poverty reduction must be seen as the mission of poor people and poor communities themselves, because it is their own self-help efforts to escape from poverty that is the driving force and necessary condition for attaining the goal of poverty elimination in all countries.

The State will support the poor to enable them to learn how to escape from poverty and to avoid falling back into poverty when risks befall them. Apart from providing direct material support to the poor, providing them with guidance on how to produce and do business, and how to develop their economic activities, given their particular conditions and circumstances, is the very condition for rapid and sustainable achievement of poverty reduction. 


\section{PART III}

\section{Creating an environment for Rapid, Sustainable Development and poverty reduction}

\section{CREATING A LEGAL ENVIRONMENT THAT SUPPORTS FAIR AND COMPETITIVE BUSINESSES}

\section{Creating a Legal Environment that supports Fair and Competitive Businesses}

To create a fair and level playing field for all enterprises, a gradual move towards establishing an integrated legal system with consistent policies and mechanisms to regulate all types of enterprises, based on the notion that the State respects and ensures the right of each citizen and each enterprise to have the freedom to conduct business in accordance with the law, is required. Available funding sources must be fully mobilized and all production powers utilized to the fullest in order to secure economic growth and increase the income of the people.

The Enterprise Law must be implemented in an accelerated and comprehensive manner, while continuing to abolish unnecessary business licenses; necessary revisions of legal documents must be made to ensure equal access to public services, resources, investment, and business opportunities, and to ensure that all types of enterprises have equal access to capital, credit, land, new technology, information, market and training opportunities as well as to Government preferential treatment and incentives.

The legal framework must be developed to ensure a transparent and stable investment environment with efficient investment promotion measures and policies.

Best corporate governance practices should be adopted by listed companies and joint stock banks and made compulsory within 18 months. Joint stock companies are encouraged to adopt these practices.

People's Committees at the provincial level should publicize master plans for land use, urban development and civil infrastructure development (including housing, water, bus stations, transportation, etc.) to facilitate investors' decisions. The information system should be improved and urban and township plans established.

The Competition Law must be enacted and effective mechanisms developed to control monopolies and supervise enterprises with monopolistic power in the pricing of inputs and outputs and in business conditions.

Supervision and inspection of enterprises, and various procedures to regulate customs clearance, traffic control and technical examinations must be streamlined and simplified in order to facilitate the operations of enterprises and to protect the legitimate rights and interests of consumers. Arbitrary forms of enterprise examination and inspection and the abuse of the inspecting function for the purpose of troubling and harassing enterprises for bribes must be totally eliminated.

In 2002, revisions will be made to the Enterprise Law and Law on Enterprise Bankruptcy, while the Law on Competition, the Pricing Ordinance and the Ordinances on Most Favored Nation Status and National Treatment shall be promulgated.

The (revised) Land Law will be rapidly implemented and the Guidance Decree of such Law released soon to enable the completion of the issuance of land use right certificates in two or three years. This will lay the legal foundation for the healthy operation of the real estate market. In addition, streamlined and simplified procedures will be applied to property transfer and leasing transactions, as well as to mortgaging land use rights as collateral for bank loans, or as equity contribution to joint-ventures.

Specific regulations will be promulgated to allow Vietnam-based banks to accept land use rights as collateral; gradually promote the development of non-banking financial institutions and have regulations on diversified types of funds mobilization and credit provision. Develop a uniform and consistent financial accounting and economic statistics systems to be applied to all enterprises regardless of their form of ownership. 


\section{Continued Reform of State-Owned Enterprises (SOEs)}

Policies and directions on the organization, renovation and improvement of the efficiency of SOEs must be rapidly implemented. They include:

Clarification and concretization of the directions for restructuring and developing SOEs, separating those whose mandates are to provide public utilities from those strictly engaged in business activities. Issue criteria for the detailed classification of SOEs into different forms distinguished by the amount and nature of shares held by the State, either all shares, dominant shares, special shares, or minority shares and no shares at all. Classifications of SOEs, according to those that are subject to merger, dissolution, bankruptcy, transferal, selloff or leasing, also should be made.

Citizens and enterprises from all economic sectors are encouraged to do business in areas that are not prohibited by law.

A new Decree to replace Decree No. 56/CP governing Enterprises Supplying Public Utilities will require that they adopt sound accounting practices and be financially independent. The State shall give equal preferential treatment to suppliers of public goods and services regardless of their form of ownership.

Implemente the Prime Minister's Decision 187/1999/QD-TTg dated 16 September 1999 on the Renovation of the management organization of State-owned Forest Farms.

Revise and amend mechanisms and policies to establish an integrated, coherent and consistent legal framework to enhance the autonomy and market-based decisions of state-owned enterprises, which should improve their efficiency and make them more accountable to their shareholders and employees.

Introduce mechanisms and policies to provide preferential treatment to selected industries, areas, products and services where there is a clear need.

Promulgate policies to enable the fair competition among businesses and to control monopolies.

Issue criteria to evaluate business performance and specify supervision and sanction mechanisms applicable to each type of SOEs, particularly those that are fully or largely owned by the State and State Corporations, to reward efficient managers and penalize inefficient ones.

Renovate the systems of accounting, auditing, reporting, and information sharing to make transparent the business operations and finances of state enterprises.

Establish the Financial Investment Company on an experimental basis to test the model where the State acts as investor and manager of capital instead of as transferor of capital funding. Correct and supplement the Regulation on Managing Investment and Construction in the direction of giving more investment decision-making power to enterprises. Replace Decrees No. 28/CP and 03/2001/ND-CP with a new one to better regulate labor, salary and income management in State-Owned Enterprises.

Issue criteria and regulations on competitive examination for key management positions in SOEs with emphasis given to capable and experienced managers. Develop a system to train and nurture enterprise managers with program and content to prepare them to meet the requirements of current business practices.

Apply policies to ensure appropriate material and spiritual incentives to enterprise managers depending on their contribution to business performance. Decision No. 83/1998/QD-TTg should be replaced with a new regulation to permit payment of a salary and salary allowance to members of the Board of Directors, the Management Board of State Corporations and large-scale independent enterprises. At the same time, regulations are needed to define their responsibilities and ensure effective sanctions if necessary.

Introduce mechanisms and policies to deal with non-performing loans of SOEs; establish and quickly operationalize an asset management company to resolve the problem of SOE debt and unused assets in order to improve the soundness of corporate finance. 
Prepare policies such that workers, especially female workers made redundant as a result of SOE reorganization, will be given opportunities to be re-trained, and to be without work while still receiving a basic salary payment for a certain period of time in order to search for new employment opportunities; should they fail to get a new job, they will be offered unemployment benefits. Revisions should also be made to policies governing redundant workers to allow early retirement and to provide support for those who wish to find new jobs.

Create close linkages between groups of depositors and borrowers in the banking system; expand successful models of sustainable micro-finance initiated by NGOs or other civil organizations; tightly link the provision of credit for cultivation with agricultural extension.

Accelerate the equitization of SOEs in which the State does not need to hold $100 \%$ ownership. The State will adopt policies to reduce inequities in the amount of preference shares held by workers of equitized SOEs; provide regulations to ensure that workers can hold such shares for a fixed period of time. More studies are needed on the possibility of using part of the enterprise's own capital (equity) to issue dividend-earning but nontransferable shares to enterprise workers. Equitization procedures should be streamlined, simplified to be more transparent to investors and to conform with the Enterprise Law and the Law on Encouraging Domestic Investment where investors are allowed to buy shares in equitized enterprises in which the State does not hold dominant shares at first issuance. A new decree to replace Decree No. 44/1998/ND-CP on the Equitization of State-Owned Enterprises also is needed.

Revise and amend a number of articles in Decree No. 103/1999/ND-CP on accelerating the transfer, sale, business subcontracting and leasing of SOEs.

Invest in, develop and establish new SOEs that are considered necessary in key industries and sectors, and in important areas and for which sufficient conditions are met, including conducting due diligence to ensure that this decision will not have medium and long term adverse effects on the state budget. SOEs that are inefficient, but not subject to be equitized, transferred, sold, business subcontracted or leased, will be merged, dissolved or declared bankrupt. Revise and amend a number of articles in Decrees No. 50/CP and 38/CP on the Establishment, Reorganization, Dissolution and Declaration of Bankruptcy of SOEs, with a view to requiring that the newly formed SOEs have the status of a shareholding company. SOEs with 100 percent state ownership will only be established in industries and sectors that either require State monopoly, or where non-State sectors are not interested in investing or it is beyond their capacity to invest. The Law on Enterprise Bankruptcy should be revised in the direction of allowing the authority that approved the establishment of the SOE to declare the enterprise bankrupt. Replace the system of management oversight by line ministries with the system of state management based on policies, laws, standards and norms; give SOEs the right to make decisions on the establishment of State corporations and business associations.

Encourage diverse forms of co-operation and joint ventures between enterprises belonging to different sectors. Promote the role of business association in providing business development services for their members, providing a bridge between Government and enterprises, promoting exports and trade, and protecting the rights of their members.

Expand implementation of the revised Labor Code. Draft the Law on Social Insurance and make additions to employment insurance policy based on the principle of "the State, the enterprise and the workers make contributions together".

Revise and amend the Law on State-Owned Enterprises to permit greater autonomy and ensure greater accountability for SOEs in their business operations in order to improve their efficiency and profitability. Issue regulations on the establishment, organization, operation, reorganization, dissolution and bankruptcy of SOEs.

3. Create conditions for land use, support business production and develop small and medium-size enterprises, farms and various types of enterprises in the private sector. 
Small and medium enterprises (SMEs) play an important role in the nation's economic growth, in creating employment and reducing poverty. The State encourages and provides support for the development of SMEs, especially those in remote and isolated areas as well as in rural areas.

Government Decree No. 90/2001/ND-CP on the development of small and medium-sized enterprises must be rapidly implemented. Establish the Office of SMEs, develop the system of organizations to promote and support SMEs at central and local levels, develop the legal framework and specific policies to encourage and support SMEs. SMEs should have easy access to Government support programs in various areas including investment and credit, land use, market information, technical consultancy, training services, human resources development and other services.

Ensure that SMEs are able to access bank credit; the State will establish various funds to support investment, offer medium and long term loans, establish a fund to provide credit services to SMEs; expand various forms of credit for lease and purchase, and for unsecured loans; provide on a selective basis preferential taxes, tax reductions and tax exemptions and financing for scientific research and technological renovation programs and for enterprises that employ poor workers, especially women. Extend preferential eligibility with respect to investment and credit to small enterprises, individual household businesses, family businesses engaged in processing activities, handicrafts and fine arts. Pay attention to developing programs to support SMEs that are managed by women.

The State allows SMEs to benefit from land-use rights, same as SOEs, in accordance with the Land Law (conversion, transferring, inheritance, secured loans, renting out land-use rights in accordance with the Land Law).

Businesses in all economic sectors should be encouraged to establish technical support centers in various regions to provide basic services and support for training and transferring skills. Develop a market for different services including accounting, auditing, marketing and advertising services; establish business incubators to nurture SMEs during their early stages. The technology market should be developed to increase technology transfer and market development between large enterprises and SMEs. Provide longer tax holidays for projects that involve technological renovation; establish a national training and job creation fund and support training services and technology transfers.

Strengthen the capacity of organizations at the central and local levels that are charged with managing and supporting SMEs. Strengthen the capacity and provide financial support for business representative, business development and business consulting organizations that work to serve SMEs. Coordinate and implement programs to develop small and medium enterprises among state management organizations, business associations, vocational centers, and state and private consulting and training facilities. Develop a sustainable network for providers of business development services.

Develop concrete policies to create a supportive environment for production and business activities, provide credit support, market information, production technology, tax exemption and infrastructure, etc. in order to provide on a wider scale effective assistance to enterprises in selected industries, remote, rural and poor areas and poor communes.

A relevant financial mechanism for SMEs should be set up soon. Continue to renovate the accounting system, tax registration and tax payment system in the direction of simplifying it to reflect the characteristics of SMEs, especially those in rural and mountainous areas, to make it more convenient for tax-payers and to avoid tax collection losses.

Encourage the development of co-operatives in accordance with the Co-operative Law, and various forms of business co-operation between natural persons and legal persons on the basis of respecting the freedom and self-determination of workers, democracy and transparency. Pursue a clear-cut resolution of the outstanding debts of old cooperatives whose form of ownership have been or have not yet been transformed. Dissolve 
cooperatives whose existence is only nominal and which have no economic basis to develop, and whose members' participation is not on a voluntary basis, etc. Encourage the development of legal consultancies for community-based organizations and facilitate their better management of community resources. Provide guidance on the implementation of policies to encourage development of cooperatives.

Encourage the development of and provide long-term protection to the farm economy. Implement Decree No.03/2000/ND-CP of the Government on development of the farm economy. Create favorable conditions for households engaging in production and business activities to participate in the market by promoting, developing and completing market institutions; at the same time promote the development of consultancy services for households and groups of households doing business, and encourage them to gradually become enterprises.

\section{Encourage foreign investment and consider it a long-term component of the national economy}

Implement Government's Resolution No. 09/2001/NQ-CP on attracting and improving the efficiency of foreign direct investment to Vietnam during the 2001-2005 period with special attention given to such pressing measures as: diversifying the forms of attracting foreign direct investment, implementing policy to allow foreign investors to establish shareholding companies and transforming a number of foreign invested enterprises that are in operation into shareholding companies; review on a regular basis legal writings issued by central ministries and provinces related to foreign investment and business certification and other certifying documents. Continue to upgrade infrastructure (roads, bridges, seaports, airports, telecommunication systems, power stations, etc) to attract FDI. Continue to implement the roadmap for harmonizing taxation regimes, land lease price, the price of services, electricity, fares for domestic flights and international seaport charges applied to foreign invested and domestic enterprises. Open more sectors to foreign investment; encourage FDI to go into export-oriented industries, primary product industries, high technology, new materials, and electronics industries, and labor intensive industries or industries where Vietnam has a comparative advantage.

Increase the share of official development assistance (ODA) for agricultural and rural development, human resources development, education, health care, science and technology, and environmental protection. Review licensed foreign invested projects in a more efficient manner to enable timely assistance and address problems; continue the policy on decentralization of state management of foreign investment; improve administrative procedures; renovate the contents and modes of investment mobilization and promotion; and improve the capacity of staff and strengthen the training of technical workers to be employed in the foreign invested sector.

\section{Implementation of the Public Administration Reform (PAR), Legal Reform and pro-poor Good Governance}

Our overall objective is to build a healthy, effective, efficient and accountable State Administration at all levels that can develop policies and provide services to meet people's needs, to encourage the creation of opportunities for the poor and the disadvantaged in order to help them realize their potential. To achieve this objective, it is necessary to establish a transparent State administration with a simple organizational structure and a contingent of government staff and civil servants whose quality, capability, profession and qualifications meet the country's requirements for socio-economic development. The PAR is to be carried out in four areas: administrative institutions, organizational structure, building the body of staff and civil servants, and public finance reform.

\section{To successfully achieve the above-mentioned objectives, the following tasks need to be performed well:}

Improve the system of legal institutions and policies and mechanisms to make them suitable to the country's industrialization and modernization. In this respect, attention is first given to improving economic institutions and those regarding the organization and operation of the administrative system. Continue to renovate the process of legal writings, drafting, and promulgation, bring objectivity into the preparation and 
drafting of legal writings, bring democracy into play and mobilize the people's intellect to improve the quality of legal writings.

Clearly identify what the Government must necessarily do, what can be jointly done by the Government, the people, and private organizations, and what should only be done by people and private organizations. The organizational structure of the Government apparatus will be reformed along the lines of reducing the number of focal points of Government ministries and agencies and applying the principle in which ministries are responsible for multi-sector and multi-field management. The conduct of management must be accountable, transparent, easy to understand and not an inconvenience to stakeholders.

Ensure that information about services, policies and development plans for the people is made public on a regular basis and is accessible for people through a one-stop shop system.

Implement soon the PAR in important ministries that directly impact the poor (such as the Ministry of Agriculture and Rural Development, the Ministry of Health, and the Ministry of Education and Training, Ministry of Labor, Invalids and Social Affairs) to ensure that the poor can have access to health care and education services, infrastructure, water and electricity supply at the local level, especially in mountainous regions and in urban poor areas.

Ensure the transparency of the local budget; define clearly the process for preparing the budget and for allocating expenditures in each sector in order to make sure a pro-poor approach is adopted.

Renovate the process of legal writings drafting and promulgation, with emphasis on bringing in the effective participation of the people in the law- and policy-making process.

Implement more vigorously the decentralization of public administration between central and local levels while strengthening the capacity and responsibility of the local administrative apparatus, and enhancing supervision and monitoring responsibilities at the grassroots level; based on this, streamline the organizational structure of local governments at different levels with a view to having fewer focal points.

Simplify and make public administration and business registration procedures more transparent; reduce transactions costs for import-export activities, and reform the delivery of public services to make it more convenient and less time-consuming for people.

Ensure strict compliance with the law, especially of agencies and civil servants, and attach great importance to providing sufficient information and to publicizing this information.

Increase the effectiveness of the administrative apparatus, strengthen the sense of responsibility and commitment to transparency of agencies in activities under their public authority and jurisdiction. Ensure transparency in budget management; renovate the auditing function with respect to administrative agencies, and commit to increasing accountability and effectiveness in the expenditure of the state budget. Bring about democracy and transparency with respect to public finances.

Strengthen methods to oppose corruption and wasteful spending, ensure prudent and frugal use of public funds in accordance with the Ordinance on Saving, first and foremost in areas such as procurement, licensing, capital investment, and project management. Efficiently resolve legal cases and long-standing civil disputes; revise, amend and have specific regulations on the compulsory registration of real estate and assets belonging to civil servants; make sure that violations by civil servants are dealt with in a timely manner.

\section{MAINTAIN MACROECONOMIC STABILITY}

\section{Improve Fiscal Policy, Implement Reforms in the Taxation System, and Broaden the Tax Base to Ensure a Sustainable Balance in the State Budget}

Implement fiscal policy based on equality and efficiency. Make public and transparent the sources of revenues and expenditures of budgets at all levels, and the use of contributions from the people. Create a sound 
and open fiscal environment to release and develop all fiscal resources, to develop and expand sources of revenue for the budget, and to mobilize foreign capital resources. Develop a public administration mechanism to ensure a balance between capital investment and recurrent expenditures, particularly to finance the maintenance of existing public assets. Link the reform of State Budget expenditure policies with better implementation of socialization polices in better-off regions to enable greater allocation of resources to disadvantaged regions. Renovate and complete the decentralization of fiscal management and budgeting.

Maximize the mobilization of all fiscal resources to achieve the objectives and tasks of socio-economic development, social equity and poverty reduction.

Consolidate the policy system and fiscal mechanisms to create a favorable, attractive and transparent environment to encourage the expansion of all economic sectors, increasing business productivity, and liberating productive capacity.

Raise the share of medium and long term capital mobilized for economic development and investment by diversifying the instruments for mobilizing capital; this includes government bonds, investment bonds, municipal bonds, housing bonds, etc; diversify the forms of non-banking monetary and financial organizations and investment funds; develop quickly markets for capital, the stock market and real-estate market in order to accelerate the process of securitizing domestic assets and capital resources.

Continue reform of the tax system following the requirements of renovation and consistent with international agreements along the following lines:

Simplify and gradually adopt a unified tax system with no distinction between enterprises belonging to different economic sectors, and between Vietnamese and foreign invested enterprises.

Gradually raise the share of revenues from direct taxes as a percentage of total state budget revenue based on completing the Business Income Tax Law along the lines of reducing the tax rate and moving towards a unified framework for taxing the income of both Vietnamese and foreign invested enterprises; promulgate the Individual Income Tax Law instead of the State Law of Income tax for high-income individuals to ensure social equity, and to create a driving force for development.

Complete the system of tax collection with respect to land along the lines of using a single type of land use tax and one form of tax collection with respect to incomes generated from land use.

Research to promulgate an asset tax in order to generate more budget revenue and to create favorable conditions for asset transfer, sale and rotation.

Complete the system of indirect taxes along the lines of gradually reducing import taxes in accordance with international agreements, ensuring that requests for trade protection are appropriate, with a defined time frame and conditions with respect to domestic production; complete the VAT along the lines of adopting a unified tax schedule; expand VAT coverage to imported goods; expand the range of goods that are subject to a special consumption tax; research the application of new taxes related to protecting domestic production during the process of global economic integration such as anti-dumping taxes, antagonistic taxes, etc.

Limit tax exemptions, gradually narrow the scope of tax-based social polices through research to ensure that preferential taxes are properly targeted; priority will be given to new investment and expansion of production, technology renovation, new product development, development of high technology technical professions, export production and labor-intensive projects that can contribute to job creation and poverty reduction.

Modernize the tax collection system; widen the range of tax payers that self declare, calculate their tax obligation, and pay directly to the State Treasury; enhance the inspection function in tax declaration, tax payment, tax calculation and tax reimbursement; strengthen the enforcement function to strictly control tax evasion, smuggling and trade fraud. 
Expand the scope of socialization in education and training, health, culture, sports and other public services where all economic sectors participate. Continue to target policies to reduce or exempt the contributions by the poor.

Continue to complete fiscal regulations and policies to create a favorable, transparent and attractive environment that allows efficient competition with regional countries.

Complete policies and mechanisms on foreign borrowings and repayment based on improving the quality of fiscal planning and assessment and of evaluating the efficiency of projects that are financed by foreign debt; renovate the mechanism to monitor foreign borrowing activities by enterprises, especially SOEs; construct an information system to analyze, forecast and evaluate safety level of ODA borrowings and the Government's debt management; increase the efficiency of using capital from the Accumulation Fund for Foreign Debt Repayment.

Implement the principle of equity in fiscal allocation policies; increase the efficiency of the State Budget in regulating macroeconomic performance and resolving social problems.

Complete policies on primary reallocation to harmonize economic benefits between the State, enterprises and workers; expand forms of redistribution by developing a public welfare system, including insurance, social welfare, preferential fiscal regimes and various forms of social support to resolve social problems, narrow the gap between the rich and the poor, and bring about social progress and equity.

Continue to reform the State budget along the lines of revenue restructuring and defining clearly the scope of budget expenditures with the goal of increasing the efficiency of using the budget as a critical tool to regulate macroeconomic performance and to resolve social problems. Prioritize capital resources from the state budget for socio-economic infrastructure development; attach special importance to raising the share of investment for agriculture and rural areas, education and training, science and technology, culture and health care.

Adopt a mechanism of direct and indirect support from the state budget for all enterprises without making a distinction between different economic sectors in order to develop human resources, provide information, promote trade, develop new markets, and provide extension and advisory services on applying modern business management tools.

Combine financial resources from the state budget with external financial assistance resources and contributions from people to implement effectively national target programs in health, education, poverty reduction, environmental protection, job creation, etc., with particular focus in areas with a high poverty rate, in ethnic minority areas and in other disadvantaged areas.

Make active use of the state budget to increase financial reserves and enhance the quality of budget planning; assess on a regular basis the efficiency of how state budget resources are utilized; increase control over budget expenditure; ensure that the State Treasury is the major body responsible for controlling state budget outflows.

Continue to amend, revise and adopt mechanisms, norms, and criteria for budget expenditure in accordance with the requirements and conditions of economic development; fully implement the policy of safeguarding investment resources from the budget, starting from the initial exploratory phase to establishing and approving the project to project implementation phase; act resolutely to prevent deficits and misspending in public expenditure.

Ensure an active balance in the state budget to increase gradually our savings, to maintain the appropriate fiscal level in order to ensure macroeconomic stability and state financial security.

More vigorously renovate the management mechanism over enterprise finance with the aim of separating state finance from enterprise finance, ensuring the freedom of state enterprises to conduct business, their right to self-determination and their responsibility for assuming liability in accordance with market economy rules. 
Renovate fiscal policies to promote the rapid development of markets for capital, stock, financial services and real-estate markets, organized to create favorable conditions for mobilizing financial resources to promote socio-economic development.

Implement fully policies to promote thrift and curb misspending and enhance the efficiency of natural resources, land and public asset management and utilization.

Take the initiative to actively achieve international financial integration with appropriate steps and roadmaps; expand cooperation and international financial relationships.

Complete the legal basis for and enhance the efficiency and quality of accounting services (Promulgate the Accounting Law) and auditing services. Increase the efficiency of State finance and budget inspection, control and monitoring activities.

\section{Implementation of an Active Monetary Policy to Stabilize the Monetary Situation, Control Inflation, and Support Economic Development}

Develop and implement a monetary policy to reinforce macroeconomic stability, control inflation, promote production and consumption, stimulate development investment, and ensure rapid and sustainable economic growth. Renovate monetary policy in the direction of using indirect instruments. Gradually improve exchange rate and interest rate policies and open market operations in order to enhance the efficiency of monetary policy implementation, and raise the convertibility of the Vietnamese dong, with the aim of favoring the poor. Enhance the role of the State Bank in monetary regulation and management and credit supervision, and strengthen the Bank 's capacity in terms of organization, institutions and personnel. Develop the secondary market, especially the inter-bank market for domestic and foreign currencies. Develop financial instruments in this market, especially exchange rate risk prevention/management instruments and transactions.

Develop capital and monetary markets involving appropriate diverse players including the banking system, non-bank financial institutions, insurance companies, investment funds and investment guarantee funds, and so on, to attract savings from society, and to expand the sources of long-term and medium-term funds. Reduce various forms of capital and credit subsidies.

Implement the Vietnamese accounting system, which includes application of international accounting standards in commercial banks, and in the task of bank management and supervision.

Implement a safe and gradual development of the stock market based on the evaluation of past operations of the Stock Transaction Center in Ho Chi Minh City. Encourage and create conditions so that qualified stock companies can put up their share certificates in the stock market including FDI and equitized enterprises

Improve the exchange rate management mechanism along the lines of ensuring both flexible management in the short run and stable management in the long run in order to encourage exports and contribute to stabilizing the moneytary market, especially the capital market. Improve exchange rate management policy and mechanisms to liberalize current account and capital account transactions, and at the same time develop a system of measures to monitor international capital flows, especially short term capital flows, control external debts, control and minimize the use of foreign currencies in the territory of Vietnam in order to enhance the position of the Vietnamese Dong. Gradually reduce the rate of foreign exchange surrender and move towards completely abolishing this regulation by 2003.

Further improve open market operations. Adopt measures to increase instruments for the open market, create conditions to attract more players to this market in order to gradually improve its instruments in the direction of turning them into key monetary regulation instruments for the State Bank. Create more harmonious coordination between the Government monetary policy and debt management policy (issuing of Government bonds). 
Establish an early warning system based on significant changes in the income statement and balance sheet of enterprises and analysis of information on corporate finances to make appropriate recommendations to credit institutions with the goal of helping them prevent or control risks (with respect to interest rates, exchange rate, debt, payment ability, etc.), thereby ensuring the safety of the banking system and macroeconomic stability.

Set up asset management companies to resolve debt problems; develop measures to address collateralized overdue loans following market-based rules.

Gradually shift from a collateral-based lending mechanism to project- and economic contract-based and market supply-demand relationship-based lending mechanism. Enhance the autonomy and self-responsibility of commercial banks in conducting their business activities, in their acceptance of competition and in their taking initiative to find customers and investment projects to lend to.

\section{Commercial Bank Reform}

Vietnam is implementing a strategy to reform the system of commercial banks in order to restore health to the banking system with the aim of improving the safety and efficiency of financial intermediation in the economy. The Government has also adopted a program to reform banking system in order to promote its development and stability in harmony with Vietnam's macroeconomic framework. The main focus of the reform is to curb the growth of bad debts and to ensure that commercial activities of the banking system will be conducted safely and efficiently. In order to reduce financial systematic risks, it is necessary to encourage the non-banking system while diversifying channels to mobilize savings, and to develop medium and long-term financial instruments.

This reform will be implemented alongside the reform of SOEs. The reform of state-owned commercial banks is aimed at reinforcing management responsibility, initiative, and capacity to generate profits and to commercialize their activities. In the reform framework, debt administration and asset management companies (AMC) will be established to address bad debts. The debt resolution will include lending reduction and debt clearance for SOEs that are disbanded, leased, and equitized according to the SOEs reform.

Also, in this reform, the addition of supplemental funds to state-owned commercial banks on a 3-year basis will be implemented according to progress made in meeting the conditions, which is defined for every stateowned commercial bank, regarding the outcome of the comprehensive organizational restructuring and regarding the results of their progress in reducing the level of non-performing loans annually. The State Bank will strengthen the regulatory framework, inspection and supervision of all banks and also will strengthen the regulatory framework regarding the rights of lenders, especially the right to impound assets used as collateral, to put these assets up for sale in the market, and the transfer of land use rights. The State Bank will put together the necessary policies and procedures to carry out bank inspections based on risk assessment.

Vietnam will continue to restructure and strengthen the joint-stock commercial bank sector. The State Bank has completed the financial assessment of joint-stock commercial banks and approved the plan to restructure this sector. Weak joint-stock commercial banks will have their licenses withdrawn or will be merged with other banks. The State Bank will continue to improve the legal framework with a view to creating favorable conditions for the expansion and development of joint-stock commercial bank activities on the basis of equal competition and respect for the law. Complete the reorganization and consolidation of joint stock banks in accordance with the approved plan, and at the same time impose strict penalties on banks that violate the law.

Create a favorable and stable environment for credit and micro finance operations to increase the flexibility of the rural finance system work in order to meet the needs of the poor. Reform and renovate the rural credit and finance systems, diversify credit instruments to attract private investment in the manufacturing and processing of agricultural products.

\section{Trade Policy}


Continue the open-door policy and actively integrate into the international community to promote development. Implement policies to protect important products within a time frame that is in accordance with the integration process.

Lay the foundations for successful negotiations for WTO accession; actively implement commitments under bilateral and multilateral trade agreements and cooperation mechanisms that our country is involved in, with special attention given to commitments under the ASEAN framework (such as AFTA, AICO, AIA), APEC, ASEM, the Vietnam - US bilateral trade agreement, and commitments made with international financial institutions.

Enterprises from different economic sectors are given freedom to engage in the business of foreign trade, including export, import and various services, excepting activities not permitted by law.

Implement the management mechanism on exported and imported goods in the period of 2001-2005 issued as an attachment to the Prime Minister's Decision 46/2001/QD-TTg dated on April 4, 2001. Continue to remove non-tariff barriers, and complete the removal of all imported goods from the temporary exclusion list in the AFTA commitment to the inclusion list by 2003; abolish non-tariff restrictions on goods in the temporary exclusion list when the import tax level applied to goods imported from ASEAN countries has been reduced lower or equal to 20 percent.

Continue to abolish restrictions applied to rice exporting and fertilizer importing enterprises. Gradually expand the use of auctions to renew garment export quotas in order to improve market access to exporters (including those from the private sector). Apply a target-based, conditional and time-bound protection policy that is in line with the country's integration process. Strengthen the capacity of institutions and the nation to establish criteria for measurement and to carry out quality inspection of goods.

Implement a roadmap to reduce import taxes levied on goods that serve as major inputs for agricultural products, in order to help decrease input costs for the poor.

Assess the application of the Commercial Law with a view to revising and amending new terms, promulgate soon the Law on Competition, Most-Favored Nation Law and Law on National Treatment; complete the commercial policy system; prepare and promulgate commercial policies in accordance with WTO regulations on certain imported goods with respect to customs quotas, tax on environmental costs, anti-dumping tariffs, tariff to penalize subsidies, and so on.

Government should encourage export activities, especially in key products that have comparative advantage, though operations of the Export Credit Support Fund, the Export Credit Guarantee Fund and prepare for the establishment of the Export and Import Bank in the near future.

Provide information and support to enterprises, especially those managed by women, in developing business strategies that fit with the integration process, to help increase their competitiveness in domestic and international markets, increase their market share in traditional markets, and find new markets.

The Government shall have various methods to help exporters and importers access information, and participate in trade exhibitions and trade fairs. Simplify administrative procedures, especially customs procedures; reduce transactions costs for export activities and costs of other export services (e.g. transportation, warehousing, etc.). Establish a system to insure export goods, especially for agricultural products, and an export bonus mechanism based on the value added of exported goods.

Study the impacts of trade policies and adopt effective measures to minimize adverse impacts on the poor caused by global economic integration and trade liberalization.

Improve market access for the poor, especially those living in rural, upland and remote areas; stimulate consumption; develop markets or centers to trade and exchange goods in poor areas to help integrate the poor with other groups; and make the market more accessible for them by exchanging goods and production experience. 
Actively implement measures to fight against smuggling and trade fraud. Take the initiative in responding to price fluctuations in international market, especially with respect to price of agricultural products and crude oil.

\section{CREATE A SOCIAL ENVIRONMENT TO BRING ABOUT SOCIAL EQUALITY, ENHANCE} GRASSROOTS DEMOCRACY AND PROVIDE LEGAL SUPPORT TO THE POOR

\section{Create conditions for people to fully participate in the development process and to have equal opportunities.}

Strengthen the capacity and create opportunities for all people to bring into full play their talents, to participate in the development process and to enjoy the fruits of development. Fulfill the goal of a "prosperous people, strong country, egalitarian, democratic and civilized society, preserving and developing our national culture and pushing back social evils".

Develop a legal framework for civil society and community organizations at the local level to improve the participation of the poor in the development process and improve their capacity to get rid of poverty.

Improve the quality of life for all with respect to food, clothing, housing, transportation, health, training, work, accessing information, culture, etc.

The Government encourages every individual to become rich through legal means, while at the same time make efforts to reduce poverty; create conditions to develop production infrastructure and capacity, knowledge and technical skills in various areas and communities so that they can develop themselves and move towards narrowing the gap in terms of economic, cultural and social development.

Pay a particular attention to improving gender equity, the advancement of women and the development of children; create conditions to enforce the rights of children in family and social life.

Ensure that all ethnic minorities will benefit directly from the process of economic growth.

Implement social equity in the fields of primary and secondary education; improve the quality of and outcomes in primary heath care, implement social security for the poor and ensure that everyone has the right to access public services.

\section{Enhance Grassroots Democracy and Strengthen Dialogue between Local Governments and Poor Communities}

Promote the participation of the people, including the poor, in policy planning and policy implementation by advancing the application of the Grassroots Democracy Decree at the district and commune levels.

The Government will continue to guide and check the implementation of the grassroots democracy decree to ensure that it is put into practice at the commune, precinct and township levels. Implement the Decree on a widespread basis throughout all hamlets, villages and sub-precinct population groups in the country. Maintain on a permanent basis the implementation of this Decree and turn it into permanent practice at the grassroots level.

Clarify functions and strengthen the management, monitoring and inspection capacity of government agencies. Effectively implement the decrees on democratization at the grassroots level and in various state agencies and state-owned enterprises.

Ensure that people will be given adequate information about economic activities, plan targets, and financial resources for development projects and programs in their localities; they are entitled to comment on and 
contribute to the development of these projects and programs, to take part in their implementation, operation, and maintenance, to contribute their labor to these projects and programs, and to express their role as the owners of those projects and programs with a view to increasing their responsibilities in utilizing and managing infrastructure projects.

Enhance the two-way information supply and exchange between the State and people through application of measures such as mass media, door-to-door communication, direct approach, community radios and videos.

Carry out mechanisms to enable communication officers to deliver information in education, technological training, marketing, state policies and regulations, and administrative procedures in order to empower local people politically and economically, taking into account the roles of tribal heads in remote areas. Make sure grassroots democracy rules are applied to national targeted programs such as Program 135 and others.

Local governments must ensure that the principle of democracy is followed, and that local people will have an opportunity to discuss and comment on development programs and projects, humanitarian assistance to the poor, contributions to building halfway houses, and so on. In the process of implementing projects and programs, priority should be given to use the local workforce to create more jobs and increase the income of the poor. Decentralize so that civil society, public associations and organizations can directly manage and participate in the construction, operation and utilization of local socio-economic development and poverty reduction projects and programs in local areas.

All poverty reduction programs and projects must be subject to monitoring and supervision by the people, the core groups being the People's Inspection Committee, the Fatherland Front and Veterans' Association at the commune, precinct and township levels. Local authorities must listen to and receive people's views and comments, and address on a timely basis their complaints, denunciations and petitions.

In developing participatory mechanisms, attention must be given to vulnerable groups like elderly, women, disable and ethnic minority people. It is necessary to take into consideration the specific work and aspirations of both men and women, so that all members of community can voice their opinions and priorities easily.

\section{Provision of Legal Support to the Poor}

Improve the legal system, enhance legal support and the poor's access to legal service; develop the legal support framework in remote areas to enable the poor's access to these services.

Complete the institutions to provide legal support; issue high-level legal regulations to form the legal basis for the organization of legal support activities. This includes developing the state system of legal support, and legal support systems of political organizations and civil societies; developing institutions for legal support lawyers, codes of ethics for these lawyers, etc.

Develop the contingent of legal personnel (lawyers, legal support workers and collaborators) to meet the diverse needs for legal support. Organize training on a regular basis for this contingent of legal personnel, with emphasis on remote areas and areas that have a strong need for legal support. Provide material aid and favorable work conditions for legal support units at the local level. Develop legal support centers, legal libraries at the commune level, both stationary and mobile ones that can reach villages and hamlets.

Continue the development of legal support services at the grass roots level in diverse forms. Issue legal leaflets to provide suggestions on the most common cases of conflict in different areas of administration, land, housing, labor, etc and to update new legal regulations.

Legal documents should be provided on a consistent basis to facilitate the work of legal support workers. Publicize and educate about state policies and legal regulations. Provide assistance on legal questions. 
Organize well the administrative courts of law; create conditions for people to approach the court easily. Ensure that a range of choices are made available with regard to conflict resolution at the local level and that decisions made at the courts or judiciary committees are transparent and publicized.

Encourage the participation of civil societies in providing legal support to their members and to the poor and disadvantaged. 
Figure 3.1: Enabling Environment for Growth and Poverty Reduction

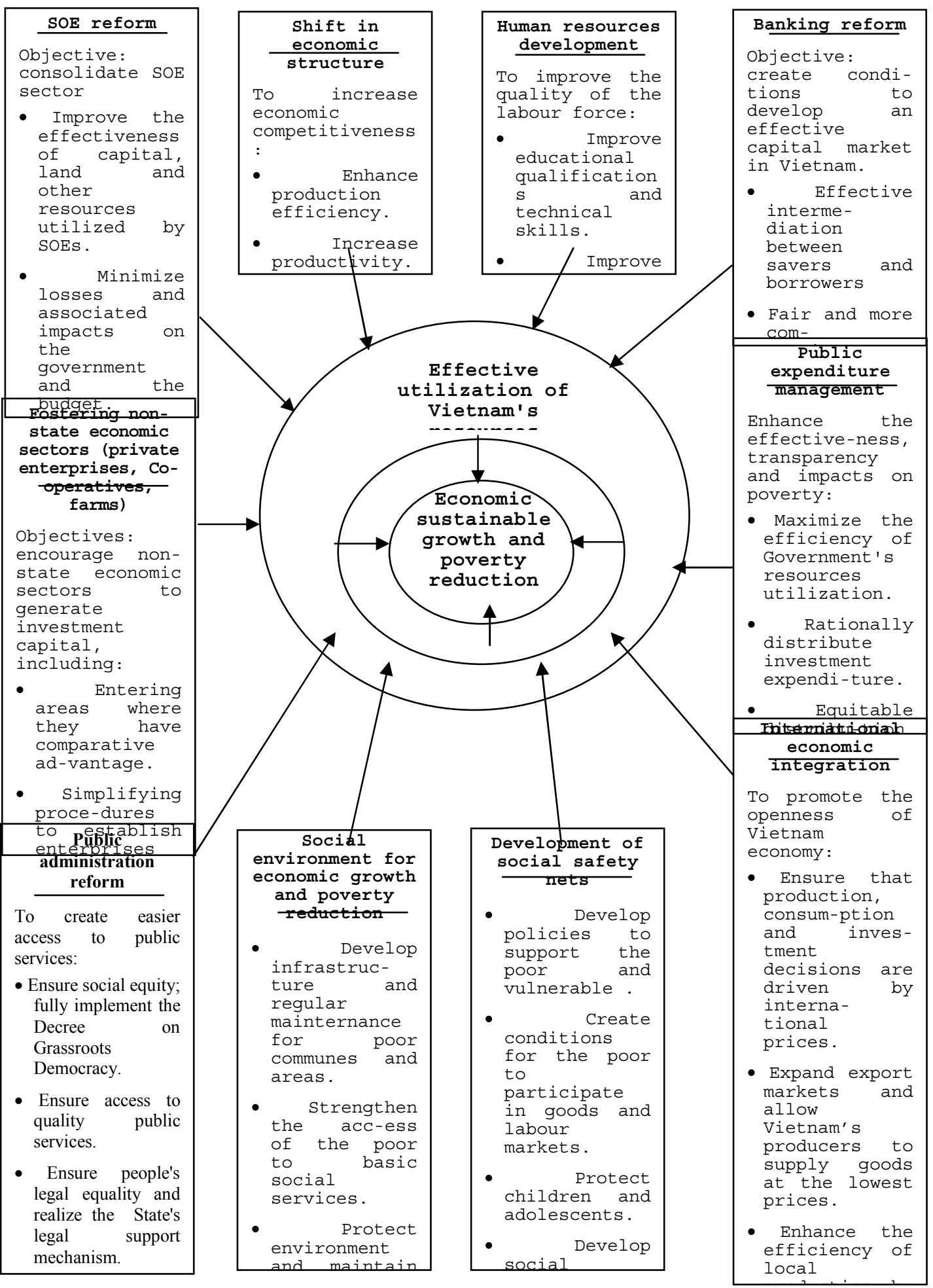




\section{PART IV}

\section{LARGE-SCALE INFRASTRUCTURE DEVELOPMENT FOR GROWTH AND POVERTY REDUCTION}

\section{THE ROLE OF large- SCALE INFRASTRUCTURE FOR GROWTH AND POVERTY REDUCTION.}

1. Large-scale infrastructure includes major and important construction projects and investments serving production, business activities and social life, which can create strong and long-lasting socio-economic development on a large scale, contributing actively to poverty reduction and improving the living conditions of the local inhabitants.

Large-scale infrastructures are major infrastructure projects, which have the level of investment capital equivalent to group-A projects as provided in construction and investment regulations ${ }^{7}$.

Large-scale infrastructure includes projects that direct serve production activities, such as those in electricity, transport, post and tele-communication, irrigation, etc. This can create the necessary support for a fast, stable and sustainable economic growth. Large-scale social infrastructure is directly related to the labor reproduction process, living environment and directly influences human physical and spiritual development. Examples are housing, scientific research institutes, schools, hospitals, cultural and sport facilities, etc. Improvement of people's living conditions and human resources development are necessary for the country's industrialization and modernization.

2. Large-scale infrastructure plays an important role in the process of growth and poverty reduction, which depends on the natural, social and economic conditions of each locality. This role demonstrates itself in three dimensions: direct, market and policy ${ }^{8}$.

Basic infrastructure of small and medium scale directly contributes to poverty reduction through projects in agriculture and basic social services related to growth and poverty reduction.

Large-scale infrastructure plays an important role both directly and indirectly through economic activities such as labor movement between regions, sectors, etc. and also contributes to enhance equality through income redistribution by tax, finance and investment policies to help the poor.

However, investment in infrastructure only is not enough to obtain growth. Infrastructure is a necessary, but not sufficient input for growth ${ }^{9}$.

3. Large-scale infrastructure projects play a significant role in socio-economic development, creating the foundation for growth and economic restructuring with a view to industrialization and modernization.

Infrastructure is an important factor to economic development through raising productivity and living conditions. Especially, large-scale infrastructure is decisive for changing the economic structure.

\footnotetext{
Under Decision No. 12/2000 of the Vietnamese Government, group-A projects are defined as those with investment capital over VND600 billion in such industries as electricity, oil and gas exploitation, chemistry, fertilizer, machinery, cement, mineral processing; transport projects such as bridges, seaports, airports, railway, roads; over vND400 billion in irrigation and other transport projects, drainage, electronics, telecommunication, etc; over VND300 billion for projects in urban infrastructure, light industries, national forests or reservations, etc; over VND200 billion for projects in health service, culture, education, broadcasting, tourism, sports facilities, etc

The interaction between growth and poverty reduction goes in three channels, namely (a) the direct channel where projects in health care, education, rural road network, etc. have a direct impact on the poor; (b) the market channel where growth helps poverty reduction through economic movement such as labour migration between sectors or areas, increased demands for consumption and re-investment through official or unofficial funding, etc; and (c) the policy channel which supplements for the market channel and guide the development towards further equality and fairness through tax and subsidy policies, public investment, credits for small and medium enterprises, etc.

For example, Bangladesh has the level of investment in infrastructure similar to that of Guatemala, but has a much lower level of income per capita. Paraguay has invested in its infrastructure ten times as much as Guatemala but has lower GDP per capita.
} 
Improving large-scale infrastructure will boost demand for investment as well as the consumption for hiquality building materials. A complete large-scale infrastructure system will help improve business environment and opportunities, raise productivity, create jobs and more incomes for workers. For example, investment in transport and energy infrastructure will allow enterprises to increase productivity and market access.

Infrastructure is important for the movement of goods between regions and countries, for the exchange of information and technology transfer, for the creation of a good environment for private investment, price reduction, and competitiveness enhancement, thus accelerating poverty reduction process.

More investment in large-scale infrastructure will quicken regional and sectoral economic restructuring towards industrialization and modernization. The capacity of individual sectors such as electricity, irrigation, and transports will be increased considerably. Investment in key economic areas will influence other areas, helping to exploit more efficiently available resources, forming spearhead products in each area, keeping economic goals close to social ones.

4. Large-scale infrastructure projects help reduce poverty on a large scale.

The efficiency of infrastructure development and investment will lead to growth and help poverty reduction. Economic growth results in increasing income; consequently there will be more budget available for investment in poor areas and poor communities through redistribution system. In fact, large-scale infrastructure projects, particularly, roads, bridges, ports, production factories and electricity transmission lines built in the $90 \mathrm{~s}$ have made an important contribution to economic growth and poverty reduction in Vietnam ${ }^{10}$.

New infrastructure investment will help improve business environment, create jobs and increase income through the expansion of production and business. Consumption will also be boosted, which in turn helps stimulate more businesses in the service sector.

Infrastructure development has the potential to reduce geographical differences and regional disparities; Different regions will have more opportunities to exchange goods and services for economic development. People will have more business opportunities, better access to market, diversifying agricultural products, raising productivity and promoting the development of non-agricultural activities in rural areas.

Infrastructure development allows minimizing loss of incomes caused by natural calamities or production shocks.

It enables areas with high potential for tourism to develop various types of tourist services, thus create more jobs and increase incomes for the local inhabitants.

5. Investment in social infrastructure will help improve physical and technical facilities for education and health services for a more sustainable development.

\footnotetext{
${ }^{10}$ According to JBIC analysis on the impact of National Highway No.5, the travelling time between Hanoi and Hai Phong is reduced by half; the number of transport vehicles doubled during 1999-2003; goods handled by Hai Phong Port increased by 1.5 times during 2001-2002; By mid-2003, 4 industrial zones along Road No.5 account for $85 \%$ of FDI coming in the North, creating 14,000 jobs; the road also help boost economic growth in nearby provinces of Hai Duong, Hung Yen and stimulate economic restructuring in the area. Data show that between 1995 and 2000, most provinces along this road recorded a growth rate higher than the country's and the Red River Delta's average.

- On the impacts of the completion of My Thuan bridge and the upgrading of National Highway No.1, data show that the travelling time between HCMC and Can Tho is reduced from 5 to 3.5 hours; the amounts of passengers and goods doubled. Tourism in Can Tho is getting a big boost, creating positive impact for the whole Delta.

- The North-South $500 \mathrm{Kv}$ line has effectively reduced electricity shortage in the Central and southern provinces. The new transmission accounts for $20 \%$ of electricity demand in the South and of the demand in the Central Province. The high voltage line allows extensions of the electricity network and increase supplies for vast populated areas. According to surveys done in the rural south, the percentage of low-income household having access to electricity supply has increased from $54 \%$ to $72 \%$.
} 
Such investment includes building new hospitals and upgrading modern equipment, bringing more doctors, nurses to remote, mountainous areas; providing high-quality health care service for everyone no matter where located with reduced unit cost. Investment in big and modern hospitals will allow communities to gain more access to basis health care.

Investment in large-scale infrastructure in education such as universities, technical colleges plays an important role for human resources development, thus modernizing production forces, accelerating economic growth and poverty reduction in a sustainable manner.

In scientific research and development, good technical infrastructure will make researchers more successful in inventing and applying new technologies to production.

Development of cultural infrastructure such as museums, parks, amusement parks, sports facilities, theatres will allow communities to enjoy healthy cultural activities, thus helping to recreate and raise people's creativeness.

Together with investment in high-quality basic services, investment in infrastructure such as water supply, drainage, housing and public facilities will help improving the inhabitants' living conditions, enhancing chances for environment protection and sustainable growth.

\section{EVALUATION OF CURRENT STATUS OF LARGE-SCALE INFRASTRUCTURE IN VIETNAM.}

\section{Achievements.}

A number of major projects in infrastructure such as roads, seaports, airports, post service, irrigation and electricity. have proved effective in meeting the demands of economic development, improving local inhabitants' living conditions, particularly for those projects with a high number of poor households.

The infrastructure network is allocated appropriately and concentrates to serve the three key economic zones, thus strongly promote growth in the rest of the country.

Different economic sectors have actively contributed to the development of the infrastructure system, thus creating more jobs and narrowing the gap between supply and demand.

The technologies used in the large-scale infrastructure system have been step by step upgraded and modernized. Some technologies have reached regional and international level.

Over the past ten years, the growth of the electricity industry responded to the needs of a fast growing economy. New investments have been focused on energy sources with new power stations coming into operation, meeting the energy demand for socio-economic development and national defence and security.

Land and railway transport networks have guaranteed smooth and safe transportation. New roads have been built or upgraded to modern technological standard. Airports and seaports have been upgraded and expanded with new technologies.

The post and telecommunication service has also been modernized with a system of electronic switchboards and digital transmission from cities to provinces and districts, which guarantees smooth communication between central and local authorities in any weather conditions and complicated situations. In 2003, there have been 8.5 telephones for every 100 inhabitants. International telecommunication network has been expanded with more than 5000 channels directly connecting to nearly 40 countries. Internet service is strongly growing, helping to boost international exchanges.

The system of irrigation works has been strengthened to serve agricultural production more effectively with 75 irrigation works throughout the country, protecting $80 \%$ of cultivation areas from drought and $70 \%$ from flooding. 
Large-scale irrigation works, dams, canals have made significant contribution to changing agricultural production structure, forming specializing areas, changing structure of crops, and husbandry, leading to higher productivity, better land use efficiency ${ }^{11}$, and rapid growth of agriculture, forestry, and fishery sector.

Housing development has been progressing, step-by-step meeting the housing demand of the community, specially for the people living in disadvantaged areas. The Mekong Delta has finalized the planning of municipalities in deep-flooded areas, 5 pilot municipalities have been established, and forming new residential areas in flooded areas. Between 1996 and 2000, 16.5 million square meters of houses have been built for the Northern Uplands and 9.5 million square meters for the Central Highland.

The network of district hospitals and health care centers has been developed. New and modern equipment have been supplied to major hospitals to expand their capacities and services.

Education and training system has recorded new progress with initial implementation of the university planning. New universities have been built in difficult regions such as the Northwest, the Central and the Mekong Delta. Job skill training is expanding under various forms.

Scientific research and development organizations have been rearranged and received more investments with a view to better meeting the requirements of socio-economic development and business competitiveness.

Water supply system for urban and rural areas have recently been improved to better serve the community 12. All cities, provincial cities, and the majority of town cities have access to water with better quality.

\section{Beside the achievements mentioned above, these are remaining problems:}

(1) In general, Vietnam's infrastructure system remains underdeveloped, failing to fully meet the demands of socio-economic development and the course of economic restructuring.

- Completion of infrastructure projects is often delayed. Inter-regional road network is short of investments and fails to meet international quality standards. The irrigation system is not yet fully integrated, slow the implementation of water reservoir system in mountainous areas is slow and, therefore, does not meet the necessary requirements for production expansion, and flood regulation. The construction of tertiary canal network doesn't meet the schedule reducing the effectiveness of investment.

- A master and sectoral plan is lacking for infrastructure building. Ecological and sustainable development has not received due attention. Overlapping infrastructure projects are causing wastes of resources.

- Large-scale infrastructure system fails to meet demands from a more modern way of life, particularly with regard to electricity, post and telecommunication, transport, etc.

- Social infrastructure is underdeveloped and still to be fully integrated. Infrastructure for education has improved but still fails to meet the demands of the population for educational attainment resulting in an undersupply of facilities and resources at a number of levels. . There lacks a detailed plan for major universities and colleges. There are not enough investments for major hospitals to meet increasing demand for health care from the population.

- Vietnam's infrastructure system is still some way behind other countries in the region, both in quality and quantity. High costs in social services are affecting the competitiveness of Vietnam in the process of

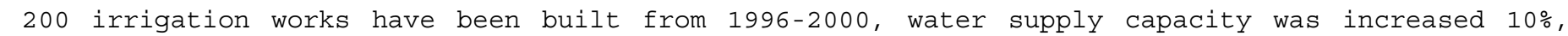

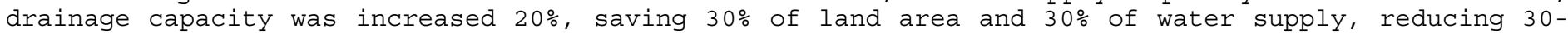
$60 \%$ management cost and creating about 40 thousand jobs.

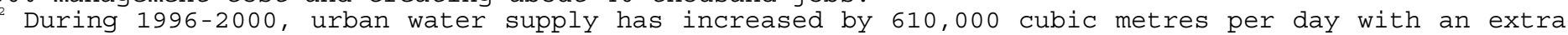

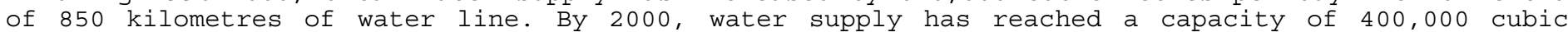

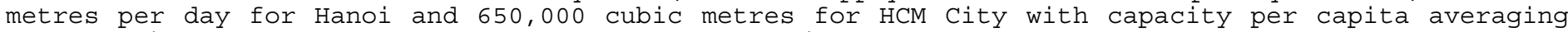
100-120 litres per day; 70-85\% of the urban population have access to clean water supply.
} 
international economic integration and in attracting foreign investment ${ }^{13}$. There are no linkages amongst the means of transportation and multi-transportation is under-developed. ${ }^{14}$

\section{(2) Resources for infrastructure investment are constrained and fragmented.}

Resources have only been provided for a number of key sectors and economic areas. Domestic resources for infrastructure are limited. Budget spending is still far from demands. Local resources for infrastructure are too small to meet demands for socio-economic development.

The investment in infrastructure project by credit resources, in particular in remote and mountainous areas faces constraints because cost recovery is and because business is reluctant to invest in these areas.

ODA sources are used for large-scale infrastructure project but mainly concentrated for major urban projects and key areas not the remote rural areas. The mechanism for ODA disbursement varies between donors and therefore causes difficulties. The counterpart fund allocation for provinces and poor regions is difficult to match, affecting the attraction of investment sources and harmonization in the disbursement process as well as the project implementation cycle.

The investment resources for project maintenance don't meet the demand, causing the quick downgrade for infrastructure project and tension of investment resources.

Funding from private sector in infrastructure investment is still limited. An incentive policy is needed to encourage the private sector and foreign investors to invest in infrastructure.

\section{(3) Project preparation and management is far from satisfaction.}

There has not been a serious evaluation of impacts resulting from the installation of large-scale infrastructure in relation to the environment. At times, this leads to noise pollution or traffic accidents. There have not been appropriate solutions to resettlement and compensation programmes, affecting the speed of site clearance and project completion.

Project management is poor due to low capability and knowledge, especially when dealing with new technologies and with different mechanism of donors. There is not any professional training for project management.

Monopoly remains in some infrastructure services, causing excessive costs and low quality and service accessibility of the poor.

\section{(4) Financing policy for infrastructure projects is slow and insufficient.}

The issuance of financing policies is slow, affecting the mobilization of funding for the projects, even when budget allocations have been decided.

The mechanism to use the soft credit sources for large projects is often not completed causing difficulties during the implementation process.

\footnotetext{
${ }^{13}$ According to surveys on comparative service costs in Asian countries, the cost to transport a container for a distance of 40 feet is USD1,500 for Vietnam, USD870 for China, USD697 for Malaysia, USD675 for Indonesia, USD540 for Singapore. 1kwh costs USD0.07 for Vietnam, USD0.05 for Malaysia, USD0.04 for South Korea, USD0.03 for Indonesia. A 3-minute international call from Vietnam to Japan costs USD6.93 while the same call costs USD2.29 from Thailand and USD0.97 from Singapore.

${ }^{14}$ In terms of road transportation, roads in developed countries often have 4-6-8 lanes, in regional countries is 2-4-6 lanes, but roads in Vietnam have 1-2 lanes. Percentage of asphalt road is $95-100 \%$, in developed countries, $60-65 \%$ in regional countries, and only $40 \%$ in Vietnam. Percentage of double road in Japan accounts for 90\%, 80\% in Korea, 30\% in China but there is no double road in Vietnam; regarding railways the percentage of electrification in Japan is $60 \%, 75 \%$ in Korea, $55 \%$ in China, but that of Vietnam is zero. Regarding airway, numbers of landing at Seoul kimpo (South Korea) are 195000 turns, at Changi airport (Singapore) are 340,000 turns and Tan Son Nhat (Vietnam) are 38,000 turns. Area of passenger lounge of Seoul Kimpo Airport (South Korea) is $175000 \mathrm{~m}^{2}$, that of Changi Airport (Singapore) is 505,000 $\mathrm{m}^{2}$, and that of Tan Son Nhat (Vietnam) is $117,000 \mathrm{~m}^{2}$
} 
The use of ODA is tied with high interest rates and equipment procurement conditions. Also, while there is no policy allowing Vietnamese contractors to bid for lower costs. A number of more developed regions could borrow soft credit funds to invest in infrastructure but, as yet, there is policies that allow them to do so.

The mechanism to mobilize capital from the private sector is not effective. The use of private funding is arbitrary, not transparent and accountable to the community. Embezzlement and waste in project management remain unchecked. Supervision by the community is not fully realized.

III. OBJECTIVES AND DIRECTIONS FOR LARGE-SCALE INFRASTRUCTURE DEVELOPMENT AIMING AT GROWTH AND POVERTY REDUCTION.

\section{Objectives for large-scale infrastructure development:}

The general objectives for 2020 are as follows:

To build up the foundation for the development of a modern infrastructure system for an industrialized Vietnam by 2020.

To form a large-scale infrastructure system with a view to guaranteeing steady and stable operation of the economy and creating a driving force for economic industrialization and modernization.

To form a regionally integrated infrastructure system for the rational distribution of resources, thereby reducing the regional development gap and ensuring all economic sectors can have equal access to infrastructure.

To build up a large-scale infrastructure system that is capable of receiving modern technologies of the world and being competitive in the process of regional and international integration.

\section{Directions for large-scale infrastructure development:}

(1) Criteria for selection of priority sectors and industries for large-scale infrastructure investments:

- Investment in infrastructure must be linked to goals for socio-economic development in general and must be planned for the years to come, thus maximizing the use of the whole system.

- Project selection of priority sectors or fields should be based on concrete analysis of choice between growth and poverty reduction in each period, each region ${ }^{15}$ and each field, harmonizing these two goals. In the same area and for the same benefit, projects that help more with poverty reduction will be selected.

- Selection must be based on criteria such as project benefits, operating costs, maintenance costs, cost recovery possibilities, etc. Based on cost-benefit analysis, prior the projects with positive benefit and higher cost recovery possibility.

In addition, evaluation should be carried out for social impacts on poverty reduction, project targeted beneficiaries, and impact expansion of project etc.

\section{(2) Directions for priority fields.}

Priority fields will be selected in parallel to the implementation of the Public Investment Programme.

For transport, investments will be continued for main transport network connecting key econ zones, for the protection of borders, post and telecommunication infrastructure.

For irrigation, investments will be focused on water supply and main channels in Tay Nguyen, the Central, the Mekong Delta and the Red River Delta.

\footnotetext{
15 Choosing investment priority aims to maximize the economic return rate (ERR) or the poverty reduction rate (PRR). If investment to have equality were needed then the return rate would be low. Some researches prove that building communal roads in poor provinces could help to achieve reduction in poverty but could not make much contribution to growth.
} 
For electricity, key projects will be Son La hydropower station and other stations in border regions, island areas and mountainous or remote areas.

For education and training, resources will be concentrated on major State universities to meet the standards of large universities in region and in the world.

For science and technology, priority will be given to research laboratories and facilities especially with regard to biological technology, informatics, material technology, etc.

For health service, investments will be focused on central and regional hospitals to upgrade treatment facilities.

For culture and information, priority will be given to radio and television broadcasting, thus helping the process of international integration.

For water supply and drainage, projects in major cities and industrial areas such as Hanoi and HCM City will receive higher priority in order to meet the demand on drinking water and step by step solve the flood issues in these cities.

For housing development, priority will be given to housing programmes in flood prone areas, calamityaffected areas in the North, the highland in the South, the coastal areas in the Central, new urban areas and industrial zones.

\section{(3) Directions for economic infrastructure development.}

- Energy will be developed in advance with a view to meet the demands of socio-economic development, national defence and security in line with the goals of industrialization and modernization. Natural resources for energy and other recycled sources will be fully exploited and effectively used. Initiative will be taken in regional and international integration in the framework of Mekong electricity network cooperation. Studies will be carried out for atomic energy. The target is to reach a total electricity generation capacity of 53 billion kwh by 2005, 88-93 billion kwh by 2010 .

- Electricity will be supplied with increased quality and greater efficiency. Special attention will be given to waste reduction in generation, transmission and usage. The target is to reduce electricity waste rate to $10 \%$ by 2010 .

- To integrate national electricity network with regional networks to guarantee a safe and effective supply of electricity throughout the country, particularly for urban areas, industrial and economic zones.

- Step by step to establish a competitive market for electricity supply; diversify investments and businesses in electricity industry with appropriate policies to encourage various economic sectors to participate; continue to carry our electricity price reform under the approved roadmap, thus further facilitating production while improving people's living conditions; enhance the competitiveness of electricity supply in order to expand cooperation in the region; implement organizational and administrative reforms in electricity industry to raise managerial capacity and productive efficiency; provide more financial sources for the electricity industry; minimize pollution and environmental damages.

- To develop transport infrastructure in line with industrialization and modernization; to meet transport demands as well as guarantee national defence and security; step by step complete the national transport network; modernize key transport lines and international air and sea ports; create a strong change on structure, size and technology in construction, industry and specific mechanism; build a network connected regions with other countries through "'open gate', transport point, important economic zones.

- To reach, by 2010, the target of 450 million tons of cargo and 112 billion tons per kilometre; 1.225 billion passengers with 57.6 billion passengers per kilometre.

In transport infrastructure development, priority will be given to technological upgrading for the existing works while building a number of new works for socio-economic development; To complete, by 2010, an 
effective transport network with modern infrastructure; to make and implement urban transport strategy with reasonable cost to meet the transport demand of cities, locomotive growth regions, rural areas; and create policies for road safety.

Priority will be given to the complete upgrading of all national highways in the main network connecting to important economic regions, border areas and the Southern Highlands, the rural road network, roads to air and sea ports; to build a new highway parallel to National Highway No.1 to clear traffic bottlenecks; inter-provincial roads in the Mekong Delta; border roads in the Northern provinces; bridges over major rivers; complete the Ho Chi Minh Highway to boost economic development in the Southern Highlands.

By 2005, all national highways will have asphalt or concrete cover; bridges over major rivers be completed and major national highways be widened.

Strength capacity for maintenance works; study and apply the advance science and technology in management and maintenance of road network.

To study the feasibility of fast-speed highway network in more developed regions, key economic zones and heavy-traffic areas.

To continue upgrading the existing railway network, guarantee railway safety while shortening time duration; open new railways to important economic centres.

To develop trans-Asia railway and road networks connecting ASEAN capital cities, industrial centres, cultural and tourist destinations, seaports, river ports, container ports, thus forming a trans-national traffic corridor.

To complete the network of national and local seaports; develop river transport; invest in more modern transport vehicles while ensuring safety and efficiency; continue to modernize domestic and international airports to serve socio-economic development and international integration.

To modernize existing and build new airways and airports; develop air traffic control system equipped with modern technologies.

To continue development of basic transport network, public transport network in major cities, thus reducing traffic jams and environmental pollution.

- To continue investments in irrigation works system with a view to reproducing cultivation land, increasing crops, changing plant structure and effectively exploiting new cultivation land, guaranteeing agricultural diversification and food security.

To strengthen and upgrading river and coastal dykes to anticipate high flooding and severe storms. To complete during 2001-2005 the irrigation and water drainage network for the Mekong Delta so as to minimize the adverse effects of calamities in the Central and Southern Highlands.

To accelerate the programme of consolidating irrigation quays and trenches on the basis of mutual investment by both the State and community; encourage private investment in irrigation works, targeting $20 \%$ $40 \%$ of funding from the community for new works and $20 \%-30 \%$ for maintenance of existing works.

To reach, by 2005, the target of 6.6 million hectors of rice cultivation and 1.5 million hectors of vegetable cultivation fully watered.

- To accelerate development of national information system in a stable, modern and long-term manner to serve the requirements for socio-economic development and national defence and security.

To create a healthy legal environment, encouraging and facilitating Vietnam's Post and Telecommunication service to reach the regional standard; expand telecommunication business with a view to preventing monopolies; apply high technologies and manufacture international standard telecommunication products for future export. 
To reach, by 2005 , the target of $100 \%$ coverage of fibre cable and for all communes to have access to telephone services; develop internet service.

To enhance the capability to integrate in international telecommunication network with competitive costs; increase the quality and time duration of broadcasting programmes; modernize technical facilities and technologies for broadcasting and step by step transform to digital technology.

(4) Directions for social infrastructure development.

To make a major move towards enhancement of educational quality to reach international standards in the specific conditions of Vietnam, practically serve socio-economic development; prioritize the quality of human resources development particularly for highly capable scientists, managers and skilful workers.

To effectively implement the Law of Education; radically reform school curriculum towards diversification and modernization to a high standard;national universities and research centres must take initiative in redefining goals, reforming methodology and contents.

Step by step modernize schools; complete the network of universities and colleges, concentrating on a number of universities, which can compete with those in the region. Priority will be given to teacher-training universities which can turn out quality teachers and researchers; build new universities according to the master plan, turning universities into training as well as researching centres; pay due attention to higher education and spearheaded research fields; expand international cooperation in education and training between universities and research centres with a view to develop the country's human resources.

To continue to invest in research and experiment capacity for scientists; facilitate studies on new technological application in order to raise competitiveness and economic efficiency.

- To invest and modernize a number of major hospitals in cities and district health centres, thus capable of providing treatment for serious illness and checking contagious epidemics; develop pharmaceutical industry into a spearheaded business, guaranteeing sufficient supply of quality and safe pharmaceutical products. The target for 2010 is to standardize practices of all pharmaceutical producers, researchers and businesses.

To invest in modern technologies and equipments in pharmaceutical production; build new industrial manufacturers for anti-biotic and pharmaceutical materials, especially those using herbal sources; guarantee sufficient and regular supply of medicines listed for the national health care programme.

- To continue to plan new inhabitant centres; provide houses for inhabitants of flooded areas in the Mekong Delta, guaranteeing their normal daily life and minimizing loss of lives and poverties.

To carry on studies on plans for inhabitant areas surrounding major urban centres and industrial zones; plans for housing development for inhabitants in natural calamity-affected areas in the Central, the Northern and the Southern Highlands.

- To make plans for clean water supply for each areas; doubling supply capacity for urban and industrial centres; to reach the target by 2010 of $90 \%$ urban dwellers having access to clean water; reducing water waste from the current $39.4 \%$ to $30 \%$ by 2010 ; complete water supply networks for major and heavily-populated cities; raise the capacity of existing water stations while building new ones where necessary. The target is a capacity of 5-5.5 million cubic metres per day by 2010 .

- To train the staff, workers in management, maintenance and guide them to use the water supply system. Improve mechanism to use the soft credit for water supply projects.

To concentrate investments in sewing drainage and waste management in urban and industrial areas; prevent regular flooding in raining season, first in Hanoi and HCM city.

IV. POLICIES AND SOLUTIONS FOR LARGE-SCALE INFRASTRUCTURE DEVELOPMENT.

To reach the objectives set out, several policies and solutions have been decided as follows: 
1. Enhance planning and planning management in order to development large-scale infrastructure, guarantees a suitable timetable for construction with long-term effectiveness and appropriate with available economic resources.

Focus to investment and construction planning, particularly, updated planning for each project based on real demand for infrastructure; scale, time and timetable should be determined for each infrastructure project.

Sectoral planning should be integrated into general planning and land-use planning, combining large-scale infrastructure with small and medium -scale infrastructure into an integrated network.

Radically reform the work of planning so that socio-economic infrastructure planning will include countrywide and inter-region characters.

Publicity and transparency are needed for general planning and socio-economic strategies, based on which sectoral plans are made; encourage community's participation in examination and supervision of project under implementation.

2. Develop large-scale infrastructure in a way that ensures the spreading impacts of dynamic economic areas to create opportunities for inter-region links.

Enhance the spreading impacts of dynamic economic areas is suitable for Vietnam's current development trend, which starts from areas with high potential of human resources, geographical advantages and other objective factors to adjoining areas.

Strengthen links between high growth centres and adjoining areas in order to guarantee a fast and balanced growth between regions through constructing national and inter-provincial transport roads, connecting to rural, remote areas and to the neighboring countries.

\section{Diversify resources for investment in large-scale infrastructure projects.}

It is necessary to guarantee that capital mobilization for large-scale infrastructure investment will accelerate economic growth while not affecting financial sources for poverty reduction.

(1) To make new policies and mechanism for maximum mobilization of resources for development.

Demands for infrastructure investment in the coming years will increase; therefore, new policies and mechanism are necessary to raise State budget incomes, meeting to the maximum infrastructure requirements.

Continue to reform tax policy and enhance effectiveness of tax management in order to guarantee longterm financial sources for large-scale infrastructure development and growth targets.

Make new policies to boost investment demands appropriate with each specific areas and mobilize to the maximum local resources; continue to issue public bonds, government bonds, project bonds, etc, to pool capital for key projects.

Study and implement plan for the development of a financial market for capital mobilization for the whole economy.

Quickly implement the amended Law of Land with a view to develop land-use rights and property market, thus enhancing capitalization for development and raising budget incomes.

Accelerate the process of rearranging and reform State-owned enterprises; accelerate equalization of SOEs, particularly large, profit-making SOEs for which 100\% control by the State is not required, thus expanding stock market and social capitalization.

Make new policies and mechanism to prevent monopolies in some infrastructure services with a view to raising economic efficiency and competitiveness.

(2) Continue to realize existing policies and mechanism that encourage private sector's participation in large-scale infrastructure development. 
Amend and complete existing legal provisions to create a sufficient and integrated legal framework for effectively implementing the Law on Domestic Investment Promotion; allow private enterprises to have landuse rights equally to State enterprises as provided for by the amended Land Law; support the private sector in capital raising, production expanding, access to market and technology information, etc.

Extend BOT investments; select and list appropriate BOT projects that can be carried out by investments from community, publicly informing of the projects for public choice; encourage foreign investors to take part in BOT projects.

Extend the mechanism of exchanging land for infrastructure; offer bids for land-use rights to raise funds for spending on urban infrastructure such as roads, water supply in urban and industrial centres.

Mobilize unused capital from the population through issuing government bonds for BOT projects.

(3) Attract more foreign capital for infrastructure development.

Attach due attention to and intensify international cooperation related to FDI attraction; initially, implement Vietnam-Japan joint initiative on improvement of Vietnam's investment environment; multilateral cooperation programmes within ASEAN, APEC, ASEM; intensify investment promotion activities in key markets like Japan, EU, the United States and others.

To attract ODA resources for infrastructure project, it is necessary to issue appropriate policies and mechanism for inviting ODA to infrastructure projects, creating firm foundation for investments by private sector in a later stage.

Guarantee sufficient counterpart fund for ODA projects; timely implementation of compensation, site clearance and resettlement of tenants to facilitate investment projects; continue to harmonize procedures for ODA projects, particularly with regard to project licensing, bidding, supervising and evaluating; organize training courses for project managers from central to local levels.

The attract of ODA and other sources of financial assistance from overseas should be carried out in the framework of a general strategy for foreign loans and payments, thus ensuring an effective use of these sources and debt payment ability. 
(4) Guarantee a fair and effective distribution of resources for infrastructure development.

Effective resources allocation must ensure enough funding for infrastructure development in key economic areas, thus raising State budget incomes, while supporting poor and less developed provinces; create favorable conditions for various sectors to invest in local industries and projects.

To ensure an effective distribution of resources through a process of selecting priority projects based on precise evaluation on economic benefit and social impact of the projects.

Investments with the State budget funding will be focused on national road network, mountainous and border areas; irrigation works; key power stations and key projects for education, science and technology, health care, etc.

Prioritize grant sources of ODA for projects of poverty reduction, health care, education, human resources development, social issues (job creation, water supply); environment protection and natural resources development.

ODA loans should be used for projects in agricultural and rural development; transport; communication; energy; social infrastructure, etc.

Private sources of capital will be directed to electricity generation and transmission projects, rural transport infrastructure, irrigation, water supply in rural and cities areas, and private and semi private schools, etc.

\section{Pay adequate attention to environment and inhabitant resettlement concerning large-scale infrastructure projects.}

\section{(1) Environment protection}

Evaluation of environmental and social impacts of large-scale infrastructure projects must be seen as a constitutional part of the projects. Evaluation results must be considered throughout the process of implementation with a view to minimizing negative impacts to environment and sustainable development.

Evaluation of environmental impacts must be incorporated as a separate item in the project record, which must prove a sustainable use of natural resources, environmental impacts and solutions involved. Financial funding for environment protection measures must be included in the estimated costs for the project.

The assessment of environment impact must keep standard requirements on environment issued by government agencies in order to use effectively natural resources for sustainable development targets.

Survey public opinions on environmental and social impacts of projects during the process of making the evaluation report.

Project investor must submit a report on environmental impact to the State management authorities before the project can be approved.

Create conditions for government agencies on environment management to supervise, monitor the project implementation.

\section{(2) Inhabitants' life stability and resettlement}

The State makes appropriate policies for compensations when using land for national defence and security purposes or for national or public interests. Compensations can be made in cash, housing or land.

Apart from site-clearance compensations, project investors must be responsible for supporting expenses for re-training farmers who have been removed from their land. If there is demand for workers, investors must offer new jobs to these farmers as first priority.

For those tenants who have to leave, the State will support expenses for them to resettle. In case of big projects when local inhabitants have to move to new settlement quarters, the State will provide moving allowances or offer them similar policies as those who go to settle down in new economic zones. 
Resettlement programmes are carried out under existing laws and regulations and in that sense; the inhabitants have become beneficiaries of the infrastructure projects. New resettlement quarters must have infrastructure appropriate to the local conditions and planning.

Funding for infrastructure in resettlement quarters will be taken from the infrastructure compensation fund on project site, land capitalization and other supporting sources.

\section{(3) Working accident reduction and traffic safety guarantee}

To promote information dissemination on work safety regulations for workers working on infrastructure construction projects, particularly for complicated and difficult projects which have high risk of work accidents such as mining channels, high-voltage transmission lines, etc.

To equip necessary facilities for work safety during construction; enhance the capacity of ministries, management authorities and project management boards in supervising the implementation of accident preventive measures on construction sites.

During the process of operating road works, it is necessary to apply measures for traffic safety. Due attention should be paid to dissemination on traffic law and regulations with a view to raising the community's consciousness for traffic law observation. Traffic will be more closely scrutinized and traffic law offences will be more severely fined or punished. The system of road signs and traffic lights will be improved and traffic police force must enhance responsibility for educating and guiding traffic law for the community.

\section{Reform management mechanism for infrastructure projects in line with current management trend.}

(1) Reform management mechanism for infrastructure investment, enhance power devolution for project management.

Urgently implement new regulations on construction investment in any stage from project formation to operation; enhance the work of examination and approval in order to avoid overlapping and ineffective investments.

Enhance decentralization while also enhancing capability and responsibility in project management by ministries, sectors and provinces; strengthen supervision and evaluation of investment projects in the whole licensing process, thus guaranteeing the mobilized capital is used properly and efficiently.

Projects supervision and evaluation have to deal with both direct and indirect benefits of the projects while pointing out necessary corrections if needed.

Carry out the measures to minimize risks in project construction and operation.

Decentralization is needed for ministries, sectors and provinces to take initiative in reviewing investment purposes and supervising the project implementation process. Community involvement in examination and supervision should be promoted.

(2) Enhance managerial capacity for large-scale infrastructure projects.

Enhance the managerial capacity of authorities involved in project management.

Standardize the work of the staff; increase training courses for project managing staff during and after the implementation of the project.

Enhance accessibility to new building technologies and new standard of management with special attention given to project supervision.

Regular reports should be made, particularly with regard to reports on evaluation results of key projects; keep regular updating of information and managerial know-how.

(3) Building relations with partners 
Close working relations between the Government and donor organizations will create favorable conditions for the long-term effect of investment in large-scale infrastructure projects.

Supporting measures associated with large-scale infrastructure services such as building rural road networks, developing human recourses, improving investment environment, enhancing project management capacity, operating capability, etc, are needed. Those community groups that are not beneficiaries of growth should be supported through poverty reduction programmes.

Strengthening relations with donors will help making strategic decisions, using strong potential and input from.

Diversifying financial assistance is necessary. Close technical supervision and examination are needed especially for large-scale infrastructure projects to make sure these projects meet environmental and social requirements. Sharing information and co-decisions between Vietnamese authorities and donors should be continued throughout the process of implementation and management of projects.

\section{Enhance the work of maintenance for large-scale infrastructure projects.}

Operating effectiveness and usefulness of infrastructure services depend greatly on the implementing and operating of the projects. Projects cannot be operated successfully without properly following maintenance requirements. Budget spending on operations and maintenance work for infrastructure services continues to be insufficient to ensure the proper upkeep of facilities ${ }^{16}$. There lacks the continuity of coordination between project management and maintenance responsible authorities, which greatly reduces the effectiveness of the projects.

In the coming time, maintenance work for previous projects and implementing projects should take the following solutions:

- Increase funding from the State budget as a separate fund for effective maintenance.

- Build a mechanism for mobilizing financial sources other than budget for maintenance work. Maintenance cost should remain as a separate item in the project spending.

- Use fees for using public infrastructure services such as roads, irrigation and other public works as a budget income, which can be spent on maintenance.

- For public works that can generate incomes such as transport, irrigation etc, and public utility businesses must add maintenance cost under existing regulations to production costs and properly follow maintenance standards.

- Extend various forms of private investment and promote society investment in education, health and other social activities; encourage local and foreign investors to invest under BOT for public service projects, thus increasing funding for maintenance.

- Decentralization in management for public projects; use unpaid labour for maintenance work.

- Financial funding for the maintenance of budget-invested infrastructure projects should be done under plan, which takes into account the public spending programme.

\section{Realize cost-reduction solutions for infrastructure services increase accessibility of the poor to infrastructure services.}

One of the reasons for the limited accessibility of the poor to infrastructure services is the fact that the service fee is often too high compared to their incomes. In order to improve accessibility for the poor, State

\footnotetext{
${ }^{16}$ Regular spending on maintenance for irrigation works is as low as $2 \%$ of total invested capital for irrigation and $8 \%$ in case of education projects, $10 \%$ in case of health care projects. Annual spending on maintenance for road network is just enough for only $30 \%$ of demands.
} 
budgetary support is needed in developing infrastructure services in rural and remote areas. Private sector should be encouraged to invest in areas where the local community is able to pay.

Appropriate fee policies should be adopted for large-scale infrastructure services in poor localities, thus helping the poor to be able to use these services.

Solutions should be found in order to raise the efficiency of building and operating infrastructure services. It is necessary to enhance management capacity and apply advanced technology with a view to reducing costs and raising competitiveness for infrastructure services. It is also necessary to have solutions for prevention of waste and downgrading of infrastructure services. 
MAJOR POLICIES AND MEASURES TO DEVELOP SECTORS AND INDUSTRIES TO PROMOTE SUSTAINABLE GROWTH AND POVERTY REDUCTION

\section{POLICIES AND MEASURES TO DEVELOP MAJOR SECTORS AND INDUSTRIES TO CREATE INCOME GENERATION OPPORTUNITIES FOR THE POOR}

The policies and measures proposed in this Part are drawn on and further elaborated from the Ten-Year Socio-Economic Development Strategy and the Five-Year Socio-Economic Development Plan, as well as sectoral programs and projects on economic growth and poverty reduction.

\section{Develop agriculture and the rural economy to achieve rapid poverty reduction}

$77 \%$ of the population and $90 \%$ of the poor currently live in rural areas. $70 \%$ of the income of rural inhabitants comes from agricultural activities. For this reason, agricultural and rural development is a crucial component of the Comprehensive Poverty Reduction and Growth Strategy.

As the area of cultivation land is limited and the traditional agricultural product market is thin, to achieve high growth and achieve fast poverty reduction, it is necessary to simultaneously implement the following measures: (i) develop science and technology; (ii) facilitate structural change in the rural economy; (iii) build up new institutions that involve the active participation of farmers in production, processing and marketing; (iv) increase investments in agriculture, particularly in rural infrastructure; (v) develop human resources; (vi) reform policies on land, business environment, finance, investment and credit in order to make investment more propoor; (vii) implement administration reforms; (viii) strengthen international cooperation. These measures aim to achieve a number of objectives including increasing productivity and reducing production costs, increasing the competitiveness of agricultural products in domestic and international markets, diversifying agricultural, forestry and fishery production, improving processing capability in order to raise product quality and better meet domestic and export demand, creating more jobs and raising rural incomes by developing rural industry, services and other off-farm activities.

\subsection{Increasing efficiency and diversifying agricultural production}

Conduct market studies and studies of comparative advantage that can be used to adjust the structure of agriculture and the rural economy. Readjust land planning and focus on intensive agricultural production for productivity improvements, and ensure that production is consistent with market demand. Develop specialized commodity production areas for rice and corn with focus on intensive production of high quality varieties to meet domestic and export demand.

Implement measures to raise the value and efficiency of rice exports. Implement policies to protect the interest of food producers. Ensure food security under all circumstances.

Develop specialized commodity production areas for industrial crops and fruit trees such as coffee, rubber, tea, pepper, coconut, (silkworm) mulberry, cotton, sugar cane, groundnut, soybean, tobacco etc. Develop specialized areas for high quality and high value vegetable, fruits and industrial crops linked with the development of processing industry, storage facilities, marketing and export promotion activities. Increase technical assistance and provide new seeds to farmers and improve their access to credit to enable them to expand production and increase their incomes, diversify income sources to cope with market price fluctuations and risks.

Implement land use planning and grant land use rights in order to increase the efficiency of land use. Allocate unused land to rural inhabitants and others who really need land for production. Continue to revise and amend the Land Law to ensure security and better implementation of land use rights (long-term tenure, transfer, inheritance, collateral etc.). In the near future, grant long-term land use right certificates to farmers, especially to those who live in mountainous areas. Make plans and implement measures to provide integrated 
support in the form of credit, seeds and knowledge to help the poor to escape from poverty and avoid selling or mortgaging their land. Adjust norms on land allocation in accordance with specific conditions of poor regions and regions where ethnic minorities live. These norms will serve as a basis for implementing landsupporting policies in accordance with living standards, cultivation habits and cropping pattern of the poor in the region.

With respect to the extremely difficult, remote and disadvantaged areas, the government will provide funds to build infrastructure, reclaim wasteland, and reallocate unused or inefficiently used land from current holders, who will receive adequate compensation, to households that lack cultivated land for production and long-term settlement.

Strengthen production and processing of animal feed, improve local veterinary services, meet the growing demand for high quality livestock products, expand hygienic and epidemic prevention programs, develop a system to monitor and report on diseases, improve food safety. Exempt the poor and ethic minority households living in disadvantaged areas from various types of production and trade related taxes.

1.2. Vigorously develop forestry, turning it into a profitable business that helps to create jobs and raise incomes for people in mountainous areas. Provide adequate incentives to people who plant forests and promote the role of the community in the protection and natural regeneration of forests. Continue the implementation of the 5 million-hectare forestry program; speed up the process of allocation of land and forest, especially in important, environmentally sensitive areas. Ensure that key annual targets are achieved including new afforestation of approximately 300 thousand hectare with protected and special-use forests making up approximately 150 thousand hectare; forest protection for total area of about 2 million hectare, of which forest regeneration combined with new planting makes up approximately 500 thousand hectare; and caring for planted forest with total area of approximately 500 hectare.

Allocate land and forest together with implementing fixed cultivation and settlement, and stabilize the livelihood of people in mountainous areas. Encourage fixed cultivation and settlement and voluntary resettlement. Provide financial support to reallocate people from vulnerable and disaster-prone areas (flash flood, land erosion etc.) towards safer areas. Ensure that people living in mountainous areas, especially poor households, can directly manage and protect their forests and are provided with appropriate incentives that link their benefits and responsibilities with the forest.

Continue to review, revise and amend policies on investment in forest development including adjusting norms and unit price in forest protection and care. Provide interest free or low interest loans for afforestation, adequately invest in infrastructures in forest areas (roads to transport materials, storage facilities, etc.), develop forest processing industry to increase the value received from forestry and create forestry-related income generating opportunities.

1.3. There is significant growth potential in aquaculture and off-shore seafood exploitation. The Government will introduce policies to encourage intensive aquaculture, and develop offshore fishing taking into account constraints in capacity, investment and technical facilities in different regions. Intensive aquaculture and fishing is considered to play an important role in accelerating economic growth and poverty reduction. The Government supports the planning and construction of dykes, water inlet sluices and channels; provides public goods such as extension services, quarantine, quality control for breed and feed in order to help farmers increase production efficiency and achieve sustainability.

Make investments to support fishery infrastructure, power transmission lines, roads etc. in aquaculture areas that are either newly established or converted from rice or salt production. In the immediate future, build and complete six national breeding centers, and environment alert centers in specialized aquaculture areas in the North, the Center and Mekong River Delta. By 2005, ensure that the area for aquaculture production is about 1.2 million hectare, with total production volume of approximately 2.6 million tons, of which shrimp production amounts to about 300 thousand tons. Ensure the sustainability of the growth of aquaculture production. Improve the access of poor fishery households to production inputs, information, extension services, credit and markets. 
Improve capacity in recovery, management and risk prevention in aquatic production including both aquaculture and fishing.

Diversify aquaculture production; rapidly expand specialized shrimp and fish areas, or integrated shrimprice and fish-rice areas by making full use of ponds, lakes, surface water, rivers, and streams to raise shrimp and fish to improve living standards. Implement policies on subsidized investment, training, technology transfer, and breeds for poor households that are engaged in aquaculture. Aquaculture and seafood production must go handin-hand with environmental protection and sustainable development.

Encourage the development of seafood farming through policies on investment support, credit on preferential terms, and other favorable policies.

1.4. Strengthen applied research and technology transfer, considering it as a most important break-through measure for raising production efficiency and diversifying incomes generated from agriculture, forestry, aquatic production and other activities of the rural sector. Pay attention to research on and development of appropriate technologies, in the first instance those seeds and breeds that have high productivity and are of high quality and value, modern cultivation technologies, effective plant protection and veterinary services, and postharvest technologies. Strengthen socio-economic and environmental research. Re-orient and re-organize the current agricultural research system. Increase budget expenditure for research, creating new varieties of breed, and technical training.

Implement training courses for local officers and poverty reduction cadre in planning for socio-economic development, project management and poverty reduction methods. Expand vocational training for rural youth. The Government provides investment support infrastructure, the students only have to contribute monthly fees. Establish a mechanism to support the expenses of vocational training facilities at the local level.

Encourage the development and raise the quality of training and agricultural extension services to farmers. Focus agricultural extension expenditures on disadvantaged areas to ensure that poor and ethnic minority peoples will reap benefits from extension services as much as other areas. Provide to the poor on regular basis market information on the application of new varieties, guidance on production techniques, experiences in production, introduction of successful business models and new effective ways to conduct business. Attach special importance to training cadre to provide extension and advisory services to women, local people and those who know the languages of ethnic minorities.

Support research to develop low-cost but highly efficient technologies that are needed by the poor. Encourage the sharing of production experience between researchers, managers, technical personnel and farmers to improve the productivity of crops and animals.

Build and disseminate effective self-help poverty reduction models for different areas, to help hungry and poor households overcome their difficulties and develop their capacity to gradually change their production methods to escape from poverty and integrate with the wider community.

Encourage the development of and provide support to a variety of voluntary joint and self-managed forms of extension services in every community to enable people to share experience in cultivating and animal breeding in order to increase income and reduce poverty.

1.5 Continue rapid implementation of the Government's Resolution No. 09/2000/ NQ-CP and No. 05/2001/NQ-CP regarding initiatives and policies aimed at changing the structure of the economy and marketing agricultural products.

Continue to support export activities and the expansion of export markets for agricultural and forestry products. Study and promulgate, within the framework of Vietnam's trade related commitments, policies to support production and marketing of a number of agricultural, forestry, and fishery products that have high economic value and have potential to become competitive, that have potential in export and/or in import 
substitution markets, such as: rice, rubber, coffee, tea, raw materials for processing (wood, sugar cane, cotton, mulberry...), shrimp, fish.

Encourage enterprises and individuals to engage in various forms of co-operation, both horizontal (production-processing-distribution) and vertical (commodity-association) to facilitate the distribution of marketed surplus for farmers. Set up appropriate legal framework to promote the implementation of various forms of economic contracts related to agricultural production between enterprises and individuals on the one hand, and farmers and local community, on the other hand.

Provide favorable conditions to enterprises, regardless of their ownership form, to access credit and obtain tax reduction and exemption, for implementing projects that invest in processing, or developing material areas supplying inputs for the processing industry, in remote and disadvantaged regions, or where the poor community lives.

Develop policies to protect the rural population when they are hit by natural calamities, storms and flooding, or exposed to market price risks; the forms of protection include market-based risk management instruments such as forward contracts, production insurance etc. and direct methods such as exemption or reduction from certain taxes, subsidized inputs (seeds, materials) for households experiencing difficulties.

1.6. Continue to encourage agricultural diversification and the development of rural professions according to Prime Minister's Decree No. 132/2000/QD-TTg dated 24/11/2000. This aims to create more jobs, increase income generated from rural industry, develop services and off-farm activities. Each locality shall promulgate, on the basis of specific local conditions, policies to institutionalize and put into effect measures in accordance with the direction specified in the Prime Minister's Decision. The Government will promulgate a master plan and directions to develop rural professions according to the market mechanism to ensure sustainable development and to protect the environment.

Focus and create opportunities for farmers to change production structure, implement agricultural diversification: the State will promulgate policies to encourage shifts in the structure of plants, animal and crops. Carry out labor-intensive multi-purpose business activities; develop commodity-oriented production to increase the value added of each unit of land and labor.

Reduce the monopoly of SOEs in agricultural product markets; create conditions for private enterprises to develop, particularly in poor areas.

Establish a supportive legal, institutional, financial and business environment to facilitate the task of setting up small and medium rural enterprises to create more non-farm employment in rural areas; encourage the private sector to provide services and provide seed capital for labor-intensive enterprises. Give special attention to female-headed SMEs operating in processing and services.

Complete the set of policies to encourage investment, technology transfer, marketing of products, greater use of domestic materials (wood, rattan, bamboo, leaves etc.). Implement policies on providing loans on preferential terms, easing land rental costs, providing tax exemption, giving freedom to do business, and marketing products.

The State provides support to develop infrastructure for traditional craft villages; in addition, provide more support for training, technology transfer, and the dissemination of information to expand and develop professions. Provide support to help set up at least one training center in each district and local area, especially to train in the local traditional profession. Encourage crafts people, co-operatives, craft and trade associations, and unions to open more training classes in their local areas.

With respect to regions that experience production difficulties and have many poor households, the Government will increase investments complemented by investments by the local community to build essential infrastructures such as roads, power supply, water supply, communications, schools, village clinics, and to support the establishment of small and medium sized rural enterprises in rural areas. 
Focus on investing in and developing non-farm businesses in rural areas: processing and storing agricultural products, producing construction materials, bamboo and rattan products, handicrafts, pottery, glass, textiles. Modernize processing industries, packaging and sales marketing, and thus, improve the quality of agricultural, forestry and fishery products, and on that basis increase the value and competitiveness of Vietnam's products. Set up handicraft and processing centers in rural areas that promotes rural industry and services. Attach special importance to developing agricultural services such as land preparation, transport, irrigation, crop and animal protection, material supply, marketing services.

Through the annual plan and national programs, the government will set aside a given share of the budget for direct investments, to create opportunities for poor farmers to shift their production structure, and expand specialized trades and professions such as: interest-free loans for mill construction, purchasing equipment; providing support for training in new techniques, organizing the supply of materials and the marketing of products.

1.7. Improve access to financial and credit services in rural areas (saving and credit); reform and renovate the rural financial and credit system, establish a sustainable credit market, create conditions to facilitate investment in modernizing and diversifying agricultural products and to mobilize private investment in processing high quality products. Enable poor households to "lend-and-borrow" money easily. Expand the savings fund system and develop concrete policies to mobilize dormant capital from communities to generate more credit resources for the rural sector. Strengthen the role and improve the organization and the general direction of the Bank for the Poor and the system of People's Credit Fund.

Improve loan procedures and formalities by introducing the one-stop shop approach in order to improve the access of the poor to capital. Pay special attention to providing medium term and long term loans and match them to the production cycle.

Apply appropriate credit policies to targeted groups; create conditions for poor and disadvantaged people, with priority given to women, to access credit at reasonable interest rates and on a timely basis to develop their production. In the near future, continue to apply the policy of providing credit at low interest rates to poor people; in the long term, policy will shift from subsidizing interest rates towards improving access of poor people, especially women, to credit by simplifying lending procedures combined with providing training.

Directly subsidize banks and credit funds that operate in disadvantaged areas to offset their additional transaction costs, thus enabling them to maintain interest rates on a par with the general level.

1.8. Reorganize production, protect and encourage household, farm and private economies to shift towards large-scale labor intensive production; continue to strengthen the collective economy with different types and diverse forms and sizes, on the principle of voluntary membership, democracy, transparency and efficiency and empowerment of participants of cooperatives. Provide economic information regularly to poor communes and households. The Government will provide farm communities with guidance to help them to select and identify products that are marketable and yield high return.

Encourage the development of formal and informal forms of assistance among farmers (self-help groups, social services groups, savings and credit groups, marketing groups, education and training groups, women's groups, etc.). Strengthen the position of farmers in cooperatives to improve their access to bank credit, insurance, extension services and marketing.

Create favorable conditions for households engaged in production and business activities to participate in the market; encourage them to gradually transform household enterprises into joint stock companies with largescale production.

1.9. Develop a disaster prevention strategy to minimize losses and stabilize livelihoods and production in disaster-prone areas. 
Strengthen the program on disaster prevention and mitigation, build the system of information collection and hydrometeorology forecasts, raise the awareness and improve the people's capacity to respond to natural disasters, build infrastructure and safe sites, build up reserves for emergency and train rescue teams. Establish the Fund for Recovery from Disaster to provide timely and effective assistance to the poor in case of disaster. Make efforts to set up the social safety net system such as the Hunger Prevention Fund, which may be utilized before the harvest period.

Annually, State budget funds will be used to invest in building and mending dykes and in funding other flood and drought prevention facilities and to build flood prevention and distribution facilities in the North. In the Central region, continue to adjust the population master plan, build flood prevention facilities, lakes to prevent water overflow, provide financing for people to build houses on stilts to withstand the effects of flooding, complete the irrigation sea dyke system, estuary dykes and flood control, reduce losses from natural calamities, especially to ensure the safety of people's homes and ensure their normal life in the deep flood areas in the Mekong river delta during the high water season.

Establish local flood prevention funds mobilized from contributions by the people according to government regulations. Furthermore, a reserve plan is needed to cope with weather problems.

\section{Industry and urban development in order to create more jobs and improve the living standards of the poor}

2.1. The development of industry contributes significantly to economic growth, job creation, increasing workers' incomes, including the poor living in urban and rural areas.

Ensure the fast and efficient development of industry so that it is more competitive and more responsive to market demand. Focus on investments to upgrade technology and modernize industries. Achieve a good balance of industries with comparative advantage, high-technology industries, strategic industries, processing industries, labor-intensive and local materials-intensive industries.

Develop and modernize industries that support agriculture and the rural sector (e.g. chemicals, fertilizer, packaging etc.). Continue to diversify and modernize the mechanical engineering industry to meet demand from agricultural production such as small tractors, processing machines, post-harvest technologies, modern insecticide spraying machine and water pumps, etc.

Develop microbiology industries to enable agriculture to shift towards environmentally safe production in order to protect consumer health, thereby ensuring sustainable penetration of the market and increasing consumer confidence.

2.2. Develop and expand the linkages between small-scale and large-scale industries in urban areas based on developing SMEs in traditional businesses which apply modern and environmentally clean technologies to create high value products. Expand subcontract activities in rural areas.

Encourage small-scale private enterprises (e.g. retail and wholesale establishments, factories) to expand their investments, adopt a long-term business perspective, and employ more workers.

Encourage large companies and enterprises in the transportation and construction sector, as well as other sectors that have the potential to absorb labor, to hire more people and to create stable jobs for the poor.

The main forms of encouragement are: create favorable conditions regarding business production site; reduce the cost of land rental (in some rural areas, zero cost rent can be applied); income-tax reduction for enterprises proportionate to the number of workers to be recruited; take back the production site of inefficient enterprises and give it to other more efficient ones to rent; give public recognition and show respect to entrepreneurs who demonstrate a commitment to the long-term development of their sector and promote job creation in that sector. 
Encourage banks and financial organizations, large enterprises and individuals to channel investments to small and medium enterprises, to provide them with economic information and to train their labor force.

Provide support to SMEs to become direct exporters and to develop stable long-term relationships with foreign trading partners.

Establish trade promotion centers and centers to support small and medium enterprises at central and local levels under Government Decree No. 90/2001/ND-CP dated on November 23, 2001 on supporting the development of small and medium enterprises.

Provide guidance and implement regulations on policies to encourage industries to move to rural areas and to set up rural industry centers. The incentives include land provision, support in inputs, investment, credit, tax and fees, market information, science, technology and environment, and labor training etc.

2.3. Encourage the urban poor to make their own efforts to escape from poverty, with assistance from the Government and the community. There should not be any discrimination between local and migrant poor.

Set up a framework and master plan of urban development in order to solve the problem of slums and temporary shacks in cities and towns, to reduce urban poverty and vulnerability; develop a national strategy on urbanization.

In order to reduce urban poverty and unemployment, it is necessary to create jobs, reduce unemployment, develop and adopt economic growth strategies and polices in urban areas, including investment programs in all economic sectors that have an impact on the poor; create jobs through development of small and medium enterprises; develop the services sector to enable poor people to create jobs for themselves.

Improve and expand the vocational training system and job services to enable the urban poor to have stable employment, increase their earnings and gradually improve their living conditions.

Develop policies aimed at providing loans to the urban poor through savings programs and community credit, including small loans for business and production activities; priority subsidies for education, health care; housing renovation and other essential infrastructures, e.g. water supply and drainage, electricity, sanitation etc.

Continue to develop programs on upgrading infrastructure systems with local outreach; gradually renovate and expand urban transport, develop public transport. Ensure the provision of basic services, e.g. water supply and drainage, sanitary and public lighting etc. to poor communities. The urban waste garbage management program will be extended based on the principle of socialization in order to reduce pollution in urban poor areas. Develop public health-care programs. Develop policies of urban housing development for the poor communities and lowincome people, i.e. current living areas will be upgraded in accordance with financial resources, while ensuring employment for the poor in urban areas. Create conditions for the poor to contribute to infrastructure projects in their commune, district, or town, so that they can have opportunities for income-generating employment.

Develop strategies and policies for urban development that includes the objective of poverty reduction, and allocate land for building houses for the poor, creating conditions for balanced urban development to reduce the gap between rich and poor. There should be balanced development between inner and outer city areas, strengthening the linkage of urban - rural areas by job creation programs in agricultural processing industries, trade and services.

Develop strategies to protect the urban environment, ensure sustainable development by minimizing health risks, especially for the poor, by adopting water, air and land pollution treatment measures.

Develop standards and procedures in urban design and planning, ensuring that environmental sanitation requirements are met taking into account demand and the poor's ability to pay in urban areas.

Implement the reform of administrative procedures taking into account the actual circumstances of poor people with respect to land and housing management, the issuance of business and construction certificates, and resident registration in urban areas. 
Develop policies to encourage the community of the poor, to mobilize the ability and initiative of the poor, including their financial resources, labor, and experiences participating in housing, infrastructure development and income generating activities.

\section{Infrastructure development to create opportunities for poor areas, poor communes and poor people to access public services}

Continue the development of infrastructure (transportation, post, electricity, etc.) to create better capacity for socio-economic development. Concentrate on developing trade and marketing infrastructures such as ports, warehouses, loading and discharging berths, market places, etc., and on providing market information in order to reduce costs and to increase the competitiveness of agricultural products.

\subsection{Electricity development and consumption in poor communes}

For poor communes located in power line-accessible areas, the Government will support capital to build electricity lines to connect to the national grid. The division of responsibility is as follows: the Government will invest in high-voltage lines, medium-voltage transformers and first-top electric meters. The next part of the transmission wire (i.e. below the first-top meters), which are low-voltage lines and lines accessed by households, will be financed by the people. Carry out management of the task of distributing and selling electricity to each household in which payment will be made to the State at the price of the first-top meter. The forms of electricity supply, payment management and organization are as follows: electricity management division at the commune level; electricity supply co-operatives, sales contractors which can be a group of several households, or local electricity companies, will be responsible for sales.

For communes that cannot access the national electrical grid (estimated to number about 200 poor communes), the Government will provide capital financing or extend concessional credits with zero interest rate to enable local people to develop their own self-supplying electricity plants, e.g. small-scale hydro-electricity plants, household generators, or group of several households using other types of energy (solar-energy, wind power, etc.).

For extremely poor households, the State will provide additional financial support in order to set up connection lines from main electricity grids to each household and also finance electrical wiring inside their homes.

The Government will provide support for training, training cadre, and staff to work as managers, operators and as maintenance personnel to increase efficiency. In the immediate future, priority will be given to remote and isolated regions and areas where the terrain is difficult. Regulations governing electricity usage in every commune also will be formulated. Government will provide instructions on lowering electricity prices for the poor to ensure that it is not much higher than the standard charge for electricity consumption in cities.

Spending on maintenance in electrical projects will be covered by annual payments from consumers. For extremely poor communes, the Government will provide partial financial support for major repairs.

\subsection{On developing road transport}

In order to achieve the identified goals and targets of developing transportation infrastructure, it is necessary to continue broad implementation of the "State and people working together" mechanism to construct and upgrade the current transportation system, including new concrete bridges instead of bamboo-made bridges (also called "monkey" bridges in the Mekong river delta), in order to improve the people's quality of life and production conditions.

Ensure that all commune centers and commune-group centers will be reached by car-accessible roads. For mountainous provinces in particular, build roads that medium and small trucks can use to reach commune or commune-group centers; in areas with difficult terrain: in the first phrase, roads will be built for motorcycles and horse-carts; in the second phase, they will be expanded to accommodate cars and trucks. Ensure that 30 
percent of roads will be made of concrete, 70 percent of rural roads can be transportable year round. Abolish 80 percent of "monkey" bridges in the Mekong River Delta area. Gradually develop public transportation; provide cargo and passenger transport in rural and poor areas.

With respect to communes in remote and isolated areas that have rural industrial zones, the State will adopt special policies to build roads connecting to the main highways and to upgrade roads that have deteriorated.

Investment in upgrading and expanding roads within the commune will mostly come from the people's contributions $(60 \%$ of total investment in the form of labor and locally produced materials), with the State providing 30\% of total investment in the form of major materials such as cement, steel etc. Priority will be given to investing in upgrading, expanding and rehabilitating existing roads, focusing on those roads that are still not yet year-round passable; new constructions will be considered when sufficient resources are found.

For inter-commune roads, connection roads from communes to districts and other main routes in poor communes, the State will provide support for most of the materials and bulldozer services; the remainder will be covered by mobilization of local resources.

In order to mobilize more efficiently and more abundantly current, and even potential, resources to develop rural transportation in general, and in poor communes in particular, an integration of targeted programs is needed; the integration of Program No. 135, the mountainous commune-group centers development program in mountainous areas, and the socio-economic development programs in Northern mountainous areas, Central Highlands and the Mekong River Delta.

Publicize the opportunity for people in poor communes and poor communities to participate in making selections and making decisions about building, upgrading and expanding road transport in areas funded by resources from the State budget, based on the Decree on Grass-roots Democracy, which closely links the benefits and obligations of local people with the investment and utilization of construction projects in transportation in their areas. Project selection and decision-making need to be made public, to be democratized, and to be based on resources that can be mobilized from these localities. Rehabilitate and upgrade the existing train system and construct other essential train lines.

Upgrade the domestic waterway system, especially in the Red River delta, and Mekong river delta, ensuring that this mode of transportation can be utilized around the clock.

Upgrade the infrastructure system in urban areas, especially in Hanoi and Ho Chi Minh City, and reduce traffic jams.

\subsection{On developing small-scale irrigation works for poor communes:}

For poor communes within Targeted Program No. 135 that do not have an irrigation system or a system that has deteriorated, the State will provide support from the state budget to invest in a new system or to upgrade. In extremely poor mountainous areas where there is no water-cultivation, the State will provide support to develop terraced fields, to create better conditions for poor people to produce food locally, or to plant forests.

For communes near main irrigation stations, the State will invest to develop irrigation canals to supply water, and provide material support in concert with the people to build the inner-field canal system.

Continue to focus investment in developing small-scale irrigation works in poor communes and poor areas.

Carry out the collection of irrigation fees for constructions that the State has invested in; the fees should be enough to cover recurrent and operating costs, and not to pay for the initial investment outlays.

Formulate regulations to define the responsibility of local authorities (at the commune level) to maintain and manage, on a long-term basis and with the participation of the community, small-scale irrigation works in their communes. 
The current situation of developing irrigation works in poor communes indicates that the contribution from the people accounted for 20-40 percent of total investment expenditure for new irrigation construction, and about 20-30 percent of total maintenance and recurrent expenditure. Explore the possibility of applying this formula on a larger scale in the coming period.

For areas that do not have water resources for developing irrigation at the local level, especially in remote and isolated areas, the State should provide more support and assistance.

\subsection{Development of the information network in the countryside, especially commune cultural-model post} offices

Continue to develop the information network in the countryside, especially in poor areas and remote areas, and in communes with extremely difficult conditions. Continue the establishment of cultural-model post offices in all communes in general and in poor communes in particular. Post office usage is very high among poor people, but the possibility for capital recovery is very difficult. The State will research mechanisms to support the development of commune cultural-model post offices.

\subsection{Development of kindergartens and nursery schools}

Kindergartens and nursery schools, especially in rural areas, play a crucial role in helping the poor to access to public services and reduce poverty sustain ably. They also help children to develop themselves and to be cared for properly, reducing their malnutrition rate, developing their intellectual skills and enabling them to go to school at the appropriate age. At the same time, they provide girl children with more opportunities to go to school instead of having to look after their younger siblings; families with very young children can increase their working time or actively finds jobs.

By 1998, 26 percent of total communes have kindergartens and 77 percent have nursery schools; the rate of kindergarten attendance is 4 percent and nursery school attendance is 40 percent. However, those rates are much lower in the Central Highland (2 percent and 25 percent) and in Mekong River Delta (1.5 percent and 14 percent). The State now is researching and developing suitable mechanism for the development of kindergartens and nursery schools, especially in remote, isolated and ethnic minority areas.

\section{Establish an education system for the people that is more egalitarian and of higher quality}

\subsection{Organize to implement the Strategy to Develop Education 2001-2010 (Decision 201/2001/QD-TTg on} December 28, 2001)

Focus on renovating educational objectives, content and curriculum with a view to standardizing, modernizing, moving closer to advanced standards in the region and the world, in keeping human resource requirements in our economic sectors, regions, and localities, promoting study linked with action, discussion and planning linked with implementation; raise high the quality of universal education; strive to increase average hours of study and the percentage of children in school all day, especially in rural areas. Continue to raise the quality of higher and post-secondary education, and vocational training.

Develop the contingent of teachers, ensure that their numbers are satisfactory, and are appropriate with respect to structure and standards. Renovate the training program and nurture teachers, lecturers, paying special attention to maintaining and raising the ethical standards of teachers.

Renovate the management of education in the direction of raising the effectiveness of state management; strongly decentralize with a view to promoting initiative and responsibility at the local level, at the grassroots education level; prevent and curb negative behavior.

Continue to complete the structure of the national education system and develop the network of schools and education at the grassroots level; improve the structure of the national education system in the direction of diversifying, standardizing, building links between universalizing education, from technical school to higher levels, university and post-graduate. Organize effective channels to further education for students who complete 
lower-secondary and upper-secondary schools. Develop the network of schools, classes, grassroots education to be responsive to the requirements of our people, economic sectors, and regions. Give priority to developing higher-level technical and industrial schools. Give priority to grassroots education for ethnic minority peoples and in remote and isolated regions.

Encourage and create the conditions for all society to participate in the development of education. Create opportunities for all to study on a regular basis, with a view to lifetime learning. Develop schools outside the public sector, with mechanisms and policies to give them priority with respect to renting land and accessing credit. Expand funds to encourage study, funds to support education, to encourage individuals and groups to invest in education. Develop community-based education centers. Renovate the regime of education fees in the direction of matching with the quality of educational services, appropriate to the capacity of the student, while providing exemptions and reductions for poor people. Pay attention to removing the gender gap in education, apply special measures to encourage women and girls in remote and isolated areas, and ethnic minorities areas, to go to school. Overcome gender-related prejudice in textbooks to promote equal opportunities in education.

Vigorously promote international cooperation in education. Encourage the expansion and vigorous promotion of international cooperation with respect to training and cooperative research with various schools and various scientific research institutions worldwide.

4.2. Continue to develop ways to expand equality of access to education, pay special attention to improving the quality of education for poor people and disadvantaged groups (including girls), consider this one of the focal points of development that is decisive for poverty reduction.

Continue to complete the set of policies on equality of access to training; access to primary and junior secondary education for children from rural households and those in poor regions is of special importance; ensure gender equality and enable girls to access education.

Continue to invest in the education system for poor communes and poor regions. Strengthen material facilities for education, including building and rebuilding classrooms that previously were built of bamboo and leaves. Provide adequate teaching and studying facilities for all primary and junior secondary schools. Pay attention to developing concrete and semi-concrete schools in areas that often suffer from natural calamities. Maintain and expand the boarding school system in remote, highland and isolated regions; implement the boarding school system in communes; construct and consolidate models of schools in regions (at the district level) to encourage poor households to send their children to school. Attract ethnic minority girls to boarding schools; increase the representation of girls in these schools.

Improve the quality of training and education in poor communes and areas, ensuring that children in poor areas have better access to high quality primary education. Make progress in improving educational programs and textbooks for school children as well as teaching and capacity building programs for teachers. Construct special policies for training staff working in disadvantaged areas such as improving the salary and allowance regime, giving priority in training and other preferential regimes for teachers. Apply various measures to raise the share of female teachers coming from ethnic minorities.

Construct the package of exemptions and full support mechanisms in primary education for children from poor households covering school fees, cost of textbooks, contribution fees, cost of meals, lodging costs, transport costs. Provide timely support to families with children in primary school living in areas affected by calamities (bad harvest, disaster) to reduce their difficulties and to prevent their children from dropping out of school. Step by step pay particular attention to poor students at the higher levels of education.

Create conditions for ethnic minority peoples to study and become fluent in the national language as well as in their own language. Give priority to training cadre in extremely disadvantaged communes and provide training for targeted peoples. Apply special selection mechanisms for regions with special difficulties. 
Adopt policies to encourage and create conditions for rural young people to study and find appropriate jobs after graduation (e.g. creating scholarship funds, funds to assist job-seekers, subsidizing people who come back to work in their homelands...).

Strengthen education and information dissemination on national targeted programs, introduce professional occupations and publicize the role of education and training in increasing income and improving living standards, in order to encourage the poor to invest in education and training.

4.3. Increase financial resources for training and education. Increase the share of spending on training and education in the state budget from $15 \%$ in 2000 to at least $18 \%$ by 2005 and to $20 \%$ by 2010 . The state budget will focus more on the primary education level, mountainous and rural areas, high quality education and sectors that have difficult attracting non-budgetary investments. Obtain concessional funding from the World Bank, the Asian Development Bank, other international organizations and other countries. Encourage the participation of the private sector in education, particularly in vocational training. Encourage various forms of investment and expansion of the labor market to increase job opportunities, and opportunities of high productivity jobs for poor people and poor regions. Implement preferential mechanisms for land use and provide concessional credit for investment in basic education.

\section{Improve the quality of health services, family planning programs, improve access and reduce health care costs for the poor.}

5.1. Strengthen and improve the grass-roots health service network. Improve access for the poor, especially women and children, to basic health services; ensure equality in accessing and using health service. Reform the operation of the Committee for Health Care at the grass roots level.

Harness the capacity of the army health service by combining military and civil health care to provide health services to local people, especially in mountainous, islands, borders, and remote areas. Regulate and develop the non-state health service.

Consolidate and develop health services in poor regions. Ensure that $100 \%$ of commune and villages will have clinics. By 2005: 100\% of inter-commune polyclinics will have doctors; $65 \%$ of all communes will have doctors (in mountainous areas: $50 \%) ; 100 \%$ of commune clinics will have midwives (60\% will be secondary midwives) and midwifery. By 2010: 80\% of all communes will have a doctor (in mountainous areas: $60 \%$ ); $100 \%$ of villages will have at least primary health-care staff.

Expanding training to develop local health staff, with priority given to on-site training of ethnic staff in mountainous, remote, and disadvantaged areas. Promulgate favorable policies (salary, health insurance, social insurance, hospital shift allowance, and preferential training...) to encourage health care staff working in mountainous, remote, isolated areas and areas that lack medical staff.

5.2. Draft and promulgate priority policy in health care for mountainous, remote and isolated regions, with special attention to ethnic minorities and poor people. Special health policy is needed for women, children, and dependent elderly who live alone. Promote the application of traditional medicine in health care. Encourage the development of herbal and traditional medicines to reduce the cost burden for the poor.

5.3. Improve the quality of public health services, especially at the grassroots level, in mountainous, remote and isolated areas. Applying the national standard for commune health services. Plan well the curative care network and define areas of specialization. Strengthen the professional capacity and medical ethics of health cadre. Promote supervision and technical assistance from the higher level to the grassroots level in health service, so that the grassroots level can become fully capable of diagnosing and curing diseases at the correct technical level, thus solving the overload problem for the higher level while improving efficiency in health care.

5.4. Continue to develop preventive health care and health improvement, reducing the infection and mortality rate. Implement effectively national targeted programs to control the spread of infectious diseases, dangerous diseases, and those commonly affecting the poor, such as malaria, goiter, tuberculosis, leprosy, and 
mental illness. Take effective measures to prevent these diseases from spreading. Take care of HIV/AIDS patients in the community and have policies about bringing up the children of those who died from HIV/AIDS. Ensure that there is no discrimination against HIV/AIDS patients that they have access to work like other people.

Implement effectively the National Action Program for Children of Vietnam and the Strategy to Care for Maternal Health in the period 2001-2010. Ensure that all children can access basic health care services. Taking appropriate and effective measures to improve mother and child nutrition. Improve the quality of health services provided to mothers and children.

Have the means to prevent and overcome quickly health consequences caused by natural disasters. Effectively implement national policy to prevent accidents, injuries and the effects of smoking. Strengthening supervision and check to ensure food quality and safety.

Continue to carry out the integration of National targeted programs between the health care sector and poverty reduction. Strengthen communication activities for health education; discourage backward customs, habits and lifestyles that are unhealthy. Increase the percentage of families that have access to clean water and hygienic latrines. Accelerate the socialization of health activities; mobilize people to participate actively in sanitation activities that promote hygiene and involve preventive health care and physical exercise to create the "All for health" movement.

5.5. Increase funding for health. In the coming years, the government will continue to increase funding for health, with priority policies to take care of the health of people living in mountainous, remote and isolated areas and regions with a high poverty rate. More funding will be provided to develop the grassroots health service network. Improve the provision of medical equipment for basic health care; ensure that the supply of medical equipment is adequate according to the Medical Equipment Category List issued by the Ministry of Health.

Establish a suitable financial mechanism to cover fully expenditures for regular health care activities of commune and district health centers, especially in mountainous, remote and isolated areas and in areas with large ethnic minority populations. Extend pre-pay health care services, health insurance, especially health insurance in rural areas, moving towards compulsory health insurance for all.

Have appropriate and effective policies and measures to reduce the cost burden for the poor for curative services. The state ensures adequate funding from the budget to carry out well pro-poor policies such as: reducing and exempting the cost of accessing health care services; buying insurance cards for the poor, the dependent elderly who live alone, the disabled, at the same time, implement the hospital fee exemption policy for ethnic minority peoples and children under 6 years old.

The State provides free of charge common medicines to treat social diseases (such as malaria, goiter, indisposition, tuberculosis, mental problems) and basic vaccines for children. The State implements targeted subsidy policies to prevent diseases in mountainous areas. The State provides ordinary medical subsidy of VND 20 thousand per capita per annum for ethnic minority people living in Region III.

5.6. Organize to implement effectively the Vietnam Population Strategy in the 2001-2010 period. Consider implementation of family planning and the reduction of the birth rate to be one of the important steps to poverty reduction. Attach special attention to publicize family planning to couples of high fertility age, targeting males. Diversify and use effectively communication channels and the other educational channels, communicate with everyone in order to improve their knowledge and commitment to family planning and to maintaining an appropriate family size. Step by step achieve an appropriate population growth rate to improve the quality of life for all strata of people; integrate population targets in the development plans.

6. Develop an advanced culture, strong national identity; improve the dissemination of information to help people expand their options 
6.1. Promote investment, develop culture and information, build an advanced culture with a strong national identity; preserve and restore our tangible and intangible cultural heritage to serve as a foundation for cultural exchanges among communities and regions throughout the nation as well as in the international arena. Consider as important culturally appropriate media activities to change habits with the aim of increasing demand for cultural services, and enrich the spiritual life of the poor.

Encourage socio-economic associations, communities and even foreigners to invest in the development of culture and information dissemination at the grassroots level in isolated, remote, rural, mountainous and ethnic minority areas.

Focus on building commune cultural centers that combine meetings and recreation areas. By 2005, ensure that all communes have cultural centers (telephones, libraries, books, newspapers, meeting rooms) that have regular operating hours. The mission of the commune cultural center is to be the home for cultural activities, to provide information, disseminate news about new policies, especially providing information that is directly relevant to the poor including information about advancement in science and technology, about good production models, about good people and good deeds, and about investment proposals to help the poor...

Encourage social associations such as voluntary youth, pupil, and student associations to come to rural areas as part of mobile information dissemination activities geared towards the poor to propagate cultural knowledge, information about new lifestyles, health and hygiene, science and technology for poor households and ethnic minorities.

Encourage communities, philanthropists, and enterprises to sponsor activities having to do with culture, sports, communication, and preserving our cultural heritage.

6.2. Upgrade the quality and expand the information system at the grassroots level in many forms (in both concentrated and dispersed form, through direct meetings) utilizing various means of communication (broadcasting, television, books, newspapers, documents, pamphlets...). Disseminate information in both national and ethnic languages.

Improve the quality of education programs to ensure that they are entertaining in order to attract and encourage the participation of children. Ensure that all communes nationwide have newspapers and magazines to improve the language ability of ethnic minority children. Enrich and maintain popular sports. Strengthen cultural and sports activities for all.

Upgrade and improve the quality of information, provide information for human development; assist people by providing more information so that they can expand their choices and decision-making capacity.

Continue to complete the nationwide broadcasting and television system, ensure that more than $90 \%$ of households can see Vietnamese television programs and that $95 \%$ will be able to hear the Voice of Vietnam by 2005. Develop and modernize the mass media network. Increase the amount of broadcasting and television time and publish ethnic language books and newspapers that are suitable for each locality. The Government will have support policies to ensure that poor communes will have a communications station to disseminate State policies and information on science and technology.

Undertake the initial investment in essential facilities such as the cultural house, library, broadcasting and television equipment, certain kinds of books, newspapers, and scientific and technical documents... Supplemental investment and the cost of operations and maintenance (O\&M) will be mobilized by communities.

Develop mechanisms for management and operation that are appropriate for each province and area. Beside the direct management carried out by the postal sectors, communes will develop their own action plan, asset management mechanism; operations expenditure, service fees and a regular maintenance plan for these facilities. 


\section{Protect the Environment and Maintain a Healthy Life for the Poor}

7.1. Implement the National Strategy for the Environment. Harmoniously combine socio-economic development with environmental protection and improvement and ensure that all people are able to live in a healthy environment. Actively integrate environment issues in plans, programs, and projects, and make it a criterion for evaluating development measures. Enhance women's participation in environmental protection and maintaining a healthy life for the poor. Pay attention to the safe use of chemicals, food safety and hygiene.

Integrate fully the environment and natural resource issues into the master plan for socio-economic development in provinces, districts, and ensure that the development is sustainable and does not cause degradation in natural resources.

7.2. Constantly improve the quality of the environment and use natural resources in an appropriate way. Pay attention to biodiversity in poor regions, sandy, arid, and marsh areas, ensuring the availability of renewable resources for production by people, especially by the poor.

Improve water quality, increasing the number of people having access to clean water. Improve the quality of natural and planted forest; enhance the social, economic, and environmental value of forest land. Upgrade ecology that is poor, improve the stability of ecology in sensitive areas such as coastal sandy, tidal areas, and bare hills.

7.3. Concentrate efforts on dealing with environmental deterioration in industrial zones, densely populated areas, crowded living quarters in big cities and rural areas by encouraging clean production with environmentally-friendly energy-efficient technologies and by tightly controlling waste. Carry out pollution control and provide emergency services to clean up environmental disasters caused by natural calamities such as floods. Develop plans to reform and clean up environmental pollution in rivers, ponds, canals, fields, and homes. Expand infrastructure development and services to suburban areas, develop satellite cities, form district and commune level industrial clusters and develop rural professions.

Implement projects on environmental recovery and protection, protect watershed forests, build national parks and protected forest areas, construct national gardens, plant trees, preserve and protect bio-diversity. Develop and improve the quality of animal-botanic garden research centers and national parks in order to maintain and preserve precious and rare genetic sources.

Establish in cities and towns public environmental protection projects such as garbage waste treatment, waste water treatment, dust and noise pollution treatment; develop auto-disintegrative (two-compartment) latrine systems in rural areas; advise and provide guidance to mountainous ethnic people about healthy and hygienic practices including ending the unsanitary practice of keeping their cattle, pigs and poultry under their homes on stilts.

Have measures to prevent environmental problems, such as using natural resources effectively, managing strictly water resources and controlling waste and carrying out resettlement at a pace that is reasonable and linked with development concerns. Carry out estimates of the environmental impact of every socio-economic development project. Apply policy measures to encourage the participation of the private sector in production projects to ensure long-term use of water resources by strengthening protection of catchments sources. Use support policies to encourage clean production processes, the use of technologies that do not harm the environment, and the effective use of energy resources.

Stop the degradation of natural resources, protect and manage natural resources such as protecting the atmosphere, oppose the destruction of forests, especially forests at the river head; continue to close off forests in vulnerable ecological areas and forests that are in the process of degrading; implement anti-drought measures and stop the process of desertification; sustain ably develop mountainous areas, protect bio-diversity, strengthen the management of bio-technology, strengthen fresh water management, and enforce safer use of harmful chemicals. 
Manage land in a sustainable manner, plan for the reasonable use of land, water resources and other natural resources; economize to protect the different types of ecological economies (shore, midland, highland, urban areas), pay attention to poor, remote and isolated areas; ensure a harmony between economic growth, poverty reduction and environmental protection. Have policies to safeguard the people's interests and link their interests to the benefits of protecting the natural resources that we hold in common.

7.4. Continue to implement the National Strategy for Rural Clean Water Supply and Sanitation during the period to 2010 (Decision No. 104/2000/QD-TTg dated August 25th, 2000). Ensure that 85\% of the rural population will have access to clean and safe water with the capacity of 60 liters/person per day and that $70 \%$ will have access to hygienic latrines and have good personal hygienic care by 2010 .

Strive that by 2005 , all kindergartens, schools, hospitals, medical stations, office buildings, and markets in rural areas will have clean water and hygienic latrines. Priority is given to provide clean water to water-shortage and disadvantaged areas (drought areas, islands, high mountains, and saline areas). Prevent water from drying up and being polluted, protect the quality of ground and surface water.

Strengthen education, mobilization, control and supervision over household and concentrated livestock breeding, and over the production process in handicraft villages in order to ensure environmental protection of communes... Provide incentive policies from the state budget to assist regions with difficult conditions, concentrating chiefly on poor people, especially mountainous areas with large ethnic minority populations. Other regions will make use of policies to mobilize the community, utilizing local contributions and the contributions of beneficiaries to build clean water, pollution prevention, environmental protection programs, etc. The Government will provide assistance in investing in projects to create resources (water containers, materials and other equipment), reserving capital from the state budget in the form of assistance finance and concessional credit to help peasants develop water supply and rural sanitation projects.

Establish the National Environmental Fund with funds from the state budget (using revenues from natural resource and pollution charges), common contributions and other voluntary programs aimed at covering the costs of environmental activities. Establish concrete policies to reward those who excel in meeting regulations and laws on protecting forests, water resources and the environment; impose strict penalties on those who break the law on natural resources and environmental protection.

Encourage business production and social service organizations to develop environmental services such as planting flowers, trees, collecting garbage, developing ecological tourism areas, and preserving ancient forests and precious birds, flora and fauna.

Establish policies to encourage the application of technologies and production processes that minimize the creation of waste matter and reduce environmental pollution. Employ tax policy, especially in the starting period, to encourage the use of clean production technologies; or to give tax exemptions to importing enterprises and manufacturers. Encourage the use of environmentally friendly gas in rural areas and develop solar energy, wind energy and other thermal energy resources. Amend regulations on environmental protection having to do with the investment process in order to ensure the freedom of citizens to invest and to protect against the danger of environmental pollution.

7.5. Complete the system of state administration on environmental protection from central to local levels. Strengthen international cooperation in the area of environmental protection, especially maintain cooperation with neighboring countries and countries in the region on preventing environmental pollution, and on transferring anti-pollution technologies and setting up models for waste treatment.

Strengthen the responsibility for environmental protection through environmental education programs in various forms, especially in the general education system. Mobilize and stimulate the participation of all strata of population, enterprises, and social organizations in environmental protection activities.

Implement adequately and concretely systems for environmental control and evaluation of different kinds of natural resources, especially in remote, isolated, and poor areas. Based on that information, we can plan the 
production process in order to ensure a harmony between economic growth, poverty reduction and environmental protection. Focus on evaluations and timely reports on the three environmental indicators: ratio of forest cover, percent of communes with access to clean water, and water and air quality; put sustainable environmental development in the annual development plan. Establish policies to stimulate and assist the community with environmental activities in order to increase the awareness and participation of the people.

Complete, supplement and establish statute documents, regulations, resolutions, standards and directions to implement Laws on Water Resources, Law on Environmental Protection, Law on Health Care for the People and other legal documents.

\section{NARROW THE GAP BETWEEN DIFFERENT REGIONS, REALIZE GENDER EQUALITY AND THE ADVANCEMENT OF WOMEN}

1. Create favorable conditions in social infrastructure and production capacity so that regions can develop on their own; narrow the social development gap between different regions

1.1. Concentrate resources on successfully implementing the National Targeted Programs for Hunger Eradication, Poverty Reduction, and Employment during 2001-2005

Continue to allocate resources and create opportunities for poor households to reduce poverty in a sustainable way: expand credit to poor households so that they can develop business production. Expand agricultural and forestry extension to provide guidance to the poor on how to do business. Replicate models for poverty reduction based on each region's particular characteristics.

Expand the range of targeted support beyond the poor communes under the 135 program of the Government, and include provision of infrastructure, support for professional development, training of poverty reduction staff, stabilizing the issue of migration and building new economic areas.

Link poverty reduction with job creation. Continue to provide loans to small projects for job creation through the National Fund for Job Creation; enhance the capacity of job service centers, improve the statistical system of information on the labor market, and train staff.

1.2. Along with implementing the National Targeted Program for poverty reduction and job creation, continue to carry out the following measures to create more opportunities and resources for poverty reduction:

Increase investment in underdeveloped areas in order to narrow the development gap between regions, and between urban and rural areas. Encourage big enterprises to invest in poor areas to create more employment, to support the development of small and medium enterprises (SMEs) in order to create more jobs and to increase income.

State budget expenditure should focus more on infrastructure development, especially roads and irrigation, and create more non-agricultural jobs in rural areas. Renovate infrastructure development mechanisms in poor areas.

Continue to improve the allocation of public expenditures to agriculture and rural development (e.g. agricultural extension, national targeted programs, etc.) to provinces, based on differences in socio-economic development, the poverty rate, and the province's own budget resources.

Mobilize the poor to build basic infrastructure as a job opportunity for them in order to increase their income. Pay attention to attracting women and men to planning, building, and monitoring infrastructure, with priority given to women's needs.

Attach special importance to the development of rural roads in poor areas. Develop special priority policies to expand rural roads as well as upgrade the quality of this network. Replace bamboo-made "monkey" bridges; create opportunities for poor localities to take the initiative in managing the development and maintenance of their own rural transport infrastructure. 
Expand the supply of grid-transmitted electricity; organize, manage and operate the electricity distribution system, especially in those remote and isolated areas that are characterized by complicated terrain and low level of consumer discipline. For border and island areas, areas that are far from the national power grid, and especially disadvantaged households that are eligible for policy-based support, the Government will finance part of the investment required for the construction of low-voltage primary line and sub-lines transmitting power to the homes of the people.

Develop rural markets, especially in mountainous, isolated, remote areas and islands, to ensure the provision of basic commodities to people and facilitate the distribution of agricultural products. The Government gives priority to providing support in terms of price and transportation costs of essential goods that serve the production and livelihood needs of farm households in extremely disadvantaged communes. Price and transport cost subsidies to extremely disadvantaged communes should be linked to agricultural extension, supporting the shift in breed structure, crop pattern, and other programs to support the poor in terms of capital, land, markets. Make sure that state subsidies reach the right beneficiaries and avoid excess reliance on state support.

Improve the investment and business environment, job security for the non-state sector. Ensure at least the minimum level of benefits for rural migrants to cities. Promote the market for services and the market for agricultural and rural products. Build small district industrial zones and craft villages to create jobs for idle agricultural workers and to increase income of farmers.

\section{Stabilize and raise the living standards of ethnic minorities}

Continue to implement the socio-economic development program for extremely disadvantaged communes (program 135), ensure that communes have essential infrastructure. Develop infrastructure and commune clusters, plan residential areas, promote agricultural, forestry and fishery production, train commune staff. Step by step narrow the gap between ethnic groups in terms of their material and spiritual lives.

Implement well the allocation of land and forests to individuals, households, and organizations in ethnic, mountainous areas, especially ethnic households. Ensure the entitlement of individual and collective land use rights to ethnic minorities and mountainous people.

Implement well the task of fixed-cultivation and fixed-residence, restrict free migration, stabilize production and improve the living standards of mountainous and ethnic peoples in a manner suitable to their customs and practices based on a master plan for population distribution in the direction of establishing concentrated population clusters, commune clusters and townships. Simultaneously, infrastructure conditions, such as transport facilities, water and electricity supply, communications, markets and so on, should be taken into careful consideration.

Effectively exploit the potential of these areas with respect to land and labor, intensify the development of forestry, cash crops, fruit trees, and traditional handicrafts in ethnic minority and mountainous areas.

Provide guidance on how to do business, transfer technology and provide information in order to develop strongly a market-oriented commodity producing economy, rapidly increase the share of industry and services in the economy and gradually move towards eliminating autarchic economy in ethnic minority and mountainous areas. Develop agricultural and forest production farms whose sizes are suitable to the management level and production capacity of each populated area. Combine agro-processing industry development with product distribution for different economic sectors in mountainous areas.

Raise the intellectual level of the people, preserve and build on traditional cultural values of ethnic peoples. Give priority to training and utilizing ethnic cadre at the local level, and gradually increase the percentage of ethnic cadres. Provide preferential treatment to and effectively utilize the contingent of village elders and village leaders and effectively implement the policy of maintaining strong solidarity among ethnic groups in ethnic minorities and mountainous areas. 
Continue to consolidate and expand the education, health care, culture and information activities of ethnic minority peoples. Preserve and develop reading and writing in ethnic languages. Provide access to kindergarten education to children from ethnic minority groups and opportunities for children from ethnic minority groups to complete primary education program in Vietnamese. Teach in ethnic languages at school for those ethnic groups that have written languages.

Provide information on poverty reduction programs in an accessible manner and in places where ethnic peoples can have easy access.

\section{Realize gender equality for the advancement of women and the benefit of children}

Organize to implement well the National Strategy for the Advancement of Women in Vietnam to 2010 (Decision No. 19/2002/QD-TTg dated January 21, 2002). Improve the material and spiritual life of women; raise and bring into play their capacity, ability and role to ensure that women can carry out their responsibilities and participate fully on an equal basis in all activities, especially in political, economic, cultural and social activities in the industrialization and modernization process in order to attain the goal of "prosperous people, strong country, and egalitarian, democratic and civilized society".

Ensure that all women can exercise their equal rights in the area of labor and work by providing enough cultivated land and basic resources, and setting targets for hiring women in newly created jobs. Complete regulations and strengthen the monitoring system to implement policies on women workers in order to ensure equality in vocational training, social insurance, labor safety and retirement policies. Mainstream gender issues in the national targeted programs. Establish a database system on the labor market and vocational training disaggregated by gender. Develop vocational training and employment service centers for women. Enhance the ability of women to access the credit system and poverty reduction resources to ensure favorable conditions so that women can be coached about how to effectively utilize this capital and how to obtain credit directly.

Take effective measures to ensure that women have equal access to education, and to improve their professional skills. Encourage girls from remote and isolated areas and ethnic regions to go to secondary school, boarding schools, colleges and universities. Provide support to poor women and girls to go to school. Have measures to correct gender inequality in major fields of study and engender vocational training. Review and improve the quality of textbooks, remove prejudicial stereotyping of women. Increase the representation of women in managerial positions at different levels. Establish the Learning Promotion Fund for women and set targets for the percent of women in different levels of training and disciplines.

Improve women's health by increasing their knowledge and improving the behavior of suppliers in providing health care and family planning services. Strengthen the basic health clinic system, including reproductive health and family planning consultations; develop active policies to encourage men to use contraceptive methods. Ensure that poor women can have easy access to health services. Enhance the quality of services before, during and after birth. Implement measures to control HIV/AIDS infections and other sexually transmitted diseases. Develop a database on occupational diseases. Improve the professional skills of health staff and the quality of services in health clinics for women and children.

Address the problem of women being overly burdened by domestic work by investing in: small-scale technologies to serve family needs, rural clean water, and energy projects. The reorganization of the kindergarten and nursery school system will also help to reduce the burden of domestic work for women and female children. Launch campaigns to raise awareness and educate about sharing family responsibilities.

Promote the role and participation of women in decision-making, leadership and management positions at various levels and sectors by overcoming discrimination against women and female children within the family, and by encouraging equal, respectful and cooperative family relationships. Create favorable conditions for women to take part in village and commune meetings and in planning, implementing and monitoring projects and programs in villages, communes, and at all levels. Review all policies on women workers and staff in order 
to ensure equal benefits from those policies. Mainstream gender issues in political and administrative training courses at various levels.

Ensure equal participation and benefits for women in the socio-economic development process by improving laws and legal documents on the protection of women's legal rights and benefits. Improve the awareness of, access to and utilization of legal tools for women. Enhance the capacity of administrative bodies and social organizations in implementing policies and strategies for the advancement of women and in effectively protecting women's legal rights and benefits. Strengthen women's rights in having the Land Use Registration Paper issued to them, enhance their role in decision making at the local level.

Strengthen the public education campaign with form and content appropriate for each area and group in order to improve the awareness and responsibility of government bodies, associations and families and all citizens in the mission of gender equality.

Respect and ensure the rights of children in the family and society. Strengthen public education and raise awareness of the role of family in nurturing children.

\section{DEVELOPMENT OF SOCIAL SAFETY NETS FOR THE POOR AND FOR VICTIMS OF NATURAL DISASTERS}

\section{Focus support on the poor, ethnic minority groups and other vulnerable people in society}

Improve the ability of the poor to access good quality basic services and resources, especially primary health care, primary education, reproductive health, sound hygiene, good nutrition, homes, and free legal aid.

Establish a priority system to help disadvantaged groups benefit from national targeted programs on social development. Establish a preferential regime for poor and vulnerable people to reduce contributions, fees and costs related to their social transactions and their access to basic social services, and in cultural and educational activities to elevate the people's intellectual level, legal knowledge and protect their right at no cost. Address the housing problem for the poor. Develop residential quarters that are flood resistant in Mekong River Delta. Have a plan to remove temporary houses for poor households.

\section{Expand social protection and the safety net}

Amend the State's policies on providing support to disabled and vulnerable people to help them to be selfemployed or to be employed by others with the aim that they will be able to earn enough to feed themselves, to participate in the community and in social activities, and to be able to reap more of the benefits of economic reform.

Complete social insurance policies with the aim of expanding coverage of the social insurance regime to all parties and ensure consistency between insurance contribution and insurance benefit.

Diversify the voluntary safety net. Strengthen measures to effectively protect plants and animals such as veterinary services and general epidemic management programs in remote areas. Develop pilot policies on plants, animal husbandry and market insurance in rural areas. Strengthening agricultural extension is considered to be the most effective method to reduce the vulnerability of the poor. Develop insurance programs on a community basis for the informal economic sector following the principle of group insurance (at minimum household insurance).

Expand social protection and the social safety net through different funds. Provide humanitarian support on a regular basis for the poor and hungry, especially for those unable to work and have no one to rely upon; organize and carry out the activities of these funds in communities and villages where the poor and vulnerable are concentrated. In that context, special attention should be given to provide assistance in kind (such as rice 
foodstuff, clothing and so on) to people in rural and selected urban areas who fall into very difficult circumstances.

Supplement policies and measures to protect and educate children in extreme difficulty, especially disabled children and orphans, street children, working children, and victims of Agent Orange and HIV/AIDS. Improve the responsibility of the family in protecting and educating children. Mobilize the whole society to protect children in extreme difficulty.

Develop a system of policies and measures to support the disabled, the elderly (those without any support), victims of toxic chemicals and HIV/AIDS.

Develop social relief centers in poor areas and in localities that often suffer from shocks in order to nurture those who lose the ability and the opportunity to earn a living. In the near future, effectively implement specific stipulations of Government Decree No. 07/2000/ND-CP dated March 9, 2000 on the policy to provide social relief in the three-year period from 2001-2003.

Adjust the method of state budget allocation to implement social policies, give local authorities the initiative, especially at the commune/district level, in order to strengthen the development of the community fund at village and commune levels.

\section{Develop solutions to support the poor and the vulnerable to improve their conditions to participate in labor markets}

Improve the access of poor workers and disadvantaged groups to the labor market, and especially their access to training. Resolve well the problem of labor redundancy. Gradually introduce the use of unemployment insurance.

Increase the number and quality of jobs created, especially in the non-state sector. Complete the Labor Law to promote the development of the labor market. Ensure job security. Oppose arbitrary dismissals; ensure stable work with rising income and comfortable working conditions. Reduce accidents at the workplace. Ensure gender equity with respect to retirement age; oppose the use of "early retirement" as a tool to solve redundancy problems at SOEs as well as other labor market problems.

\section{Develop an effective system of emergency social relief solutions}

Develop an effective system of emergency social relief solutions for poor and vulnerable people who are hurt by natural disasters, accidents, and other negative social shocks; improve this policy based on adopting emergency relief measures, including:

Improve the mechanism to establish and coordinate the Emergency Relief Fund.

Help the poor to take preventive measures against and fight effectively natural disasters such as storms, flood, drought, pests, etc. by organizing training, and transferring knowledge and practical experiences about managing natural disasters. Provide a share of the needed financial support to help them improving housing conditions to prevent storms, flood.

Reorganize populated areas, production infrastructure and social infrastructure to facilitate efforts to prevent and combat natural disasters and to provide relief. Organize and prepare aid facilities to respond rapidly and in a timely fashion to limit the negative effects of natural disasters; provide guidance for the poor so that they can take the initiative to help each other when hit with natural disasters. 
Organize assistance to help the poor recover from natural disasters so they can quickly resume normal life and production; for example, provide them with necessary factors of production (such as seeds, trees, livestock, tools for cultivation); solve environmental problems after the natural disaster has struck. Build facilities to store food, foodstuffs, and clothes in each community where natural disasters are frequent so they can be distributed quickly to disaster victims.

5. Expand the participation and enhance the role of domestic social organizations and nongovernmental organizations in the process of building and implementing the social safety net

The Fatherland Front at all levels takes the lead and coordinates with governments of different levels and mass organizations to develop measures to motivate agencies, enterprises and the entire people to take part in social relief and to help the poor.

Encourage relief aid and humanitarian assistance from non-governmental organizations, mass organizations, and social organizations to develop the social safety net, to effectively help the vulnerable, especially the elderly without support, orphan children, and victims of toxic chemicals and HIV. 


\section{PART VI}

\section{Mobilizing and allocating resources for economic growth and poverty reduction}

For the successful realization of the CPRGS's objectives, our preliminary funding estimates of the investment requirements for the Five Year Development Plan 2001 - 2005 for the industries and sectors: agriculture, forestry, fishery; industry and construction; transportation, post and communications; education; culture; health; science and technology; services; public sector; and various national target programs on poverty reduction is about VND $840-980$ thousand billion (US\$ $60-70$ billion), equal to 1.5-1.75 times compared to total investment implemented during the 1996-2000 period.

\section{INVESTMENT FOR DEVELOPMENT}

\section{Investment requirement for economic development}

1.1. Agriculture, forestry, and fishery: the investment requirement is about VND $110-133$ thousand billion. Of this amount, funding for agriculture (changing the structure of plant and animal production, new perennial crop cultivation, production of varieties, infrastructure investment, constructing focal production zones, basic processing, preservation and technology transfer...) requires VND 53-62 thousand billion; for forestry, to complete the New Five Million Hectare Forestry Project, developing economic forests, creating raw material zones combined with the construction of paper, powdered paper, plywood manufactures, requires VND 10 - 13 thousand billion; for fishery, to continue to invest in intensive farming, expanding cultivated areas to 1,2 million hectare including ocean fish farming, building fishery infrastructure, developing off-shore fishing fleets, requires VND 21 - 27 thousand billion; for irrigation, to upgrade existing facilities to increase their productivity from $60 \%$ by 2000 to $80 \%$ by 2005 , build reservoirs to reduce flooding in the Central region, for containing fresh water in mountainous areas and in the Mekong river delta; build and consolidate the sea dyke line, works to control salt water invasion; continue to implement the canal solidification project, consolidate the crucial dyke system, jetty, sewer and build infrastructure to divert flood water and to slow down flooding, requires about VND 26 - 30 thousand billion.

1.2. Industry and construction: The investment requirement is estimated as VND 370 - 400 thousand billion, of which, the funding requirement for electricity is VND 85 - 95 thousand billion; cement is VND $30-$ 35 thousand billion; chemicals and fertilizer is VND 58 - 65 thousand billion; oil and gas is VND 55 - 60 thousand billion. Carry out deepening investment, renovate technology, modernize production sectors in stages, first developing sectors that have competitive advantage, win over the domestic market and vigorously promote exports such as: processed agricultural, fishery and forestry products, textiles, leather, shoes, electricity and information technology products, selected machinery and consumer products. Selectively build heavy industry facilities (oil and gas, metallurgy, manufactures, basic chemicals, fertilizer, construction material...), information technology and telecommunication industries.

1.3. Transport, post, communications: the investment requirement is VND $126-147$ thousand billion, of which, funding needs for transport infrastructure is VND $94-110$ thousand billion; post and communications is VND 30 thousand billion. Invest in upgrading and developing road, river, sea route, port and airport systems; complete upgrading of National Highway No.1 and construct the Ho Chi Minh road, upgrade the existing railway system, expand the road system to economic centers, to remote and isolated areas.. Effectively address the problem of traffic jams, consolidate the inter-province traffic system in the Mekong river delta, and improve traffic flow between urban areas to Tay Nguyen, mountainous areas.

Build a broad, integrated, modern and high quality communications system. Focus on implementing large information projects such as the information satellites VINASAT, VISAT; attach special importance to investing in frontier, island, remote and isolated areas. 
1.4. Training and education: the investment requirement is about VND $30-40$ thousand billion, mainly investments to renovate, upgrade and expand training and education facilities, improve the quality of education, with special attention to ensuring enough schools, classrooms and teachers in isolated, remote and mountainous areas; renovate training and teaching methods, training to improve the quality of teaching staff, especially ethnic minority teachers.

Continue to invest, upgrade and expand the kindergarten system in all areas, especially in rural and difficult areas. Modernize vocational technical schools; increase rapidly the number of trained and skilled workers among the labor force. Focus on the National University, regional universities, universities in key disciplines, and teacher training universities.

1.5. Science, technology and environment: the investment requirement is approximately VND $6-14$ thousand billion to invest in building the material and technical conditions of research institutes in science, new technology and strengthening the competitiveness of commodities in market. Apply modern and advanced technology (information technology, biology, new materials, and automation technology). Focus on national laboratories in accordance with Decree No 850/QD-TTg of the Prime Minister, build the information technology infrastructure, Hoa Lac high technology zone...

Protecting and enhancing the environment for the poor, build and consolidate $25 \%$ of the observation and environmental analysis stations, upgrade $30 \%$ of the stations to monitor water and air environment with modern and advanced standards. Build and replicate model wastewater and solid waste treatment plants in industrial zones and craft villages.

1.6. Health care: the investment requirement is estimated to be VND $16-28$ thousand billion. Complete the master plan, consolidate and upgrade the basic health care network, improve the quality of health services, strengthen the capacity of health professionals and improve medical equipment; improve and expand the targeted health programs, develop preventive healthcare, community healthcare; improve the access of the poor to good basic health services; support and subsidize the health expenses of the poor.

\subsection{Housing, water supply and drainage, and public services}

The investment requirement is estimated to be VND $118-130$ thousand billion. Focus on infrastructure development, trade and legal services, housing, expanding water supply and drainage; pay greater attention to the task of replacing dilapidated houses, unsafe slum housing in urban areas, and especially to the housing of the poor in the Northern Mountainous and Central Highland region, and in the Mekong River Delta region which is subject to frequent flooding.

1.8. Culture, Information and sport: The investment requirement is estimated to be VND $14-15$ thousand billion. Invest to expand and upgrade broadcasting, the television system, publishing, newspapers, developing the national sports complex, sport centers in provinces and cities, building grassroots culture, information, and legal support services (training legal supporting staff, building legal libraries, providing and disseminating legal documents...) for the poor, for people living in remote, mountainous areas and for ethnic groups. 
1.9. State administration and other sectors: the investment requirement is VND 50-63 thousand billion.

Table 5.1: Total investment requirement (VND thousand billion, at 2000 price)

\begin{tabular}{lc}
\hline \multicolumn{1}{c}{ Total } & $\begin{array}{c}\text { Total investment required } \\
\text { for period 2001-2005 }\end{array}$ \\
\hline - Agriculture, Forestry, fishery and Irrigation & $\mathbf{8 4 0 - 9 8 0}$ \\
- Industry and construction & $110-133$ \\
- Transportation and post & $370-400$ \\
- Education and training & $126-147$ \\
- Technology, science and environment & $30-40$ \\
- Health and social affairs & $6-14$ \\
- Housing, public services, water supply & $16-28$ \\
- Culture, information and sports & $118-130$ \\
- State administration & $14-15$ \\
- Other sectors and activities & $26-28$ \\
\end{tabular}

Source: Ministry of Planning and Investment

\section{Mobilization capacity for total social investment}

According to the preliminary calculation of ministries, provinces, programs, projects and foreign cooperation and investment commitments, it is possible to mobilize over a period of five years VND 840 thousand billion, including:

Domestic resources to be mobilized are estimated at about $21 \%$ of GDP, totaling about VND 560 thousand billion, representing two thirds of total capital investment, or about USD 40 billion.

External resource mobilization: estimated to be about US\$ 20 billion, of which, total registered capital of direct foreign investment projects (FDI) and increases in the capital of existing projects is about US\$ 15 billion (US\$ 12 billion in registered capital from new projects that are granted licenses and US\$ 3 billion in increased capital from existing projects). The funds available for implementation is estimated at US\$ 11 billion; total Official Development Assistance (ODA) is estimated to total US\$ 9 billion (US\$ 7,5 billion in loans and US\$ 1,5 billion in grants). 
Table 5.2. Projections on capital resource mobilization for 2001-2005 period

(at 2000 price)

\begin{tabular}{|c|c|c|c|c|}
\hline \multirow[b]{2}{*}{ Resources } & \multicolumn{2}{|c|}{ 1996-2000 } & \multicolumn{2}{|c|}{ 2001-2005 (minimum) } \\
\hline & $\begin{array}{l}\text { Implementat } \\
\text { ion } \\
\text { (VND thou. } \\
\text { billion) }\end{array}$ & $\begin{array}{c}\text { Percentage } \\
\text { of total } \\
(\%)\end{array}$ & $\begin{array}{c}\text { Mobilization } \\
\text { ability } \\
\text { (VND thou. } \\
\text { billion) }\end{array}$ & $\begin{array}{c}\text { Percentage } \\
\text { of total } \\
(\%)\end{array}$ \\
\hline Total & 555 & 100.0 & 840 & 100.0 \\
\hline Of which: & & & & \\
\hline - Domestic capital & 320.5 & 57.7 & 561 & 66.8 \\
\hline - Foreign capital & 234.5 & 42.3 & 279 & 33.2 \\
\hline I. State sector (public investment) & 295.8 & 53.3 & 467 & 55.5 \\
\hline 1. Domestic mobilization & 198.9 & 35.8 & 341.0 & 40.6 \\
\hline - State budget (exc. ODA) & 83.9 & 15.1 & 123.2 & 14.7 \\
\hline - Credit (excl. on-lending ODA) & 17.7 & 3.2 & 55.8 & 6.6 \\
\hline - State enterprise & 97.3 & 17.5 & 162 & 19.3 \\
\hline $\begin{array}{l}\text { 2. Official development assistance } \\
\text { (ODA) }\end{array}$ & 96.5 & 17.4 & 126 & 15.0 \\
\hline II. Private sector & 259.6 & 46.8 & 373 & 44.4 \\
\hline 1. Domestic private sector & 121.6 & 21.9 & 220 & 26.2 \\
\hline 2. Foreign direct investment (FDI) & 138 & 24,9 & 15.3 & 18.2 \\
\hline
\end{tabular}

Of the resources listed above, the mobilization capacity from the state sector (public investment) is about VND 467 thousand billion, representing 55.5\%, of which, state budget (excluding ODA) mobilization is about VND 123 thousand billion, representing 14.7\%; state credits (excluding on-lending ODA) is about VND 56 thousand billion, or 6.6\%; state own enterprises VND 162 thousand billion, or 19.3\%; ODA is estimated to total about VND 126 thousand billion, or 15\%; resources to be mobilized from the domestic private sector is estimated to total VND 220 thousand billion, or 26.2\%; FDI is estimated to total about VND 153 thousand billion, or $18.2 \%$ of total investment.

Thus, the state sector will continue to play an important role with the biggest share $(55.5 \%)$, the private sector's share, which is projected to increase from 21.9\% (1996-2000) to 26.2\% (2001-2005), is still low and occupies only one fourth of total social investment. The private sector has much potential and the Government will instruct ministries, central agencies and provinces to continue to study ways to remove difficulties and to take more effective measures to mobilize additional funds for the Strategy.

\section{Priority direction for the period 2001-2005}

Given the amount of limited resources relative to demand, investment priority for allocation to the sectors will be as follows:

Agriculture and rural development sector: prioritize to shift the structure of plant and animal production, expand production and develop infrastructure (e.g. flood protection and irrigation, rural roads, drinking water and electricity...), processing and post-harvest activities; afforestation and forest protection; aquaculture, applying new varieties, with priority has been given to poor, remote and mountainous communes and ethnic groups. 
Health care: prioritize to develop the basic health care network, ensure that $100 \%$ of communes have medical stations with basic equipment and medicine, increase health staff to remote, mountainous and difficult areas; invest in preventative health care, and primary health care; upgrade hospital systems, polyclinics, and the quality of health service especially at the commune level. Enhance the monitoring and support provided by the higher levels of health care to the local level, enabling local health care service providers to identify and treat diseases and illnesses in a timely manner. Have effective methods to provide financial support for the health care of the poor.

Training and education: prioritize investment on upgrading, and building new schools to ensure enough schools from kindergarten to upper secondary schools. Rehabilitate schools with special attention paid to those in difficult areas and areas that frequently suffer from floods and natural disasters. Continue to invest in renovating training contents and programs, in improving the quality of teaching, providing adequate pedagogical equipment to primary and lower secondary schools. Pay attention to developing and expanding teacher training centers to ensure that there are enough teachers for the schools.

Transport: pay attention to investing in and ensuring the efficiency of developing transport, especially in rural areas; determine clearly the assignment of responsibility and the setup of institutions to oversee investment and management of rural roads. Provincial and district transport master plans must be closely integrated with the national transport master plan. Continue the program of the State and the people working together, ensuring that $60 \%$ of inputs are from local people in the form of labor, local materials, and a portion in cash. The Government will provide $30 \%$ of total inputs in the form of necessary materials such as steel, construction equipment and technical support.

Science and technology: attach special importance to the development of infrastructure, information technology, software technology, and information industry.

Environmental protection: continue to invest in environmental protection to ensure sustainable development. Implement and expand projects to improve the environment, resolve the problem of environmental pollution.

For programs and projects that directly target difficult regions, and regions with many poor households, such as the Hunger Elimination and Poverty Reduction and Employment Program, the Population and Family Planning Program, the Programs to prevent social diseases, dangerous infectious diseases and HIV/AIDS; the Program for clean water and hygienic rural environment; the Program for the development of culture, education and training, the Social and Economic Development Program for Extremely Disadvantaged Communes (Program 135), the Five Million Hectare Forestry Project, ensure that these programs are integrated into the social development plans of sectors and provinces.

With respect to state budget expenditures, priority should be given to provinces and cities with low HDI and GDI indicators with the aim of reducing the gap between regions and encouraging provinces to promote polices that benefit the poor.

\section{Estimated disaggregation of investment capital from all sectors of society}

On the basis of the above objectives and through mechanisms and policies to encourage investment that is appropriate, there are two possible scenarios: (1) low, and (2) high, for the allocation structure of social investment capital by sector and activities: 
Table 5.3. Allocation of investment capital

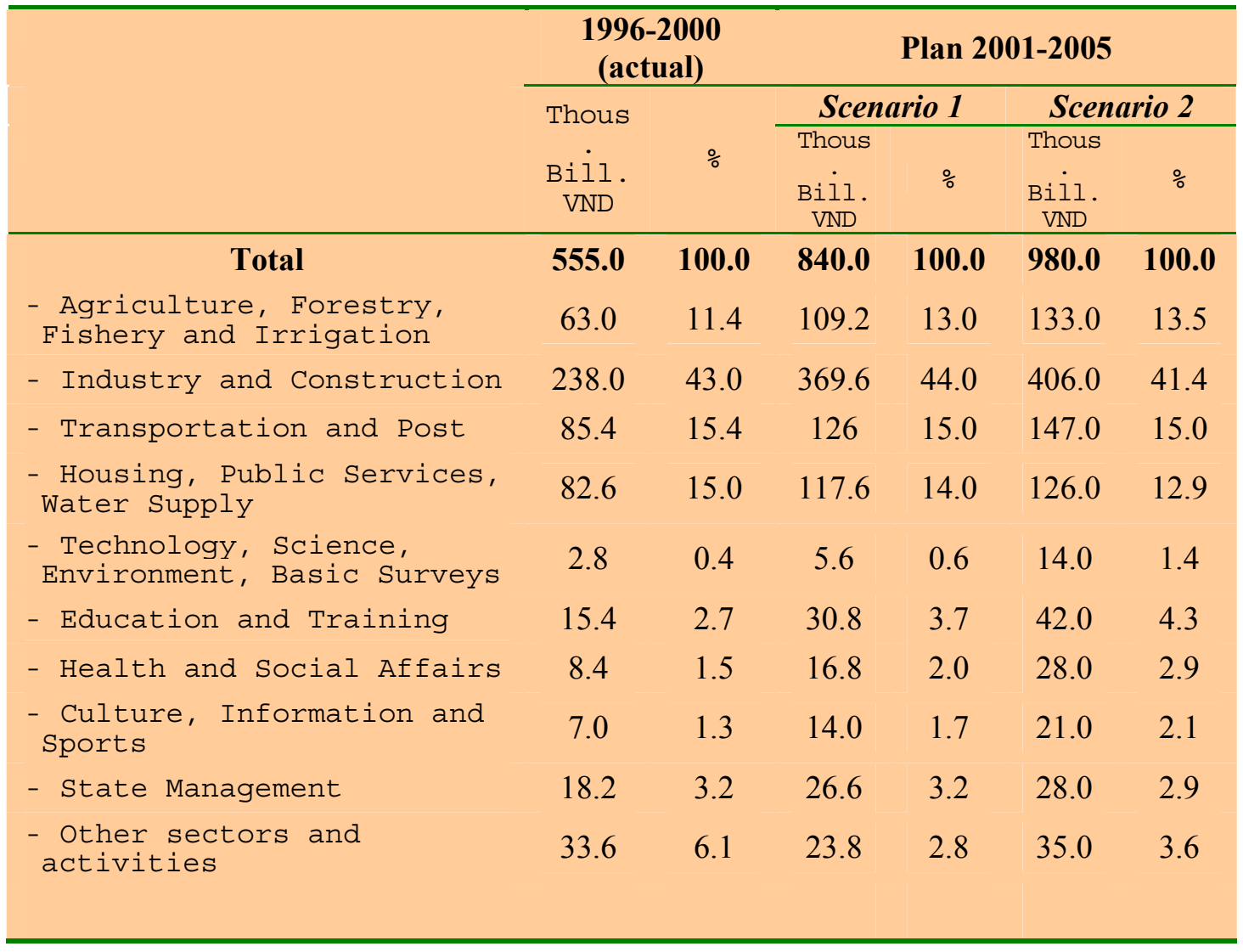

Under Scenario 1, the mobilization capacity can be up to VND 840 thousand billion (US\$ 60 billion). With this amount, the requirement for attaining the minimum objectives that we have laid out can be met. Of this amount, investment in agriculture, forestry, fishery and irrigation will be about VND 109 thousand billion or $13 \%$ of the total; industry and construction will be about VND 369 thousand billion, or 44\%, transportation and post 126 thousand billion, or 15\%; science, technology and environment VND 5.6 thousand billion, or $0.6 \%$; training and education VND 31 thousand billion, or 3.7\%; health, culture, sports, VND 30 thousand billion, or $3.7 \%$; housing, water supply, public services VND 117.6 thousand billion, or 14\%; public administration VND 50.4 thousand billion, or $6 \%$.

Given limited resources, the laid-out objectives can be achieved quantitatively, but not qualitatively (e.g. rural roads, health clinics, schools, facilities, etc. will just meet the minimum quality standards).

This is a great challenge and practical measures are needed to mobilize more domestic and external resources as well as to utilize more efficiently current resources to fulfill the objectives of the Strategy.

Scenario 2, assumes a higher total investment capital of VND 980 thousand billion (US\$ 70 billion), representing an increase of VND 140 thousand billion compared to Scenario 1, of which agriculture, forestry, fishery, and irrigation is about VND 133 thousand billion or $13.5 \%$ of total; industry and construction is about VND 406 thousand billion or $41.4 \%$, transportation and post VND 147 thousand billion or 15\%; science, technology, environment and basic surveys VND 14 thousand billion or 1.4\%; training and education VND 42 thousand billion or 4.3\%; health, culture, sports, VND 28 thousand billion or $2.9 \%$; housing, water, public infrastructure and services VND 126 thousand billion or 12.9\%; public administration and other VND 63 thousand billion or $6.5 \%$. Under this scenario, all objectives in general can be achieved in both qualitative and quantitative terms. 
To implement the Strategy, we will strive for Scenario 2. In order to obtain the additional capital relative to Scenario $1,50 \%$ of the additional funding will be mobilized from domestic resources, mainly from the private sector and households. The State will continue to revise investment policies, strongly encouraging the private sectors and other sectors of the economy to vigorously expand their investment. Additional methods will be promoted to mobilize the remainder of the additional funding from the international community and from foreign investors for the Comprehensive Poverty Reduction and Growth Strategy.

\section{STATE BUDGET EXPENDITURE (PUBLIC EXPENDITURE)}

\section{Investment capital requirement from the state budget}

The requirement for capital expenditure from the state budget is high, about VND 190-200 thousand billion, of which:

Agriculture, forestry and fishery will require more than VND 50-60 thousand billion mainly for developing new variety of plants and husbandry, aquaculture infrastructure, upgrading and renovating irrigation systems, building reservoirs with flood preventing in Central part, and repairing deteriorated dykes.

Transport, post and communications will require VND 60-70 thousand billion for building new and upgrading 5,000 km of highway, restoring bridges along the Thong Nhat railway, expanding and gradually modernizing important sea ports such as Hai Phong, Sai Gon, Da Nang, Can Tho; consolidating and developing inter-provincial roads in Mekong river delta, Central Highlands, and Northern Mountainous areas...

Education and training, health, social and other services ... will require 50-65 thousand billion for expanding the school network, improving the quality of teaching, strengthening primary health care; resolve the problems of urban water supply and drainage ...

\section{Requirement for current expenditure from state budget}

The requirement for recurrent expenditure in the state budget for the 2001-2005 period is about VND 450460 thousand billion (not including repayment of principal), of which, agriculture, forestry and fishery accounts for more than VND 20 thousand billion; transport, post and communication for VND 20 thousand billion; health and social spending for VND 100 thousand billion. Training and education have highest share of recurrent spending, about VND 110-120 thousand billion, mainly to meet basic objectives, such as covering $80 \%$ of primary school costs (for cities and towns, the state budget covers 60-80\%); 60\% for secondary schools (for cities and towns, 40-50\%); 20\% for vocational training (cities and towns, 5-10\%), and to cover the cost of exempting school fees and other supporting policies for children from poor households in remote, mountainous and ethnic areas.

The recurrent expenditure of programs and projects during the 2001-2005 period is estimated to total about VND 10 thousand billion, representing an increase of 1.5 times compared to the 1996-2000 period.

The cost of asset maintenance over the five year period 2001-2005 is estimated at VND 52 thousand billion, an increase of VND 20 thousand billion or 164\% of maintenance costs during the 1996-2000 five year period. Of this amount, the financing requirement for maintenance in agriculture, irrigation, fishery is VND 4.6 thousand billion, equal to 2.8 times the 1996-2000 period; for transport, post and communications, it is VND 16 thousand billion, equal to 2.1 times the 1996-2000 period; for training and education it is VND 9 thousand billion, equal to 1.9 times; for health care it is VND 2.5 thousand billion, equal to 2.3 times. For the 3 year period from 2003-2005 the maintenance requirement is estimated at VND 32.5 thousand billion, of which 
transportation, post will require VND 10.2 thousand billion; training and education will require VND 5.7 thousand billion.

In addition, reform of SOEs and state-owned commercial banks must be financed by the state budget for the 3 year 2001-2003 period is estimated to total about VND 35 thousand billion in order to finance labor redundancy, and to resolve bad loans and accumulated losses. Of this amount, the cost of SOE restructuring is VND 10.6 thousand billion (resolving SOE bad debts is estimated to total VND 4.6 thousand billion, the cost of covering redundancy is estimated to total VND 6 thousand billion); the provision of regulation capital for financial companies is estimated to total VND 1.5 thousand billion; the cost of reforming the four state-owned commercial banks is estimated to total VND 17 thousand billion.

\section{Mobilization capacity from state budget}

Carry out Renovation and reform of the legal and policy system, ensure that the mobilization rate of the state budget is about $20 \%$ of GDP, of which, revenues from taxes and fees will account for approximately $18 \%$.

The state budget for the five year period 2001-2005 is estimated as follows: assuming a GDP growth rate of $7.5 \%$ per year on average, and the budget share as stated above, we estimate that state budget revenues for this five year period will total VND 620 thousand billion, of which, revenues from taxes and fees will be VND 560 thousand billion.

Based on our requirements and capacity to raise revenues for the state budget, the state budget expenditure over this five year period (excluding repayment of principal) is estimated at about VND 630 thousand billion, a increase of VND 220 thousand billion, or 1.5 times that of the 1996-2000 period, of which investment expenditure will total VND 185 thousand billion, an increase of VND 60 thousand billion, or 1.48 times; current expenditure will total VND 445 thousand billion, a increase of VND 157 thousand billion or 1.5 times that of the 1996-2000 period. The proposed breakdown of budget expenditure is as follows: 
Table 5.4: State Budget expenditure in the period 2001-2005

(excluding principal repayment)

Unit: 1,000 billion

\begin{tabular}{|c|c|c|c|c|c|c|}
\hline & \multicolumn{3}{|c|}{ 1996-2000 (actual) } & \multicolumn{3}{|c|}{ 2001-2005 (estimated) } \\
\hline & \multirow[t]{2}{*}{ Total } & \multicolumn{2}{|c|}{ Of which } & \multirow[t]{2}{*}{ Total } & \multicolumn{2}{|c|}{ Of which } \\
\hline & & $\begin{array}{l}\text { Invest- } \\
\text { mint }\end{array}$ & $\begin{array}{l}\text { Recur- } \\
\text { rent }\end{array}$ & & $\begin{array}{l}\text { Invest- } \\
\text { ment }\end{array}$ & $\begin{array}{l}\text { Recur- } \\
\text { rent }\end{array}$ \\
\hline Total & 414.4 & 126.0 & 288.4 & 630.0 & 185.0 & 445.0 \\
\hline Of which: & & & & & & \\
\hline $\begin{array}{l}\text { Agriculture, forestry, } \\
\text { fishery and irrigation }\end{array}$ & 42.0 & 29.4 & 12.6 & 65.8 & 46.2 & 19.3 \\
\hline Transportation and post & 49.0 & 37.8 & 11.2 & 72.8 & 54.6 & 18.2 \\
\hline $\begin{array}{l}\text { Housing, water supply, } \\
\text { public infrastructure } \\
\text { and services }\end{array}$ & 18.2 & 14.0 & 4.2 & 28.0 & 21.0 & 7.0 \\
\hline $\begin{array}{l}\text { Science, } \\
\text { basic } \\
\text { environment }\end{array}$ & 7.0 & 2.8 & 4.2 & 14.0 & 4.2 & 9.8 \\
\hline $\begin{array}{lr}\text { Education, } & \text { general } \\
\text { training, } & \text { and } \\
\text { vocational training }\end{array}$ & 65.8 & 8.4 & 57.4 & 114.8 & 14.0 & 100.8 \\
\hline $\begin{array}{l}\text { Health and } \begin{array}{r}\text { social } \\
\text { affairs } \\
\text { security, } \\
\text { allowance...) }\end{array}\end{array}$ & 75.6 & 8.4 & 67.2 & 119.0 & 12.6 & 106.4 \\
\hline
\end{tabular}

Table 5.5: Structure of State Budget expenditure in the period 2001-2005 (excluding principal repayment)

Unit: $\%$

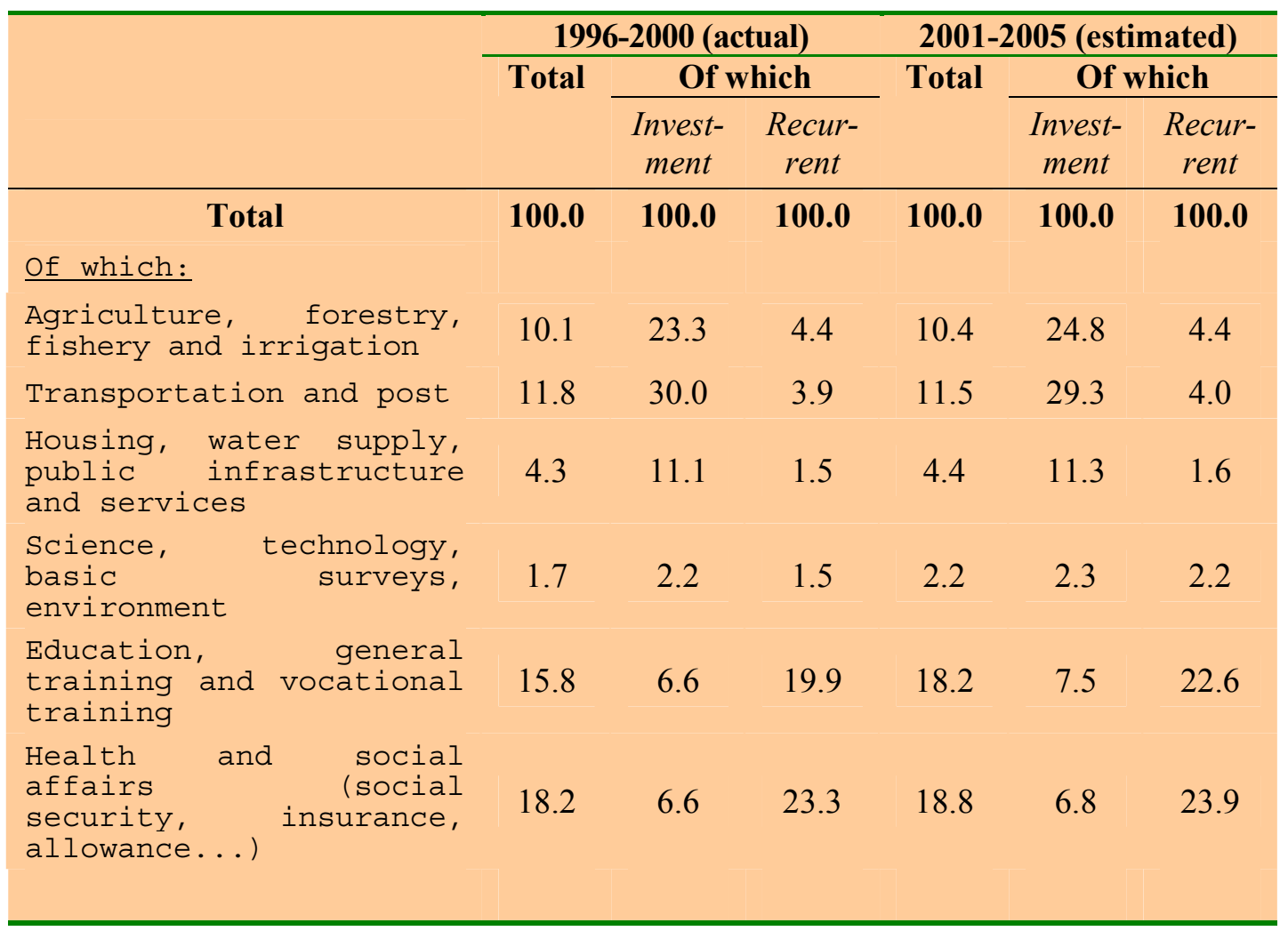


The 2001-2005 five year expenditure plan for the six sectors (listed above), that are most closely linked to poverty reduction, is estimated to total about VND 420 thousand billion, representing two thirds of total budget expenditure, or 1.6 times actual expenditures in the 1996-2000 period. Of this amount, agriculture, forestry, fishery and irrigation requires VND 65.8 thousand billion, for an increase of 55\%; transportation and post VND 72.8 thousand billion, for an increase of 50\%; housing, water supply, public infrastructure and services VND 28 thousand billion, for an increase of 54\%; science, technology and environment VND 14 thousand billion, for a 100\% increase; education and vocational training VND 114.8 thousand billion, for an increase of $75 \%$; health and social spending VND 119 thousand billion, for an increase of 57\%.

The sectoral agencies and provinces will provide a more detailed breakdown of the overall five year-plan expenditure estimate into medium term and short term plans to ensure that program and project targets will be achieved.

\section{POVERTY REDUCTION}

\section{Expenditure requirement for poverty reduction targets}

1.1. Based on initial calculations prepared by ministries and agencies working with an international costing team, the expenditure requirement to meet selected social and poverty reduction objectives of eight sectors (agriculture and rural economy, health, education, urban, electrification, transport, labour and social insurance, and national programs) over the 2003-2005 three year period is VND 84 thousand billion, of which VND 54 thousand billion covers recurrent expenditure and VND 30 thousand billion covers capital expenditure. 
Table 5.6: Projections on state spending priorities for 8 selected social objectives and poverty reduction objectives over 3 years, 2003-2005. Unit: VND billion

\begin{tabular}{|c|c|c|c|c|}
\hline & 2003 & 2004 & 2005 & Total \\
\hline Total & 28,330 & 27,870 & 28,275 & 84,475 \\
\hline - Recurrent & 17,280 & 18,001 & 18,719 & 54,002 \\
\hline - Investment & 11,050 & 9,869 & 9,556 & 30,473 \\
\hline \multicolumn{5}{|l|}{ Of which: } \\
\hline Agriculture & 5,002 & 4,906 & 4,772 & 14,681 \\
\hline - Recurrent & 3,001 & 2,944 & 2,863 & 8,808 \\
\hline - Investment & 2,001 & 1,963 & 1,909 & 5,872 \\
\hline Health & 3,752 & 3,835 & 3,971 & 11,558 \\
\hline - Recurrent & 3,276 & 3,348 & 3,384 & 10,008 \\
\hline - Investment & 476 & 487 & 587 & 1,550 \\
\hline Education & 4,520 & 4,555 & 4,589 & 13,664 \\
\hline - Recurrent & 1,778 & 1,813 & 1,847 & 5,438 \\
\hline - Investment & 2,742 & 2,742 & 2,742 & 8,226 \\
\hline Urban development & 1,500 & 1,500 & 1,500 & 4,500 \\
\hline - Recurrent & 75 & 75 & 75 & 225 \\
\hline - Investment & 1,425 & 1,425 & 1,425 & 4,275 \\
\hline $\begin{array}{l}\text { Electricity } \\
\text { (All capital expenditure) }\end{array}$ & 1,248 & 261 & 75 & 1,584 \\
\hline Transportation & 3,083 & 2,982 & 2,890 & 8,955 \\
\hline - Recurrent & 925 & 1,041 & 1,175 & 3,141 \\
\hline - Investment & 2,158 & 1,941 & 1,715 & 5,814 \\
\hline $\begin{array}{l}\text { Labor and social insurance } \\
\text { (All recurrent expenditure) }\end{array}$ & 7,225 & 7,731 & 8,272 & 23,229 \\
\hline National targeted programs & 2,000 & 2,100 & 2,205 & 6,305 \\
\hline - Recurrent & 1,000 & 1,050 & 1,103 & 3,153 \\
\hline - Investment & 1,000 & 1,050 & 1,103 & 3,153 \\
\hline
\end{tabular}

Source: Vietnamese ministries and international costing team

With respect to agriculture and the rural economy, the main spending priorities are basic infrastructure and improved research, provision of new varieties, extension services, improving, upgrading and building irrigation systems in remote areas. The budget for these activities is estimated at about VND 14.7 thousand billion.

With respect to health care, the focus is on improving quality and access to basic health care for the poor; reducing the incidence of infectious diseases among the poor, and preventing HIV/AIDS. The total budget allocation for these activities is VND 11.5 thousand billion for the 2003-2005 period, of which, VND 10 thousand billion will be for recurrent expenditure and VND 1.5 thousand billion for capital expenditure.

With respect to education, the focus is on upgrading infrastructure and facilities for education universalization and improving the quality of education in remote areas and ethnic groups, and the exemption of education charges for poor households. The proposed budget allocation for these activities is VND 13.7 thousand billion, of which VND 5.4 thousand billion will be for recurrent expenditure and VND 8.3 thousand billion for capital expenditure. 
With respect to urban infrastructure, the total budget is estimated at VND 4.5 thousand billion, of which VND 0.2 thousand billion will cover recurrent expenditure and VND 4.3 thousand billion will cover capital expenditure to improve housing, the water supply system, and electricity supply in poor urban areas.

With respect to electrification, the budget for the 2003-2005 period is estimated at VND 1.6 thousand billion to connect remote communes to the national electricity grid. The government will finance the provision of high voltage lines, transformers and electricity meters. The connection of low-voltage electricity grid to individual households will be funded by local budgets, concessional credits and contributions from the poor.

With respect to transport, priority will be given to developing road links to communes in remote and isolated areas and to upgrading existing rural roads in poor districts. The total cost of implementing these activities is about VND 9 thousand billion comprising recurrent costs of more than VND 3 thousand billion and capital costs of VND 6 thousand billion.

With respect to labor and the social safety net, this covers the cost of national programs and social safety nets implemented through MOLISA and provinces, including the cost of direct spending on social guarantees and protection centers, on transfers and other costs associated with social guarantees and protection activities, the cost of national programs for job creation, drug control, and prostitution control, the cost of providing support to prevent pre-harvest hunger and disaster relief. Total expenditure, which is mainly recurrent, is about VND 23.2 thousand billion.

With respect to national targeted programs, the most significant of these are program 135, the national job creation program, and the rural water and sanitation program. The total budget for all these activities over the period 2003-2005 is estimated at VND 6.3 thousand billion, comprising VND 3.1 thousand billion of capital expenditure and VND 3.2 thousand billion of recurrent expenditure.

\subsection{Some programs and important projects that need to be expanded to disadvantaged areas}

Develop irrigation in the Central Highlands and Central Region (from Thanh Hoa to Ninh Thuan) to expand total irrigated land to about VND 8 thousand hectares and develop reservoirs for flood prevention in the central provinces. The total budget for all these activities over the 2001-2005 period is estimated at VND 23 thousand billion, of which for Central highland, VND 3 thousand billion is for the Central Highlands and VND 20 thousand billon is for the Central Region.

Develop infrastructure in density residential areas, upgrade floors to reduce flood damage and build houses for 200 thousand households in the Mekong River Delta. The total budget is about VND 7 thousand billion.

Demolish houses that are dilapidated (made of bamboo, leaves, unsafe in times of flooding) for 440 thousand ethnic minority households and households in areas subject to heavy flooding, those whose living conditions are much too difficult, including 100 thousand households in the Northern Mountainous region, 90 thousand households in 4 Central Highland provinces, 130 thousand households in the Mekong River Delta, and 120 thousand households in other provinces. The budget is estimated to total about VND 10 thousand billion.

Support mountainous people to make terraced farms for fixed settlement, to develop fruits and special plants to replace opium in upland areas... Total investment support (2001-2005) will be about VND 200 billion.

The list of industries and sectoral activities presented above may be incomplete and there may be overlapping estimates of investments for economic growth and poverty reduction among the various sectors... Notwithstanding, these sectors and industries are important and their expenditure requirements are substantial. Many resources will be drawn upon to move forward the implementation, which will be prioritized with respect to resource allocation during the process of integrating them into the investment development plans of the ministries, provinces, and with various national targeted poverty reduction programs.

\section{National targeted programs related to poverty reduction}

The national targeted programs include: the Hunger Elimination and Poverty Reduction and Employment Program, the Social and Economic Development Program for Extremely Disadvantaged Communes, programs to develop education, culture, and health, the Five Million Hectare Forestry Project... these programs are directly related 
to poverty reduction. The investment funding for these programs and projects come from different sources: direct allocation from the state budget and the provincial budget, integrated funding from various programs and projects, loans, and funds mobilized from the communities. Funds from the state budget are estimated to account for $30 \%$ of the total investment for these programs and projects.

According to estimates made by the provinces and ministries responsible for managing these programs and projects, the cost of the eight programs and national projects in the Five Year Plan (2001-2005) is about VND 70-75 thousand billion (USD 5-5.5 billion). The breakdown is as follows:

Table 5.7: Total investment requirement for national programs and projects

\begin{tabular}{lc}
\hline \multicolumn{1}{c}{ Total } & $\begin{array}{c}\text { Total investment 2001-2005 } \\
\text { (Thousand billion) }\end{array}$ \\
\hline \multicolumn{1}{c}{ 1. Poverty reduction and employment } & $\mathbf{7 0 - 7 5}$ \\
2. Clean water and hygienic rural environment & $8.0-8.5$ \\
3. Population and family planning & $3.5-4.0$ \\
4. Program to prevent communicable and & $5.0-5.5$ \\
dangerous diseases and HIV/AIDS & $1.5-2.0$ \\
5. Cultural development program & $6.5-7.0$ \\
6. Training and education program & $8.5-9.0$ \\
7. Program for the social and economic & \\
development of communes experiencing & \\
special difficulties & $10.0-11.0$ \\
8. Five million hectare forestry project & \\
\hline
\end{tabular}

Based on the demand and mobilization capacity, the total budget for these projects and programs for the five year 2001-2005 period is estimated to be twice the total investment made during the 1996-2000 period, about VND 60 thousand billion, of which the state budget will cover one third. The objectives and estimated cost of these programs are:

\subsection{National targeted program for hunger eradication, poverty reduction and employment}

The focus is on building infrastructure in poor communes, providing support for production and developing professions and crafts, training and staff development for poverty reduction cadre, supporting agricultural, forestry and fishing extension and providing credit for production. Provide support for people to migrate to new economic zones and for fixed cultivation and resettlement of poor communes.

The total investment for these activities is about VND 22.5 thousand billion.

\subsection{National targeted program for clean water and hygienic rural environment}

The focus is on developing the central water supply system and providing clean water and a hygienic rural environment for difficult areas and areas with many poor households and providing interest-free or low interest credit.

The total investment for these activities is about VND 7.1 thousand billion.

\subsection{National targeted programs on population and family planning}

Carry out population planning and redistribution programs among the regions; continue to invest in primary health care services for poor, difficult, remote and isolated regions; invest in improving the system to provide information on family planning and strengthen the capacity of staff working on family planning programs. 
Total investment for these activities is about VND 2.5 thousand billion.

\subsection{National targeted program to prevent communicable and dangerous diseases and HIV/AIDS}

Focus on implementing projects to prevent malaria, goiter, leprosy, tuberculosis, and petechial fever, expand programs to provide vaccines and immunize, prevent malnutrition, provide community health care; ensure food safety, prevent the spread of HIV/AIDS...

The total budget for these activities is about VND 4.5 thousand billion.

\subsection{National targeted program for cultural development}

Continue to invest in and complete the nationwide broadcasting and television system, ensuring that 90-95\% households can watch television and listen to the Voice of Vietnam. Carry out investments to preventing the deterioration and to renovate historical sites and monuments; have projects to research, survey, and preserve traditional communes, villages and festivals of ethnic minority peoples. Advance the collection and preservation of non-material objects, establish databanks on non-material culture, and develop information and cultural activity models at communes and villages. Ensure that all communes have cultural centers (with telephone, library, meeting rooms ...).

The total budget for these activities is about VND 1.3 thousand billion.

\subsection{National targeted programs on education and training}

Build on the achievements of universalizing primary education and eliminating illiteracy; achieve universal lower secondary education; renovate teaching programs and the contents of textbooks; implement projects to train informatics professionals and bring informatics into schools, pay attention to teacher training and development, improve basic materials used in schools, teacher colleges, vocational and career centers, build universities and professional secondary schools....

The total budget for these activities is about VND 6 thousand billion.

\subsection{Social, economic development programs for extremely disadvantaged communes (program 135)}

The focus is on building infrastructure in extremely disadvantaged communes, planning and developing commune clusters; relocating populations; vigorously promoting agricultural and forestry production; training commune and village cadre. Ensure that by the year 2005, all communes will have basic infrastructure such as electricity, schools, health centers, inter-commune roads, markets and clean water. As regards the commune clusters, establish polyclinics, schools, agricultural extension centers, electricity and water supply systems...

The total budget for these activities is about VND 7.6 thousand billion.

\subsection{Five million hectare forestry project}

In addition to protecting more than 10 million hectare of forest, continue the new plantings on 1.43 million hectare, including 390 thousand hectare of protected forest; special use forest, and 1 million hectare of production forest. Carry out forest regeneration and plantings by adding 650 thousand hectare of forestry land and assigning households the task of protecting 2 million hectare of forestry land.

The total budget for these activities is about VND 8.5 thousand billion.

In addition, continue to provide investment support, mobilize resources from communities and beneficiaries to implement projects that receive support from the international community and government agencies such as: agricultural diversification; rural infrastructure development; poverty reduction in six Northern Mountainous provinces; poverty reduction in five central provinces; community based rural development; forest protection and rural development...

\section{Implementation mechanism}

Continue decentralization; expand the autonomy of local authorities to take the initiative in prioritizing projects and programs; put the grassroots in charge of the management and construction of local economic development and poverty reduction projects in line with the direction, goals and plans that are approved by the Government to ensure their effectiveness and to avoid risks. Enhance the role, accountability and management capacity of local bodies in human resource allocation and implementation of poverty reduction projects. Set clear criteria for budget allocation and for prioritizing public projects at the local level. 
Integrate and move towards unifying the scope of national targeted programs, paying special attention to achieving the targets of programs such as commune cluster development, resettlement and fixed cultivation, and socio-economic development programs for extremely disadvantaged communes in mountainous, remote and isolated areas.

Identify and establish concrete mechanisms to mobilize the participation of the people in the tasks of project development, implementation, monitoring and evaluation. Ensure the principle of empowerment in selecting project objectives, resource allocation, implementation and monitoring and dissemination of the State's decisions and directions on poverty reduction, on objects and sectors that receive investment support and incentives; ensure the transparency, equality, efficiency and sustainability in allocating and developing investment projects; strengthen the management capacity and ownership of beneficiaries. Allow for greater ownership and initiative at the commune and district level in managing and using the Community Fund, Social Relief Fund, etc.

Enhance the efficiency of capital utilization of development investment programs, national targeted programs, pro-poor programs and projects. Strengthen the decentralization of management and utilization of ODA resources. Simplify investment and administrative procedures to accelerate program and project implementation. 


\title{
PART VII
}

\author{
Implementation, monitoring
}

\section{and evaluation of the Poverty reduction and growth strategy}

\section{IMPLEMENTATION}

The implementation of the Comprehensive Poverty Reduction and Growth Strategy is based on an integrated approach that includes institutional reform, increasing the resources and strengthening the capacity of implementing agencies as well as building mechanisms to ensure the participation of agencies and people at all levels from the policy making stage to monitoring and evaluation of the Strategy to ensure the sustainability of the results and to avoid risks in the process of implementing the strategy.

\section{Assignment of responsibility to ministries, agencies and provinces}

1.1. The implementation of the Comprehensive Poverty Reduction and Growth Strategy needs focused guidance and close coordination among governmental agencies including: Government Office, Ministry of Planning and Investment, Ministry of Labour, Invalids and Social Affairs, Ministry of Finance, the State Bank of Vietnam, Government Organization and Personnel Committee, Steering Committee of SOE Reform and Development, Ministry of Agriculture and Rural Development, Ministry of Fishery, Ministry of Industry, Ministry of Transport and Communications, Ministry of Health, Ministry of Education and Training, Ministry of Construction, Committee for Ethnic Minorities and Mountainous Areas, Ministry of Science, Technology and Environment, General Statistical Office, Central Office of the Women's Union, etc. At the same time, research to establish a Steering Committee for the Comprehensive Poverty Reduction and Growth Strategy in order to help the Prime Minister provide guidance in the task of implementing the strategy.

1.2. The Prime Minister assigned to the Ministry of Planning and Investment the task of leading and cooperating with other concerned organizations in order to guide line ministries, sectoral agencies and provinces to set up plans and to integrate the CPRGS into the national and their annual and five year socio-economic development plans; on a regular basis, to inspect, monitor and prepare a comprehensive overview of the implementation of the strategy to report to the Prime Minister.

The Ministry of Planning and Investment will take a leading role in coordinating with line ministries to establish the Inter-ministerial Working Unit including representatives from concerned line ministries to coordinate the implementation of the CPRGS. The function of this Unit, in cooperation with line ministries and provinces, is to carry out, monitor and evaluate progress in implementing the Strategy.

A Secretariat will be formed to assist the Inter-ministerial Working Unit.

1.3. Based on the strategy, line ministries, government agencies and provinces will, within their sphere of functions, concretize and incorporate the objectives of the Comprehensive Poverty Reduction and Growth Strategy into their annual plans for implementation. They will organize on an annual basis the monitoring and evaluation, and report the results of implementing the objectives and targets that fall under their responsibility to higher-level organizations; at the same time, they will propose appropriate measures and policies to improve performance.

1.4. The General Statistical Office, Ministry of Labour, Invalids and Social Affairs and other concerned ministries, using as the basis the monitoring and evaluation indicator system laid out in the Strategy, will plan surveys and collect other needed information in their working programs. The General Statistical Office coordinates on a regular basis with concerned ministries and social organizations to conduct qualitative and quantitative surveys to evaluate the social and economic results and impacts of the Strategy on the whole society, particularly the poor. Estimate costs, strengthen staff capacity and improve material facilities for effective information collection. 
1.5. Every year, based on the funding capacity of the state budget and progress made in implementing the Strategy, the Ministry of Planning and Investment, the Ministry of Finance, governmental agencies and provinces will determine the level of expenditures needed to implement the Strategy.

\section{Promote the capacity of the implementation apparatus}

Assign responsibility to concerned line ministries, provincial and local authorities regarding monitoring and evaluation of the implementation of the Strategy and other sectoral activities within the framework of the Strategy.

Strengthen the network and contingent of poverty staff at all levels, especially in extremely disadvantaged communes. Increase their professional level and provide support to help them carry out their tasks.

3. Complete mechanisms to encourage the participation of the people, and civil and social organizations in the implementation, monitoring and evaluation of the Strategy.

3.1. Promote widely the propagation and dissemination of the Comprehensive Poverty Reduction and Growth Strategy to reach all the people. The General Statistical Office, Ministry of Labour, Invalids and Social Affairs and other concerned sectoral ministries and agencies will on an annual basis organize the collection of information based on the system of monitoring and evaluation indicators contained in the Strategy. Step-by-step develop a widely accessible website on the Comprehensive Poverty Reduction and Growth Strategy.

3.2. Institutionalize the consultation process for the Comprehensive Poverty Reduction and Growth Strategy among line ministries and sectoral agencies, poor communities, business organizations, domestic and international social organizations and local community-based organizations, etc. in order to improve the quality of the monitoring and evaluation of the Strategy. Establish criteria and procedures to evaluate and select public investment programs and projects with priority given to assessing its social and economic benefits.

3.3. Identify, analyze and evaluate possible risks that may occur during the implementation of Comprehensive Poverty Reduction and Growth Strategy and have appropriate policies to minimize them.

\section{MONITORING AND EVALUATION OF THE IMPLEMENTATION}

\section{Objectives of monitoring and evaluation}

Organize the monitoring and evaluation of the implementation of the Comprehensive Poverty Reduction and Growth Strategy in order to ensure that the laid-out targets are achieved within the projected timetable and resources. Based on an overall assessment of the progress in and results from implementing the strategy, uncover irrationalities in the current mechanism, policies, and sectoral development measures. On that basis, make suitable adjustments and policy amendments to implement the Strategy more effectively.

The monitoring and evaluation of the Strategy covers three main points: (i) monitoring and evaluating the effectiveness of economic growth and poverty reduction; (ii) progress made in resource mobilization and implementation; (iii) assessment of the impact of policies and programs on poverty reduction; and socioeconomic impact of programs that affect the poor.

The monitoring and evaluation of growth and poverty reduction targets will be conducted at all levels, national, sectoral, and local, and will be disaggregated according to rural/urban, gender and social quintile.

\section{System of indicators to monitor and evaluate the Strategy}

The system of indicators to monitor and evaluate the Comprehensive Poverty Reduction and Growth Strategy includes: (i) indicators to monitor outputs of economic development and poverty reduction; (ii) indicators to monitor and evaluate inputs of resources for the Strategy; (iii) indicators to monitor and evaluate the achievements according to the targets laid out in the Strategy; and (iv) indicators to evaluate the impact of every program and strategy affecting the poor and the whole society. This system of indicators will be developed in detail by regions, provinces, rural/urban areas and gender and some further disaggregated according to economic sector, social quintile and ethnicity. 
The system of indicators used to monitor and evaluate the Comprehensive Poverty Reduction and Growth Strategy, listed in table form, includes:

- Development objectives (indicators related to goals of the strategy covering the different socio-economic sectors related to the poor).

- Indicators that are targets for a given period, to the year 2005 and 2010 in particular.

- Intermediate indicators (monitoring indicators) that are used to monitor actual progress in implementing the development objectives.

Each indicator is shown with its statistical frequency and monitoring organization (see Appendix 1).

\section{Responsibility for monitoring and evaluation of the CPRGS}

In order to have unbiased, reliable and high-quality assessments of the CPRGS, the information collected for CPRGS evaluation must be systematic, comprehensive, practical and updated on a regular basis.

In order to provide information for the monitoring and evaluation of the Strategy, the General Statistical Office will conduct on a bi-annual basis the household living standard survey. The format of these surveys will combine a fixed module and an alternate module. Promulgate the Law on Statistics, encouraging the dissemination of information and data to users and improving the policy analysis capacity of Government officials.

Independent research organizations (NGOs, universities, etc.) will organize consultations with the people, collect and analyze data to assess the present situation and trends with respect to economic growth and poverty.

Based on their analysis and assessment, line ministries and provinces will prepare and make public thematic and summary reports of the implementation of the Comprehensive Poverty Reduction and Growth Strategy within the scope of their sector or locality.

The Ministry of Planning and Investment will coordinate with line ministries to prepare and make public the Annual Report on Implementation of the CPRGS.

The Government of Vietnam welcomes the participation of specialists, domestic and international organizations, which include donors, NGOs, social and professional organizations at the local and community level, etc. in the preparation and implementation of the Comprehensive Poverty Reduction and Growth Strategy.

The Government of Vietnam calls on international donors to provide financial and technical support for the CPRGS and hopes that they will link their medium term (3 to 5 years) country support strategy with this Strategy in order to provide favorable conditions for the Government to allocate resources to achieve the goals and complete the tasks of this Comprehensive Poverty Reduction and Growth Strategy.

Appendix 1: Vietnam's Development Objectives.

Appendix 2: Three year Medium term Macroeconomic Framework of Vietnam

Appendix 3: Policy Matrix, Measures and Time Frame. 


\section{Appendix 1: DEVELOPMENT OBJECTIVES OF VIETNAM}

\section{A. ECONOMIC OBJECTIVES}

\begin{tabular}{|c|c|c|c|}
\hline Objectives, Targets & Monitoring indicators & $\begin{array}{l}\text { Reporting } \\
\text { frequency }\end{array}$ & $\begin{array}{c}\text { Reporting } \\
\text { agencies }\end{array}$ \\
\hline \multicolumn{4}{|c|}{ Target 1. Growth of the economy } \\
\hline $\begin{array}{l}\text { GDP in } 2010 \text { to double GDP } \\
\text { in } 2000\end{array}$ & $\begin{array}{l}\text { - Gross Domestic Product (GDP) } \\
\text { - Use of Gross Domestic Product (Savings - } \\
\text { Consumption) } \\
\text { - GDP per capita } \\
\text { - Income per capita of cities and provinces } \\
\text { - Consumer Price Index }\end{array}$ & & \\
\hline $\begin{array}{l}\text { Value-added in industry and } \\
\text { construction to grow by } 10.0- \\
10.5 \% \text { on average during the } \\
\text { period } 2001-2010\end{array}$ & $\begin{array}{l}\text { - Gross production output growth rate of } \\
\text { industry and construction. } \\
\text { - Value-added growth rate of industry and } \\
\text { construction }\end{array}$ & & \\
\hline $\begin{array}{l}\text { Value-added of agriculture, } \\
\text { forestry and fishery to grow } \\
\text { by } 4.0-4.5 \% \text { on average } \\
\text { during the period } 2001-2010\end{array}$ & $\begin{array}{l}\text { - Gross production output growth rate of } \\
\text { agriculture } \\
\text { - Value-added growth rate of agriculture, } \\
\text { forestry and fishery } \\
\text { - Value and volume of total food production } \\
\text { - Per capita volume of food production }\end{array}$ & Annual & $\begin{array}{l}\text { General } \\
\text { Statistical } \\
\text { Office }\end{array}$ \\
\hline $\begin{array}{l}\text { Value-added of services to } \\
\text { grow by } 7.0-8.0 \% \text { on average } \\
\text { during the period } 2001-2010\end{array}$ & $\begin{array}{l}\text { - Total retail sales of goods and services } \\
\text { - Value-added growth rate of services }\end{array}$ & & \\
\hline $\begin{array}{l}\text { Export growth rate to more } \\
\text { than double GDP growth rate }\end{array}$ & $\begin{array}{l}\text { - Export growth rate } \\
\text { - Import growth rate }\end{array}$ & & \\
\hline $\begin{array}{l}\text { By 2010: the share in GDP of } \\
\text { agriculture will be } 16-17 \% \text {; } \\
\text { industry } 40-41 \% \text { and services } \\
42-43 \%\end{array}$ & $\begin{array}{l}\text { - Share in GDP of agriculture } \\
\text { - Share in GDP of industry } \\
\text { - Share in GDP of services }\end{array}$ & & \\
\hline $\begin{array}{l}\text { By } 2010 \text { : the share in the } \\
\text { total labour force of industry } \\
\text { will be } 23-24 \% \text {; agriculture, } \\
\text { forestry and fishery } 50 \% \text {, } \\
\text { services } 26-27 \%\end{array}$ & $\begin{array}{l}\text { - Share in total labour force of agriculture } \\
\text { - Share in total labour force of industry } \\
\text { - Share in total labour force of services }\end{array}$ & & \\
\hline
\end{tabular}




\begin{tabular}{|c|c|c|c|}
\hline Objectives, Targets & Monitoring indicators & $\begin{array}{l}\text { Reporting } \\
\text { frequency }\end{array}$ & $\begin{array}{c}\text { Reporting } \\
\text { agencies }\end{array}$ \\
\hline $\begin{array}{l}\text { To ensure that domestic } \\
\text { saving exceeds } 30 \% \text { of GDP, } \\
\text { to mobilize VND } 840 \\
\text { thousand billion (US\$ } 60 \\
\text { billion) for development } \\
\text { investment in the period } \\
2001-2005 \text {, of which VND } \\
220 \text { thousand billion (US\$ } \\
15.7 \text { billion) will come from } \\
\text { the domestic private sector } \\
\text { and US\$ } 11 \text { billion from FDI } \\
\text { Total funding for poverty } \\
\text { reduction }\end{array}$ & $\begin{array}{l}\text { - Share of savings as percent of GDP } \\
\text { - Total capital mobilized annually } \\
\text { - Total capital mobilized annually by economic } \\
\text { sector } \\
\text { - Total funding mobilized for CPRGS } \\
\text { - Total funding from CPRGS allocated to } \\
\text { targeted programs } \\
\text { - Total funding from CPRGS allocated for } \\
\text { provinces, disaggregated, down to the district } \\
\text { level }\end{array}$ & Annual & $\begin{array}{l}\text { Ministry of } \\
\text { Planning } \\
\text { and } \\
\text { Investment }\end{array}$ \\
\hline \multicolumn{4}{|c|}{ Target 3. Efficiency of resource utilization } \\
\hline $\begin{array}{l}\text { Total funding for CPRGS, } \\
\text { breakdown by targeted } \\
\text { program }\end{array}$ & $\begin{array}{l}\text { - Total funding for CPRGS, breakdown by } \\
\text { province, down to commune level } \\
\text { - Total households receiving support from } \\
\text { CPRGS, breakdown by province } \\
\text { - Percentage of people mobilized in the } \\
\text { program relative to the requirement, details } \\
\text { provided for every program and province } \\
\text { - Percentage of financial resources mobilized } \\
\text { for the strategy relative to the requirement, } \\
\text { details provided for every program and } \\
\text { province } \\
\text { - Percentage of financial resources mobilized } \\
\text { on time for every program and province }\end{array}$ & Quarterly & $\begin{array}{l}\text { Provinces } \\
\text { and } \\
\text { Programs }\end{array}$ \\
\hline
\end{tabular}




\section{B. SOCIAL AND POVERTY REDUCTION OBJECTIVES}

\begin{tabular}{|c|c|c|c|}
\hline Objectives, Targets & Monitoring indicators & $\begin{array}{l}\text { Reporting } \\
\text { frequency }\end{array}$ & $\begin{array}{c}\text { Reporting } \\
\text { agencies }\end{array}$ \\
\hline \multicolumn{4}{|l|}{ 1. Poverty reduction } \\
\hline $\begin{array}{l}\text { From } 2000 \text { to } 2010 \text {, reduce } \\
\text { the incidence of poverty by } \\
\text { two fifths according to } \\
\text { international standards and } \\
\text { by three fifths according to } \\
\text { national standards. } \\
\text { From } 2000 \text { to } 2010 \text {, reduce } \\
\text { the international standard- } \\
\text { based food poverty incidence } \\
\text { ( } 2,100 \text { Kcal per capita daily) } \\
\text { by three fourths. }\end{array}$ & $\begin{array}{l}\text { - Rate of poor households living below the } \\
\text { poverty line based on international standards. } \\
\text { - Rate of poor households living below the } \\
\text { poverty line based on national standards. } \\
\text { - Number of households who escape from } \\
\text { poverty. } \\
\text { - Poverty depth. } \\
\text { - Share of } 20 \% \text { poorest quintile in total } \\
\text { consumption. } \\
\text { - Percent of food-based poor households living } \\
\text { below the international standard poverty line. }\end{array}$ & $\begin{array}{l}\text { Annual and } \\
\text { every two } \\
\text { years } \\
\text { (household } \\
\text { living } \\
\text { standard } \\
\text { survey) }\end{array}$ & $\begin{array}{c}\text { GSO; } \\
\text { MOLISA } \\
\text { and } \\
\text { provinces }\end{array}$ \\
\hline
\end{tabular}

2. Provision of basic infrastructure services to extremely disadvantaged groups and urban poor people

Provide basic infrastructure to $80 \%$ of poor communes by 2005 and $100 \%$ by 2010 .

Expand the national transmission grid to 900 poor commune centers by 2005 .

Provide essential infrastructure, especially water supply and environmental hygiene, for poor areas in cities and towns.

Ensure that $80 \%$ of urban and $60 \%$ of rural population will have access to clean and safe water by $2005 ; 85 \%$ of rural population to have access to clean and safe water by 2010 .
- Percentage of poorest communes with car accessible roads leading to commune centre.

- Percentage of poor communes with smallscale irrigation works.

- Percentage of poor communes with health stations.

- Percentage of poor communes with primary schools, kindergartens and infant schools.

- Percentage of poor commune-clusters with junior-secondary schools.

- Percentage of poor communes with markets or inter-commnune markets.

- Percentage of poor communes with cultural model post offices.

- Percentage of communes with radio stations.

- Percentage of poorest communes with electricity

- Percentage of poor households in urban areas with access to essential infrastructure.

- Percentage of poor households with access to clean water.

- Percentage of poor rural communes and poor urban districts with clean and hygienic drinking water system.

\section{Job creation}




\begin{tabular}{|c|c|c|c|}
\hline Objectives, Targets & Monitoring indicators & $\begin{array}{l}\text { Reporting } \\
\text { frequency }\end{array}$ & $\begin{array}{c}\text { Reporting } \\
\text { agencies }\end{array}$ \\
\hline $\begin{array}{l}\text { Increase the share of trained } \\
\text { workers in the total } \\
\text { workforce to } 30 \% \text { in } 2005 \\
\text { and } 40 \% \text { in } 2010 \text {. } \\
\text { Increase the ratio of rural } \\
\text { working time utilization of } \\
\text { people of working age to } \\
\text { about } 80 \% \text { by } 2005 \text { and } 85 \% \\
\text { by } 2010 . \\
\text { Reduce the share of urban } \\
\text { unemployed among the total } \\
\text { number of people of working } \\
\text { age to about } 5 \% \text { in } 2004 \text { and } \\
\text { to less than } 5 \% \text { by } 2010 \text {. }\end{array}$ & $\begin{array}{l}\text { - Number of jobs created annually. } \\
\text { - Number of new jobs created annually. } \\
\text { - Ratio of female workers in total newly created jobs. } \\
\text { - Number of jobs in non-state sector. } \\
\text { - Number of new jobs in non-state sector. } \\
\text { - Percent of landless poor households that have } \\
\text { found jobs. } \\
\text { - Percent of poor households with access to } \\
\text { credit and loans for job creation. } \\
\text { - Number of workers by sectors (agriculture, } \\
\text { industry and services) } \\
\text { - Percent of trained workers in total labour } \\
\text { force. } \\
\text { - Total workers trained annually. } \\
\text { - Coefficient of rural working time }\end{array}$ & $\begin{array}{l}\text { Annual } \\
\text { (employ- } \\
\text { ment and } \\
\text { statistical } \\
\text { surveys) }\end{array}$ & $\begin{array}{c}\text { GSO, } \\
\text { MOLISA } \\
\text { and } \\
\text { provinces }\end{array}$ \\
\hline \multicolumn{4}{|l|}{ 4. Education universalization } \\
\hline $\begin{array}{l}\text { Increase the rate of children } \\
\text { of primary school education } \\
\text { age going to primary schools } \\
\text { to } 97 \% \text { (junior secondary } \\
\text { school to } 80 \% \text { ) by } 2005 \text { and } \\
\text { to } 99 \% \text { (junior secondary to } \\
90 \% \text { ) by } 2010 \text {. }\end{array}$ & $\begin{array}{l}\text { - Rate of net primary school enrolment. } \\
\text { - Rate of net junior secondary school } \\
\text { enrolment. } \\
\text { - Rate of kindergarten enrollment at the age of 3- } \\
5 . \\
\text { - Rate of primary education completion. } \\
\text { - Rate of junior secondary universalization. } \\
\text { - Literacy rate among people aged } 15-24 \text {. } \\
\text { - Rate of class repeaters and drop-outs. } \\
\text { (These indicators are classified by gender and } \\
\text { ethnicity) }\end{array}$ & $\begin{array}{l}\text { Annual and } \\
\text { every two } \\
\text { year } \\
\text { (household } \\
\text { living } \\
\text { standard } \\
\text { surveys) }\end{array}$ & $\begin{array}{c}\text { Ministry of } \\
\text { Training and } \\
\text { Education, } \\
\text { GSO and } \\
\text { provinces }\end{array}$ \\
\hline $\begin{array}{l}\text { By } 2010, \text { strive to improve } \\
\text { the quality of education and } \\
\text { increase the rate of children } \\
\text { attending two sessions at the } \\
\text { primary school level. }\end{array}$ & $\begin{array}{l}\text { - Rate of children attending two sessions (full } \\
\text { day). }\end{array}$ & $\begin{array}{l}\text { Annual and } \\
\text { every two } \\
\text { year } \\
\text { (household } \\
\text { living } \\
\text { standard } \\
\text { surveys) }\end{array}$ & $\begin{array}{c}\text { Ministry of } \\
\text { Training and } \\
\text { Education } \\
\text { GSO and } \\
\text { provinces }\end{array}$ \\
\hline
\end{tabular}




\begin{tabular}{|c|c|c|c|}
\hline Objectives, Targets & Monitoring indicators & $\begin{array}{l}\text { Reporting } \\
\text { frequency }\end{array}$ & $\begin{array}{c}\text { Reporting } \\
\text { agencies }\end{array}$ \\
\hline $\begin{array}{l}\text { Eliminate gender gap in } \\
\text { primary and secondary } \\
\text { education by } 2005 \text { and the } \\
\text { gap among ethnic minorities } \\
\text { in primary and secondary } \\
\text { education by } 2010 \text {. }\end{array}$ & $\begin{array}{l}\text { - Proportion of females and males at primary, } \\
\text { secondary and tertiary education levels. } \\
\text { - Literacy rate between females and males aged } \\
15-24 \text {. } \\
\text { - School enrolment rate of ethnic children } \\
\text { compared to that of Kinh children at primary } \\
\text { and secondary levels in } 2010 \text {. }\end{array}$ & & \\
\hline $\begin{array}{l}\text { Eliminate illiteracy for } 95 \% \\
\text { of illiterate under- } 40 \text {-year-old } \\
\text { women by } 2005 \text { and } 100 \% \\
\text { by } 2010 .\end{array}$ & - Rate of literate under-40-year-old women. & & \\
\hline \multicolumn{4}{|c|}{ 5. Reduce Birth Rate, Child Mortality Rate and Child Malnutrition Rate } \\
\hline $\begin{array}{l}\text { Maintain the trend reduction in } \\
\text { the birth rate in order to reach } \\
\text { the average substitution level } \\
\text { for the whole country by } 2005 \text {; } \\
\text { in remote and poor areas by } \\
2010 \text {. }\end{array}$ & $\begin{array}{l}\text { - Population growth rate. } \\
\text { - Prevalence of contraceptive use/availability. }\end{array}$ & & \\
\hline $\begin{array}{l}\text { Reduce the mortality rate of } \\
\text { under- } 1 \text {-year-old children to } \\
30 / 1,000 \text { by } 2005 \text { and less } \\
\text { than } 25 / 1,000 \text { by } 2010 ; \\
\text { reduce mortality rate of } \\
\text { under- } 5 \text {-year-old children to } \\
36 / 1,000 \text { and less than } \\
32 / 1,000 \text { by } 2005 \text { and } 2010 \\
\text { respectively. }\end{array}$ & $\begin{array}{l}\text { - Infant Mortality Rate. } \\
\text { - Mortality Rate of Children under } 5\end{array}$ & $\begin{array}{l}10 \text { years } \\
\text { (General } \\
\text { Population } \\
\text { Survey) } \\
\text { every } 2 \\
\text { years } \\
\text { (household } \\
\text { living } \\
\text { standard } \\
\text { surveys) } \\
\text { and annual }\end{array}$ & $\begin{array}{l}\text { GSO, MOH, } \\
\text { National } \\
\text { Committee } \\
\text { for Popula- } \\
\text { tion and } \\
\text { family } \\
\text { planning, } \\
\text { and } \\
\text { provinces }\end{array}$ \\
\hline $\begin{array}{l}\text { Rapidly reduce the rate of } \\
\text { children of low birth weight } \\
\text { (less than } 2,500 \text { grams) to } 7 \% \\
\text { by } 2005 \text { and to } 5 \% \text { by } 2010 .\end{array}$ & $\begin{array}{l}\text { - Percentage of low birth weight (less than } \\
\text { 2,500 grams) children. } \\
\text { (These indicators are disaggregated by gender } \\
\text { and ethnicity) }\end{array}$ & & \\
\hline \multicolumn{4}{|c|}{ 6. Reproductive health, HIV/AIDS, epidemics and other social diseases } \\
\hline $\begin{array}{l}\text { Reduce the maternal } \\
\text { mortality rate to } 80 / 100,000 \\
\text { live births by } 2005 \text { and to } \\
70 / 100,000 \text { live births in the } \\
\text { whole country by } 2010 \text { (the } \\
\text { rate for mountainous areas is } \\
100 / 100,000 \text { ). }\end{array}$ & $\begin{array}{l}\text { - Maternal mortality rate. } \\
\text { - Number of births attended by a health } \\
\text { professional. }\end{array}$ & $\begin{array}{l}\text { Annual and } \\
\text { every two } \\
\text { years } \\
\text { (household } \\
\text { living } \\
\text { standard } \\
\text { surveys) }\end{array}$ & $\begin{array}{l}\mathrm{MOH}, \mathrm{GSO} \\
\text { and } \\
\text { provinces }\end{array}$ \\
\hline
\end{tabular}




\begin{tabular}{|c|c|c|c|}
\hline Objectives, Targets & Monitoring indicators & $\begin{array}{l}\text { Reporting } \\
\text { frequency }\end{array}$ & $\begin{array}{c}\text { Reporting } \\
\text { agencies }\end{array}$ \\
\hline $\begin{array}{l}\text { Maintain the achievement of } \\
\text { polio eradication; minimize } \\
\text { the number of people } \\
\text { sickened by cholera, typhoid, } \\
\text { hemorrhagic fever, malaria, } \\
\text { and plague, etc. }\end{array}$ & $\begin{array}{l}\text { - Proportion of children sickened by cholera, } \\
\text { typhoid, hemorrhagic fever, malaria, plague, } \\
\text { etc. }\end{array}$ & & \\
\hline $\begin{array}{l}\text { Contain the rate of } \\
\text { HIV/AIDS transmission }\end{array}$ & $\begin{array}{l}\text { - Proportion of HIV/AIDS infected people age } \\
\text { 15-49. } \\
\text { - Proportion of children infected by HIV/AIDS. }\end{array}$ & & \\
\hline $\begin{array}{l}\text { Control and move towards } \\
\text { containing social diseases. }\end{array}$ & $\begin{array}{l}\text { - Proportion of people infected by social } \\
\text { diseases. }\end{array}$ & & \\
\hline \multicolumn{4}{|c|}{ 7. Development of culture and information, improve the spiritual life of people } \\
\hline $\begin{array}{l}\text { By } 2005, \text { strive for } 80 \% \text { of } \\
\text { households to attain the } \\
\text { status of cultured family; } \\
50 \% \text { of villages, hamlets, } \\
\text { urban districts to attain } \\
\text { national culture standards; } \\
78 \% \text { of commune, districts } \\
\text { with cultural houses. }\end{array}$ & $\begin{array}{l}\text { - Percent of households attaining cultured } \\
\text { family status. } \\
\text { - Percent of village, hamlet, urban districts } \\
\text { attaining the national culture standard. } \\
\text { - Percent of communes and districts with } \\
\text { cultural houses. }\end{array}$ & & \\
\hline $\begin{array}{l}\text { Ensure that more than } 90 \% \\
\text { of households can see } \\
\text { Vietnam Television programs } \\
\text { and that more than } 95 \% \text { can } \\
\text { hear the Voice of Vietnam } \\
\text { radio by } 2005 \text {. }\end{array}$ & $\begin{array}{l}\text { - Percent of households that can see Vietnam } \\
\text { Television programs. } \\
\text { - Percent of households that can hear the Voice } \\
\text { of Vietnam radio. }\end{array}$ & Annual & $\begin{array}{l}\text { Ministry of } \\
\text { Culture and } \\
\text { Informa- } \\
\text { tion; } \\
\text { GSO }\end{array}$ \\
\hline $\begin{array}{l}\text { Increase the amount of } \\
\text { broadcasting and television } \\
\text { time in ethnic languages. }\end{array}$ & $\begin{array}{l}\text { - Amount of time broadcasting ethnic } \\
\text { languages. }\end{array}$ & & \\
\hline \multicolumn{4}{|c|}{ 8. Improve living standards, preserve and develop ethnic minority cultures } \\
\hline $\begin{array}{l}\text { Preserve and develop the } \\
\text { ability to read and write in } \\
\text { ethnic languages. }\end{array}$ & - Rate of ethnic language illiteracy. & & \\
\hline $\begin{array}{l}\text { Ensure the entitlement of } \\
\text { individual and collective } \\
\text { land- use rights in ethnic } \\
\text { minority and mountainous } \\
\text { areas. }\end{array}$ & $\begin{array}{l}\text { - Rate of ethnic peoples with land-use right } \\
\text { titles for all forms of land-use. } \\
\text { - Rate of ethnic peoples leading nomadic life. }\end{array}$ & Annual & $\begin{array}{l}\text { MOTE, } \\
\text { General } \\
\text { Land Office, } \\
\text { GCOP and } \\
\text { provinces }\end{array}$ \\
\hline $\begin{array}{l}\text { Increase the proportion of } \\
\text { ethnic minority people in } \\
\text { governing bodies at various } \\
\text { levels. }\end{array}$ & $\begin{array}{l}\text { - Percent of ethic peoples working in governing } \\
\text { bodies at various levels. }\end{array}$ & & \\
\hline
\end{tabular}




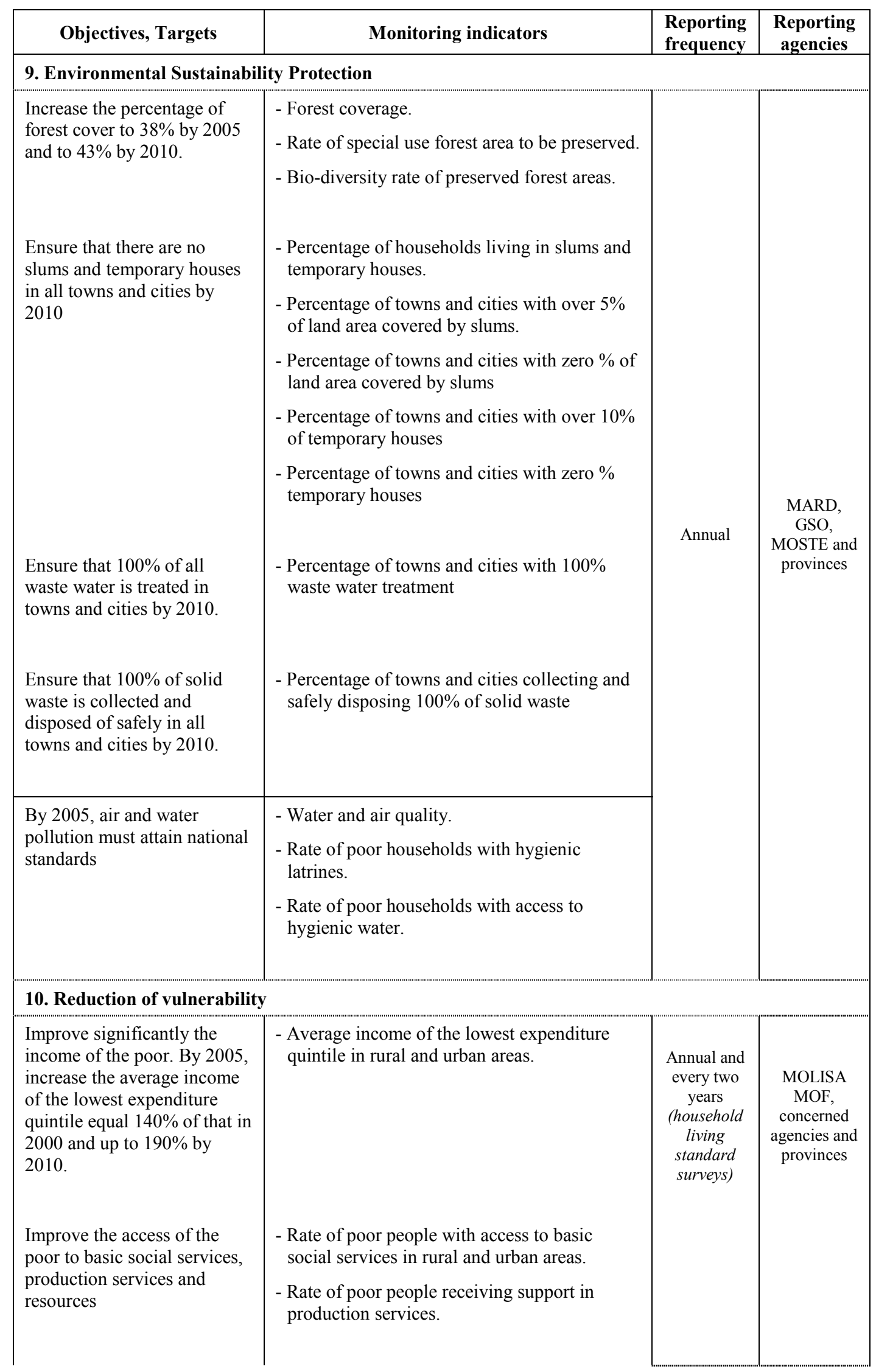




\begin{tabular}{|c|c|c|c|}
\hline Objectives, Targets & Monitoring indicators & $\begin{array}{l}\text { Reporting } \\
\text { frequency }\end{array}$ & $\begin{array}{c}\text { Reporting } \\
\text { agencies }\end{array}$ \\
\hline $\begin{array}{l}\text { Expand the official social } \\
\text { safety net (health insurance, } \\
\text { social insurance, etc.) and } \\
\text { diversify the voluntary safety } \\
\text { net (school insurance and } \\
\text { insurance of crops, diseases, } \\
\text { production equipment, } \\
\text { agricultural extension, etc.) }\end{array}$ & $\begin{array}{l}\text { - Percent of people participating in official and } \\
\text { voluntary insurance system. } \\
\text { - Percent of the disabled, dependent elderly } \\
\text { people living alone and other policy-qualified } \\
\text { people receiving social welfare. } \\
\text { - Percent of poor people receiving essential } \\
\text { support (e.g. shelter, recurrent and emergency } \\
\text { relief support). } \\
\text { - Number of social welfare centres. } \\
\text { - Number of humanitarian aid funds. } \\
\text { - Percent of poor people with health insurance. }\end{array}$ & & \\
\hline Ensure job security & $\begin{array}{l}\text { - Percent of people benefiting from } \\
\text { unemployment insurance. } \\
\text { - Percent of redundant workers benefiting from } \\
\text { support policies such as training, credit, etc. }\end{array}$ & & \\
\hline $\begin{array}{l}\text { Fully resolve the problem of } \\
\text { child labor and street } \\
\text { children. Protect them from } \\
\text { economic exploitation and } \\
\text { sexual abuse. }\end{array}$ & $\begin{array}{l}\text { - Percent of children cared for who are in } \\
\text { difficult situations (orphans, disabled } \\
\text { children, street children and child workers). }\end{array}$ & & \\
\hline $\begin{array}{l}\text { Develop strategy for natural } \\
\text { disaster relief and prevention. } \\
\text { By } 2010 \text {, reduce by half the } \\
\text { rate of poor people falling } \\
\text { back into poverty due to } \\
\text { natural disasters and other } \\
\text { risks. }\end{array}$ & $\begin{array}{l}\text { - Rate of poor people falling back into poverty } \\
\text { due to natural disasters. }\end{array}$ & & \\
\hline \multicolumn{4}{|c|}{ 11. Gender Equality and Advancement of Women } \\
\hline $\begin{array}{l}\text { Increase the number of } \\
\text { women in elective bodies and } \\
\text { in government bodies at all } \\
\text { levels (national, provincial, } \\
\text { district and commune). } \\
\text { Increase the participation of } \\
\text { women in agencies and } \\
\text { sectors at all levels by an } \\
\text { additional 3-5\% in the next } \\
10 \text { years. }\end{array}$ & $\begin{array}{l}\text { - Percent of women in the Party's Central } \\
\text { - Percent of women in the National Assembly. } \\
\text { - Percent of women representatives in elected } \\
\text { agencies. } \\
\text { - Percent of women leaders in ministries and } \\
\text { central agencies and institutions. } \\
\text { - Percent of women entrepreneurs. } \\
\text { - Percent of land-use right titles granted to both } \\
\text { husband and wife. }\end{array}$ & $\begin{array}{l}\text { Annual and } \\
\text { every } 5 \text { year } \\
\text { (term of } \\
\text { election) }\end{array}$ & $\begin{array}{l}\text { National } \\
\text { Assembly } \\
\text { Office; } \\
\text { Party's } \\
\text { Central } \\
\text { Committee } \\
\text { Office, } \\
\text { GCOP and } \\
\text { related } \\
\text { agencies }\end{array}$ \\
\hline $\begin{array}{l}\text { Reduce the vulnerability of } \\
\text { women in family violence. }\end{array}$ & - Gender Development Index (GDI). & & \\
\hline
\end{tabular}




\begin{tabular}{|c|c|c|c|}
\hline Objectives, Targets & Monitoring indicators & $\begin{array}{l}\text { Reporting } \\
\text { frequency }\end{array}$ & $\begin{array}{c}\text { Reporting } \\
\text { agencies }\end{array}$ \\
\hline $\begin{array}{l}\text { Ensure grass-roots } \\
\text { democracy }\end{array}$ & $\begin{array}{l}\text { - Percent of communes having staff to monitor } \\
\text { the poverty reduction strategy. } \\
\text { - Percent of communes that are provided with } \\
\text { information on poverty reduction programs. } \\
\text { - Percent of communes with complaints and } \\
\text { lawsuits. Percent of petitions to be settled. } \\
\text { - Percent of communes with no social evils. } \\
\text { - Percent of communes with libraries of law. } \\
\text { - Number of coaching and propagating courses } \\
\text { on State laws and policies. }\end{array}$ & $\begin{array}{l}\text { Annual and } \\
\text { every } 2 \text { year } \\
\text { (household } \\
\text { living } \\
\text { standard } \\
\text { surveys) }\end{array}$ & $\begin{array}{c}\text { GSO, } \\
\text { GCOP, } \\
\text { Ministry of } \\
\text { Judiciary } \\
\text { and } \\
\text { provinces }\end{array}$ \\
\hline Ensure budget transparency & $\begin{array}{l}\text { - Proportion of communes that publicise their } \\
\text { budget revenue and expenditure. }\end{array}$ & & \\
\hline
\end{tabular}




\section{Appendix 2:}

MEDIUM TERM MACROECONOMIC FRAMEWORK, 3 YEARS 2002-2004

\begin{tabular}{|c|c|c|c|c|c|}
\hline & 2000 & $\begin{array}{c}\text { Estimated } \\
2001\end{array}$ & 2002 & 2003 & 2004 \\
\hline \multicolumn{6}{|l|}{ Outputs and prices } \\
\hline \multicolumn{6}{|l|}{ - Real GDP (\%) } \\
\hline Official & 6.8 & 6.8 & 7.0 & $>7$ & 7.5 \\
\hline Fund Staff estimates ${ }^{(1)}$ : & 5.5 & 5.0 & 5.3 & 6.5 & 7.0 \\
\hline - CPI (end of period, December, \%) & -0.6 & 0.8 & 4.0 & 3.5 & 3 \\
\hline $\begin{array}{l}\text { Current Account Balance } \\
\text { (including official transfers) }\end{array}$ & 2.1 & 2.2 & -1.9 & -3.2 & -1.7 \\
\hline \multirow{2}{*}{\multicolumn{6}{|c|}{ Exports and Imports }} \\
\hline & & & & & \\
\hline - Growth rate of exports of goods $(\%)^{(2)}$ & 25.2 & 4.0 & $4^{(3)}$ & $12-14$ & $12.5-14$ \\
\hline - Growth rate of imports of goods (\%) & 34.5 & 2.3 & 10.0 & 15.0 & 11.0 \\
\hline \multicolumn{6}{|l|}{ State Budget/GDP (\%) ${ }^{(4)}$} \\
\hline \multicolumn{6}{|l|}{ - Total revenue (including grants) } \\
\hline Official & 20.4 & 20.6 & 19.5 & 19.8 & 19.8 \\
\hline Fund Staff & 21.1 & 21.8 & 20.8 & 21.3 & 21.6 \\
\hline \multicolumn{6}{|l|}{$\begin{array}{l}\text { - Total expenditure (excluding on- } \\
\text { lending) }\end{array}$} \\
\hline Official & 23.2 & 23.5 & 22.0 & 22.7 & 22.7 \\
\hline Fund Staff & 23.9 & 25.2 & 24.7 & 25.0 & 24.8 \\
\hline \multicolumn{6}{|l|}{$\begin{array}{l}\text { - Overall fiscal balance (excluding } \\
\text { on-lending) }\end{array}$} \\
\hline Official & -2.8 & -2.9 & -2.5 & -2.9 & -2.9 \\
\hline Fund Staff & -2.8 & -3.5 & -3.9 & -3.7 & -3.2 \\
\hline $\begin{array}{l}\text { Gross official reserves (number of } \\
\text { weeks imports of goods and non-factor } \\
\text { services) }\end{array}$ & 8.9 & 9.1 & 9.0 & 9.2 & 9.4 \\
\hline
\end{tabular}

Sources: Vietnamese authorities and IMF staff projections and estimation.

(1) - International organizations (IMF, WB and ADB...) have different projections of GDP growth rate due to alternative methodologies used to estimate GDP and its components on an expenditure basis.

(2) - Fluctuation between the official (ceiling margin) and IMF staff (floor margin) estimations.

(3) - The planed target of early 2001 is $10 \%$. However, after couple of recent months the export growth rate is slowing down, IMF estimates the growth rate of export of goods in 2002 is $4 \%$ and Vietnam Government expects a higher growth rate.

(4) - The Total revenue/GDP, Total Expenditure/GDP calculation are based on the current GDP projection of Vietnam excluding the costs of SOE reform and commercial bank reform. IMF staff estimates current GDP lower and takes into account the current expenditure of structural reform. Other differnces in coverage and assumptions underlying the projection. 
Appendix 3:

POLICY MATRIX, MEASURES AND TIMETABLE FOR IMPLEMENTATION

Policy areas and Objectives

Policies, measures and timetable for implementation during 2003-2005

A. Macroeconomic and Structural Policies to promote economic growth, raise income and create opportunities for the poor.

I. Create legal environment for fair and competitive business

1. Create a fair business forms of enterprises and increase the transparency of regulations and policies environment for different

Remove impediments for registration and start-up of businesses and create a level playing field for different forms of enterprises through implementation of the Law on Enterprises, continue to revoke or modify business licenses in the remaining sub-sectors where restrictive licensing exists.

Create equal conditions for all types of enterprises to access capital, credit, land, technology, profession, information, and current preferential systems of the State.

Develop and improve a legal framework to ensure a stable and predictable investment environment and to promote openness, and transparency of measures and policies to encourage greater investment.

Create more favourable conditions for attracting foreign investment.For example, gradually remove the dual pricing system imposed by the State on state-supplied services for business activities of domestic and foreigninvested enterprises.

Promote direct foreign investment in export production and in social sectors.

Unify step by step the legal framework, policy and conditions for domestic and foreign-invested enterprises.

Issue implementing regulations for Decree No. 90/CP on promoting development of small and medium size enterprises (2002-2003).

Promote the activities of the farm economy by implementing Decree No. 03/CP (2002-2003).

Promulgate regulations to implement the Revised Land Law (2002) and issue land-use right certificates to all land users (2005).

Prepare conditions to unify the Law to Encourage Domestic Investment and the Foreign Investment Law (2003).

Promulgate the Bankruptcy Law (revised) applied to all types of enterprises (2003).

Revise and amend some articles of the Labour Law (2002).

Promulgate State Law on Price (2002).

Promulgate State Law on Trade Arbitration (2002-2003).

Implement the Decree No. 132/CP on the development of rural professions.

Revise and amend selected articles of the Co-operative Law (2003).

Promulgate the Best Company Management Rules and require all companies listed on the Stock Market and Joint stock banks to implement them within 18 months; encourage joint stock companies to implement these Rules also.

Construct the legal framework to allow for establishing business associations.

Construct and approve the Electricity Law.

2. Reform state-owned enterprises (SOEs) to strengthen their efficiency and competitiveness.
Implement a medium term five - year SOE reform program during the 20012005 period, with annual targets to improve efficiency and to curtail losses in this sector. Complete the equitization, transfer to employees, sale, contracting out, leases, mergers, divestitures and liquidation of around 2,800 SOEs. Of which, complete equitization, sale and liquidation of, in 2002: 400 SOEs, in 2003: 500 SOEs.

Promulgate criteria for the classification of SOEs and State Corporations 


\begin{tabular}{|c|c|}
\hline & $\begin{array}{l}\text { into business- oriented SOEs and public-service SOEs (2002). } \\
\text { Issue guidance for transforming SOEs into single owner limited liability } \\
\text { companies (2002). } \\
\text { Promulgate a new decree to replace Decree No. 44/1998/ND-CP on SOE } \\
\text { equitization. } \\
\text { Promulgate the Decree on Social Welfare Fund to extend to workers of } \\
\text { SOEs (2002). } \\
\text { Promulgate Decree on the Treatment of Redundant Workers (2002). } \\
\text { Develop an incentive mechanism to encourage redundant workers to resign } \\
\text { voluntarily during the process of implementing the SOE reform program. } \\
\text { Develop a pilot plan to restructure several selected corporations (about } 3 \text { ). } \\
\text { Then, complete the plan to restructure } 3 \text { corporations (2002) and start the } \\
\text { action plan (2003). } \\
\text { Promulgate the Decree on SOE Debt Clearance. } \\
\text { Develop a set of criteria to supervise and evaluate the business performance } \\
\text { and effectiveness of SOEs. Complete the system of debt control of } 200 \text { large } \\
\text { SOEs in order to have suitable reform policies. Develop the system of debt } \\
\text { control to all SOEs in order to have policies to limit risks, clear bad debts, } \\
\text { re-arrange or liquidate ineffective SOEs. } \\
\text { Carry out performance assessment/diagnostic audits of several large SOEs. } \\
\text { Complete the performance assessment/ diagnostic audits of } 30 \text { SOEs ( } 2002 \text { ) } \\
\text { and another } 30 \text { SOEs ( } 2003 \text { ) if there is enough financial support. } \\
\text { Revise and amend Decree No. 103/CP on the sale, transfer, contracting out, } \\
\text { and leasing of SOEs ( } 2002 \text { ). } \\
\text { companies to improve their accounting and financial reports (2002). } \\
\text { SOEs (2003), including proper incentive mechanisms. }\end{array}$ \\
\hline \multicolumn{2}{|c|}{ II. Create a stable macroeconomic environment } \\
\hline $\begin{array}{l}\text { 1. Fiscal policy and public } \\
\text { expenditure management: } \\
\text { Implement appropriate fiscal } \\
\text { policies to safeguard } \\
\text { medium-term sustainability }\end{array}$ & $\begin{array}{l}\text { Strengthen tax system, increase tax base along the lines of developing the } \\
\text { sources of tax revenue and increasing the efficiency of the tax payment system } \\
\text { but still remain pro-poor tax policies and system. Amend some articles of the } \\
\text { Revised State Budget Law (2002). }\end{array}$ \\
\hline & $\begin{array}{l}\text { Gradually implement the recommendations that are agreed upon in the Public } \\
\text { Expenditure Review. Increase expenditures for basic social services and rural } \\
\text { infrastructure and bias public expenditure in favor of poor provinces. }\end{array}$ \\
\hline $\begin{array}{l}\text { Increase budget transparency } \\
\text { to improve the information } \\
\text { base for decision-making } \\
\text { and target setting. }\end{array}$ & $\begin{array}{l}\text { Improve budgetary revenue and the expenditure monitoring system at all } \\
\text { levels. } \\
\text { Continue to make public information on annual budgetary revenues and } \\
\text { expenditures at various levels in a more scientific and proper manner. }\end{array}$ \\
\hline $\begin{array}{l}\text { 2. Monetary policy: } \\
\text { Implement prudent monetary } \\
\text { policy to control inflation }\end{array}$ & $\begin{array}{l}\text { Introduce monetary and credit controls with an aim to improving the } \\
\text { effectiveness of monitoring monetary policy and meeting the targeted objectives. } \\
\text { Continue to implement a basic interest rate policy with an aim to move } \\
\text { towards liberalizing interest rates. }\end{array}$ \\
\hline
\end{tabular}


Reform banking sector and financial organizations to mobilize domestic capital resources.

Foreign exchange policies to increase competitiveness, liberalize the current account

3. External debt policies to keep debt service burden at a serviceable level

\section{Trade policy:}

Measures to open trade, promote exports and international integration, and strengthen the country's competitiveness.
Develop and implement the plans for restructuring four state-owned commercial banks (SOCBs) in accordance with the overall framework for banking sector reform (2002-2004).

Complete the international accounting standard (IAS)-based financial audits for four large SOCBs by independent auditing companies (2003); resolve all inadequate issues of auditing (2004).

Separate preferential and policy-based credit activities from the State-owned commercial banks, and let them operate in a competitive environment.

Address audit qualifications laid out in the IAS Audit Report on 2000 accounts (2003).

Resolve non-performing loans of state-owned commercial banks to $20 \%$ of total debts (2002) and another 30\% of non-performing loans (2003).

Complete the separation of the Bank for the Poor from the Bank for Agriculture and Rural Development of Vietnam and let it act as a policy-based bank. (2003). Increase Bank for the Poor's lending to disadvantaged areas.

Restructure and reinforce joint stock banks, close or merge weak banks and ensure that they are in compliance with prudential regulations. Reduce the number of total joint stock banks to 28 (2003).

Implement Decision No. 1627 to reclassify all non-performing loans in the four SOCBs and to phase-in provisioning within 3 years (2003-2005) to bring loan loss provisions in line with international standards and to allow for financial status assessment of SOCBs.

Promulgate a decree guiding the implementation of the revised Land Law to create favourable conditions for transfer, leasing, and mortgage to borrow loans from banks and to make contribution to joint ventures.

Provide concrete guidelines on regulations to allow foreign banks operating in Vietnam to accept land use rights as collateral.

State-owned commercial banks should raise gradually the share of credit to private small and medium enterprises and enterprises operating in rural and disadvantage areas.

Allow Postal Savings and the People Credit Funds to receive deposits and expand their operating scope in order to lend for production development.

Increase flexibility and transparency of the foreign exchange regime. Develop inter-bank foreign exchange market.

Build a system and measures to control the foreign capital rotation, especially short-term capital. Control and limit using foreign currencies within Vietnam territory.

Reduce gradually the ratio of foreign exchange surrender.

Monitor all debts including debts incurred by government, SOEs, and those guaranteed by Government, debts of joint venture companies (including FDI loans) and private sector debts.

Promote vigorously economic integration; strictly implement commitments in the process of integration.

Make active preparations to take part in committed bilateral and multi-lateral cooperation mechanisms. Carry out the bilateral trade agreement with the United States, paving the way for accession to the World Trade Organization (WTO).

Implement trade polices for rural, mountainous and island areas; review the performance of the Law of Trade (2002-2003). Increase the access to markets of the poor, particularly from rural, remote and isolated areas. 


\begin{tabular}{|c|c|}
\hline & $\begin{array}{l}\text { Continue to remove quota restriction barriers imposed on restricted import } \\
\text { goods, excluding the barriers on petroleum, lubricant, diesel and sugar... } \\
\text { Strictly implement Decision No. 46/QD-TTg on the export-import } \\
\text { mechanism in the period 2001-2005. } \\
\text { Put all import goods that are currently in the Temporary Exemption List } \\
\text { (TEL) into the Inclusion List (IL) with reduction of minimum rate import } \\
\text { tax to } 20 \% \text { in order to implement CEPT/AFTA agreements (2003). } \\
\text { Continue to remove quantitative restrictions imposed on rice exporting } \\
\text { enterprises and on fertilizer imports. } \\
\text { Increase gradually activities to organize quota auctions for garment exports to } \\
\text { create favourable conditions for exporters (including those from private sector) } \\
\text { to access the market. Expand the rate of quota auctions for garment exports to } \\
35 \% \text { and apply measures to improve auction procedures (2003). } \\
\text { Promulgate the Law of Competition (2003); promulgate the State Law on } \\
\text { National Treatment and Most Favoured Nation Status (2003); promulgate } \\
\text { the State Law on self-defense measure in international trade business (2002- } \\
\text { 2003). } \\
\text { Implement the Customs Law (2002) to simplify and rationalize customs } \\
\text { procedures (2002-2005). } \\
\text { Operate effectively the Export Support Fund, the Export Credit Guarantee } \\
\text { Fund (2002-2005). } \\
\text { Publish all trade laws, decrees, decisions, and rules of procedures in official } \\
\text { gazettes. }\end{array}$ \\
\hline $\begin{array}{l}\text { Protect the poor from the } \\
\text { negative impact of trade } \\
\text { liberalization }\end{array}$ & $\begin{array}{l}\text { Undertake research to examine the impact of trade policy reforms on the } \\
\text { poor. }\end{array}$ \\
\hline \multicolumn{2}{|c|}{ III. Public Administration reform; promote grass roots democracy and legal support for the poor. } \\
\hline $\begin{array}{l}\text { Accelerate the reform of } \\
\text { public administration, } \\
\text { providing the poor with } \\
\text { knowledge of the Law and } \\
\text { their legal rights and } \\
\text { obligations. }\end{array}$ & $\begin{array}{l}\text { Implement Decree No. } 136 / 2001 / \mathrm{QD}-\mathrm{TTg} \text { issued by the Prime Minister on } \\
\text { accelerating public administration reform in four areas: administrative } \\
\text { institutions, management bodies, personnel strengthening and public } \\
\text { expenditure. } \\
\text { Prioritize administration reform in key agencies that directly relate to the } \\
\text { poor, such as MARD, MOH, MOTE, etc. to ensure the access of the poor to } \\
\text { basic services of health, education, infrastructure, etc. in provinces, } \\
\text { especially mountainous and urban poor areas. } \\
\text { Ensure that all citizens have access to information about the law and their } \\
\text { legal rights and obligations, and that the poor have better access to the } \\
\text { justice system. } \\
\text { Improve targeting for the poor and the allocation of resources to pro-poor } \\
\text { programs. } \\
\text { Implement the action plans embedded in the Legal Needs Assessment. }\end{array}$ \\
\hline
\end{tabular}




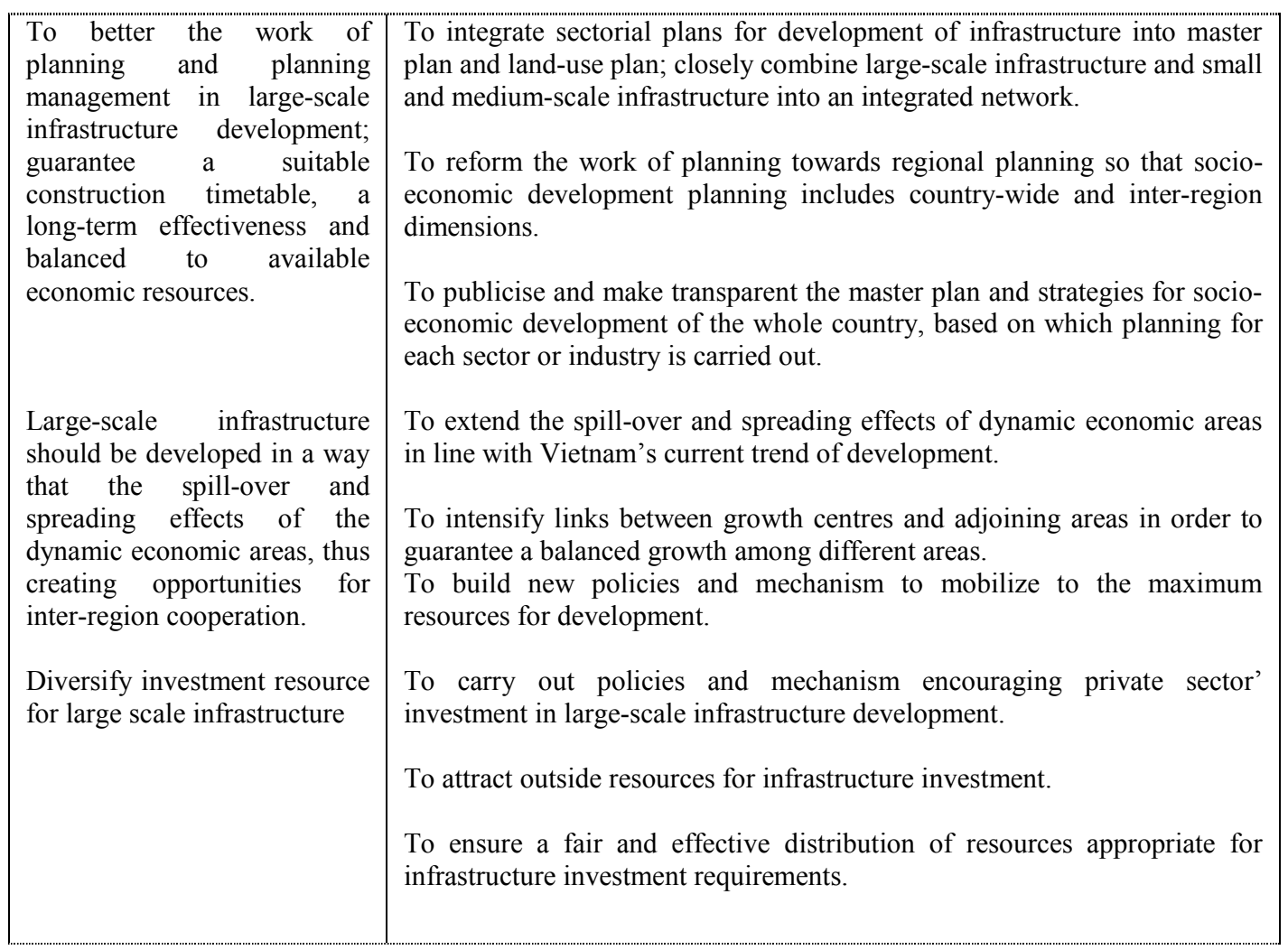


To pay due attention to environmental and resettlement problems that arise from large-scale infrastructure projects.

\section{Reform}

management mechanism for infrastructure service projects in line with current management trend.

Enhance the work of maintenance for large-scale infrastructure projects.

Realize cost-reduction solutions for infrastructure services, increase accessibility of the poor to infrastructure services.
To observe environmental standards imposed by the State environment authorities; efficiently use natural and human resources with a view to sustainable development.

To carry out surveys of public opinions on environmental and social impacts of infrastructure projects.

To facilitate the State environment protection authorities in examining, supervising the implementation of environment commitments set out in the project's Environmental Impacts Evaluation Report.

To reform the management mechanism for principal construction investment, enhance management devolution for projects.

To harmonize relations with partners.

To increase State budget funding for maintenance work as a separate cost item.

To build a mechanism for mobilizing non-budget funding for maintenance cost. Maintenance cost is allocated as separate from project spending.

To fully account fee incomes from public work investment.

To extend private sector investments and promote society investment in education, health and social activities; encourage local and foreign investors to invest in BOT for public work projects.

Devolution of management for public works, using unpaid labour in the maintenance work.

To have appropriate fee policy to large-scale infrastructure services in poor localities so that the local community can use the services.

To have solutions to raise the efficiency of building and operating infrastructure services; enhance management capacity and apply advanced technology with a view to reducing costs and raising competitiveness for infrastructure services; apply solutions for prevention of waste and downgrading of infrastructure services.

\section{Policies and measures to develop major sectors and areas to ensure sustainable growth and for}

I. Policies and measures to develop sectors and areas and create opportunities for the poor.

1. Develop agriculture and the rural economy to reduce widely poverty
Continue to implement the Government's Resolution No. 09 and No. 05 on directions and policies to shift the economic structure and product sale.

Implement Resolution No. 13 to continue reform and improve the efficiency of Cooperatives; Resolution No. 14 to continue reform of mechanisms and policies to encourage the private sector.

Provide concrete guidelines to protect land use rights in accordance with the Revised Land Law. Advance the task of planning land use and link it to land transfers. Complete land classification and accelerate the process of issuing land use right certificates to farmers, including those living in mountainous communes.

Develop rural industrial zones at the district and commune level. Implement Decree No. 90 on support policies for developing small and medium enterprises.

Diversify professions and encourage developing off-farm professions in rural areas. Implement Decision No. 132 issued by the Prime Minister on developing rural professions. 


\begin{tabular}{|c|c|}
\hline & $\begin{array}{l}\text { Promote measures to help poor households that need cultivation land to be } \\
\text { given enough land for production, to stabilize their livelihood, reduce } \\
\text { poverty and gradually become richer. Allocate un-used and under-utilized } \\
\text { land to poor farmers. } \\
\text { Encourage all economic sectors to invest in the agricultural sector; develop } \\
\text { household-scale economies; disseminate economic models for farming in } \\
\text { order to promote agricultural diversity and development. } \\
\text { Complete rural financial policies, expand access to financial and credit } \\
\text { resources in rural areas. Increase the role of the People's Credit Fund and } \\
\text { micro fiscal programs in rural areas. } \\
\text { Develop regulations and standards regarding the safety and quality of } \\
\text { agricultural products, and work jointly with farmers and traders to apply a } \\
\text { monitoring mechanism for quality assurance. } \\
\text { Continue to liberalize input markets (fertilizer, insecticide, etc.) and output } \\
\text { markets (rice, coffee, etc.). } \\
\text { Create an environment that enables farmers to become more market oriented } \\
\text { by establishing a system for rapid access to market prices and price } \\
\text { forecasts. Facilitate the development of closer links between farmers, } \\
\text { traders, processors and exporters. } \\
\text { Policies to develop and manage fishery resources. Implement Decision No. } \\
\text { 132 issued by the Prime Minister on the fiscal mechanism for rural road } \\
\text { development programs, fishery infrastructure and rural professional } \\
\text { infrastructure. } \\
\text { Research and issue policies on supporting production and consumption of } \\
\text { important agricultural, forestry and fishery products that have high } \\
\text { economic value, are competitive, have a large consumer market, both export } \\
\text { and import substitutions, using technical, economic and market analysis to } \\
\text { assess Vietnam's comparative advantage for producing these commodities. } \\
\text { Raise annual investment in agricultural research with a fair share going to } \\
\text { research for upland farming. Increase spending on extension to put in place a } \\
\text { highly qualified extension service that is responsive to the needs of farmers, } \\
\text { especially in ethnic minority areas. Encourage co-payments by farmers for } \\
\text { extension services for industrial crops. }\end{array}$ \\
\hline $\begin{array}{l}\text { 2. Develop industry and } \\
\text { urban areas to create more } \\
\text { jobs and to improve the } \\
\text { living standard for the poor. }\end{array}$ & $\begin{array}{l}\text { Develop agricultural industries (chemicals, fertilizer, packaging, etc.) } \\
\text { Develop industries to process agricultural, forestry and fishery products, and } \\
\text { microbiological industry. } \\
\text { Implement Decree No. } 90 \text { on encouraging the development of small and } \\
\text { medium scale enterprises in specific traditional sectors and professions with } \\
\text { modern technology. } \\
\text { Develop the legal framework to permit establishing business associations. } \\
\text { Develop an enabling policy environment for the operation of Business } \\
\text { Development Service (BDS) providers, regardless of their ownership } \\
\text { structure. [BDS refers to training, consultancy, technical services, } \\
\text { accounting and auditing services, market information services, computer } \\
\text { services, internet and telephone, advertising, etc).] } \\
\text { Provide guidance and implement regulations on preferential policies to } \\
\text { encourage industries to relocate to rural areas. } \\
\text { Establish a strategy for urban development; promote urban-rural linkages } \\
\text { that include suburban development along the lines of masterplans. }\end{array}$ \\
\hline
\end{tabular}




\begin{tabular}{|c|c|}
\hline & $\begin{array}{l}\text { Integrate the development of urban infrastructure with job creation to reduce } \\
\text { urban unemployment. Promote the efficiency of employment promotion and } \\
\text { vocational training centers; accelerate the export of workers and experts. } \\
\text { Carry out the reform of public administration procedures to reflect the actual } \\
\text { situation of the urban poor in such areas as land and housing management, } \\
\text { business and construction certificate issuance, residency registration, etc. } \\
\text { Develop criteria, process and norms in urban planning and design to ensure } \\
\text { that sanitation and environmental requirements are met and that also take } \\
\text { into account the requirements of the urban poor and their ability to pay. } \\
\text { Develop housing development policies for the urban poor; upgrade current } \\
\text { residential neighborhoods squares taking into account the economic } \\
\text { condition of the urban poor and also ensuring their employment. } \\
\text { Create access to basic social services for all urban people, including } \\
\text { unregistered migrants. Develop measures to help poor people find } \\
\text { appropriate jobs in urban areas. } \\
\text { Review labour migration policy and household registration policy to make it } \\
\text { easy for people to move to better-paying jobs. } \\
\text { Develop decrees on the demand side of energy management and energy } \\
\text { efficiency }\end{array}$ \\
\hline $\begin{array}{l}\text { 3. Develop infrastructure and } \\
\text { create opportunities for the } \\
\text { poor to access public } \\
\text { services. }\end{array}$ & $\begin{array}{l}\text { Implement policies to ensure the provision of basic infrastructure, especially } \\
\text { water supply and hygienic conditions for all poor areas, poor communes and } \\
\text { poor quarters in cities and towns (Program No. 135. No. 143). } \\
\text { Continue the mechanism of the "State and people will do it together" to } \\
\text { develop infrastructure in rural areas. The Government will provide support to } \\
\text { train and coach staff responsible for effective management, operation, and } \\
\text { maintenance of basic infrastructure construction. Formulate regulations on } \\
\text { basic infrastructure construction at the commune level. } \\
\text { Promote the use of local labor in carrying out infrastructure projects. } \\
\text { Strengthen the participation of local people in planning, implementation and } \\
\text { maintenance of local infrastructure projects. }\end{array}$ \\
\hline $\begin{array}{l}\text { 4. Training and Education: } \\
\text { Build a more equal and } \\
\text { higher quality education for } \\
\text { people. }\end{array}$ & $\begin{array}{l}\text { Consolidate and develop the gains from primary education universalization } \\
\text { and eradication of illiteracy, with the goal of achieving universalization of } \\
\text { the net enrollment rate of primary education and gender equality, paying } \\
\text { special attention to disadvantaged areas and communities. } \\
\text { Increase the net enrolment rate in lower secondary education with the aim of } \\
\text { achieving universal lower secondary education by } 2010 \text {. }\end{array}$ \\
\hline $\begin{array}{l}\text { Move towards completion of } \\
\text { junior secondary education } \\
\text { universalization and } \\
\text { illiteracy eradication. }\end{array}$ & $\begin{array}{l}\text { Raise the budget expenditure for education and training from } 15 \% \text { of total } \\
\text { budget expenditure to } 18 \% \text { in } 2005 \text {, moving in the direction of increasing } \\
\text { expenditure for basic education. Continue policies on package exemption of } \\
\text { school fees for poor children, extend preferential loans to poor students to } \\
\text { cover training fees. } \\
\text { Raise the awareness of parents in remote, isolated and ethnic minority } \\
\text { communities about the value of education through information, education } \\
\text { and communication. } \\
\text { Provide improved school infrastructure and facilities for basic education in } \\
\text { difficult areas to replace "leaf" schools and start the move towards full-day }\end{array}$ \\
\hline
\end{tabular}




\begin{tabular}{|c|c|}
\hline & $\begin{array}{l}\text { schooling for such communities. } \\
\text { Expand the lending of textbooks and books for children to schoolchildren } \\
\text { from ethnic minorities. } \\
\text { Encourage the participation of the private sector in education and training, } \\
\text { especially vocational. Adjust the rate of training levels; focus on training for } \\
\text { a skilled workforce. } \\
\text { Develop special policies for teachers and training staff working in } \\
\text { disadvantaged areas, complete the salary and allowance regime, training } \\
\text { priorities and other preferential regimes. Have appropriate policies to } \\
\text { strengthen, train and stabilize the livelihood of teachers and training staff } \\
\text { working in disadvantaged areas and to train them on new teaching programs, } \\
\text { methodologies and information to improve teaching. } \\
\text { Improve curriculum and teaching in tertiary education by linking scientific } \\
\text { research and technology transfer in universities and colleges with research } \\
\text { institutes. } \\
\text { Implement priority regimes regarding land use and preferential loans for } \\
\text { investment in education infrastructure. } \\
\text { Promote training according to location; apply the appointed selection } \\
\text { enrolment for disadvantaged areas. }\end{array}$ \\
\hline $\begin{array}{l}\text { 5. Health: Improve quality of } \\
\text { health services; increase the } \\
\text { equity and efficiency of the } \\
\text { health care system: } \\
\text { concentrate on developing } \\
\text { basic health care and } \\
\text { community health care. }\end{array}$ & $\begin{array}{l}\text { Implement Instruction No. } 06 \text { issued by the Party's Central Secretariat on } \\
\text { strengthening and completing the grassroots-based health care network; } \\
\text { continue support policies on primary health care tasks for people, especially } \\
\text { for poor people and poor areas. } \\
\text { Continue investments to develop health stations and ambulatory health } \\
\text { groups in mountainous, remote and isolated areas. } \\
\text { Maintain the achievements in abolishing infant poliomyelitis and tetanus. } \\
\text { Continue to implement extended vaccination in } 10 \text { kinds of vaccine for } \\
\text { children. } \\
\text { Have appropriate policies to provide financial support to health services for } \\
\text { poor people. } \\
\text { Encourage the development of traditional medicine in light of Instruction } \\
\text { No. } 25 \text { issued by the Prime Minister. } \\
\text { Implement Government Resolution No. } 90 \text { on the socialization of health, } \\
\text { education and culture. } \\
\text { Continue investment and complete policies for the National Action Plan on } \\
\text { HIV/AIDS control and prevention. Mobilize the masses to strive to control and } \\
\text { prevent HIV/AIDS and to manage the care of those infected with HIV/AIDS. } \\
\text { Have appropriate preferential mechanisms and policies for medical } \\
\text { personnel working in disadvantaged, remote and isolated areas. } \\
\text { Strengthen information dissemination, education and propagation of } \\
\text { hygienic practices, disease prevention and health improvement for poor } \\
\text { people and poor areas. } \\
\text { total budget expenditure in } 2005 \text { and to } 8 \% \text { in } 2010 \text {. Implement appropriate } \\
\text { policies to channel financial resources to support health care for the poor. } \\
\text { Implement the National Strategy on Maternal Health Care for the period of } \\
2001-2010 . \\
\text { Promote of health insurance and free-of-charge health }\end{array}$ \\
\hline
\end{tabular}




\begin{tabular}{|c|c|}
\hline & $\begin{array}{l}\text { examination and treatment for the poor. Continue to expand the scope and } \\
\text { level of support for medical examination, treatment and medicines for poor } \\
\text { people and disadvantaged children. } \\
\text { Increase population coverage of health insurance by mobilizing premium } \\
\text { collections among those who can afford to pay. } \\
\text { Implement Decision No. } 147 \text { issued by the Prime Minister on the } \\
\text { implementation of the National Population Strategy of Vietnam for the } \\
\text { period 2001-2010, strengthening information dissemination on family } \\
\text { planning. }\end{array}$ \\
\hline $\begin{array}{l}\text { 6. Develop a modern culture } \\
\text { closely lined to the identity } \\
\text { of the nation and improve } \\
\text { the provision of information } \\
\text { to help people expand their } \\
\text { capacity to make choices. }\end{array}$ & $\begin{array}{l}\text { Promote investment to develop culture and information; develop a modern } \\
\text { culture closely linked to our national identity. } \\
\text { Concentrate investment on the development of commune cultural centers, } \\
\text { which can be extended to meeting houses and recreation areas. The } \\
\text { Government will provide primary material support to build essential } \\
\text { infrastructure works such as cultural houses, post offices, radio and } \\
\text { television stations, library of technological and scientific books, etc. }\end{array}$ \\
\hline \multirow[t]{2}{*}{$\begin{array}{l}\text { 7. Strengthen environmental } \\
\text { protection and ensure a } \\
\text { healthy environment for the } \\
\text { poor. }\end{array}$} & $\begin{array}{l}\text { Continue implementation of Decision No. } 104 \text { issued by the Prime Minister on } \\
\text { the National Strategy for Rural Hygiene and Clean Water to the year } 2010 . \\
\text { Approve and implement the National Strategy for Environmental Protection } \\
\text { (NSEP) 2001-2010. Strengthen capacity in government agencies at the } \\
\text { central and local level for environmental assessments. Improve } \\
\text { environmental monitoring and disclosure of environmental data; } \\
\text { Limit and roll back the environmental degradation in industrial zones and } \\
\text { densely populated areas in cities and rural areas. } \\
\text { Strengthen education, mobilization and control of environmental hygiene with } \\
\text { respect to animal breeding at the household level and at the large scale level, } \\
\text { and in craft villages. }\end{array}$ \\
\hline & $\begin{array}{l}\text { Supplement, complete and develop new legal normative documents to } \\
\text { provide concrete guidelines for implementation of the Water Resource Law, } \\
\text { Environmental Protection Law and other legal documents. Expand the range } \\
\text { of regulatory instruments and incentives for pollution reduction. } \\
\text { Build construction works to clean the environment such as wastewater and } \\
\text { rubbish treatment stations, dust and noise treatment facilities in cities, } \\
\text { townships. Develop auto-disintegrative latrines in rural areas. Improve the } \\
\text { quality of natural resource management with respect to the poor, who } \\
\text { mainly depend on natural resources for their livelihood. Develop the } \\
\text { framework to enable community participation in natural resources } \\
\text { management. } \\
\text { Encourage the use of biogas in rural areas and develop solar, wind energy } \\
\text { and other energy resources. } \\
\text { Develop the classification of forestry and reform forest data collection. }\end{array}$ \\
\hline $\begin{array}{l}\text { Strengthen the sustainability } \\
\text { of using natural resources in } \\
\text { rural areas. }\end{array}$ & $\begin{array}{l}\text { Implement the transfer of land and forests to farmers in association with } \\
\text { fixed-cultivation and fixed-residence and stabilize the livelihood of } \\
\text { mountainous farmers. } \\
\text { Research, revise and amend policies on standard price norms in caring for } \\
\text { protected forests, afforestation and protective forest protection. } \\
\text { Evaluate the current forest classification system and improve the monitoring } \\
\text { system of forest covering level. }\end{array}$ \\
\hline
\end{tabular}




\begin{tabular}{|c|c|}
\hline & $\begin{array}{l}\text { Integrate the National Program on } 5 \text { million hectare afforestation with the } \\
\text { Forestry Assistance and Co-operation Program. } \\
\text { Implement the Water Resource Law to improve the sustainable management } \\
\text { of water resources, river headed forests and land resources. } \\
\text { Develop prudently fishery production, ensuring the environment assessment } \\
\text { and proper area selection to be carried out. }\end{array}$ \\
\hline \multicolumn{2}{|c|}{ II. Ensure the balanced development, increase gender equity and advancement for women } \\
\hline $\begin{array}{l}\text { 1. Promote balanced and } \\
\text { sustainable economic growth } \\
\text { between regions. }\end{array}$ & $\begin{array}{l}\text { Continue increasing investment in less developed areas with the aim of } \\
\text { reducing the development gap between different areas, urban and rural areas } \\
\text { in particular. } \\
\text { Ensure an appropriate population distribution across areas; increase step by } \\
\text { step the quality of life for all population strata with the aim of reducing the } \\
\text { gap in living standard between different strata and groups; bring population } \\
\text { variables into development plans. }\end{array}$ \\
\hline $\begin{array}{l}\text { 2. Promote gender equity, } \\
\text { enhance the participation of } \\
\text { women at all levels of } \\
\text { leadership. }\end{array}$ & $\begin{array}{l}\text { Implement Decision No. } 19 \text { issued by the Prime Minister on the National } \\
\text { Strategy for the Advancement of Women to the year } 2010 \text {. } \\
\text { Ensure that the names of both husband and wife appear on land-use rights } \\
\text { certificates by } 2005 \text {. } \\
\text { Increase the number of women in government-elected bodies. } \\
\text { Reduce inequality in making decisions in families. Increase the role of } \\
\text { women with respect to their family's assets. } \\
\text { Strengthen women's access to credit resources and capital from the National } \\
\text { Strategy for Poverty Reduction, creating conditions for them to access social } \\
\text { services fully, equitably and equally. } \\
\text { Have policies to reduce the vulnerability of women against family violence. }\end{array}$ \\
\hline $\begin{array}{l}\text { 3. Create conditions to } \\
\text { enable all social strata to } \\
\text { fully take part in economic } \\
\text { growth }\end{array}$ & $\begin{array}{l}\text { Ensure that ethnic minorities in the mountainous areas benefit from growth. } \\
\text { Evaluate and disseminate models to support disadvantaged areas and ethnic } \\
\text { minorities, and encourage them to take part in the economic development } \\
\text { process. } \\
\text { Encourage NGOs and socio-political organizations to take part in poverty } \\
\text { reduction by providing a legal framework for NGOs. } \\
\text { Improve the access of the poor to legal support services. Help the poor } \\
\text { improve their knowledge of their legal rights and obligations. } \\
\text { Increase the two-way information system between local government and } \\
\text { poor families. } \\
\text { Implement fully the Decree on Democracy at the Grassroots Level, and } \\
\text { create an enabling environment for poor households to take part in local } \\
\text { economic development plans. }\end{array}$ \\
\hline
\end{tabular}


1. Minimize social impacts on the poor in the process of adjustment

2. Minimize the impacts of natural disasters on the poor working conditions in a market economy.

4. Provide targeted assistance to vulnerable
3. Protect worker rights and groups.

Reduce negative impacts on the poor caused by ongoing reforms. Broadly disseminate information on policy changes to facilitate farmers in changing their production and business operations.

Ensure job security, extend unemployment insurance, training for the redundant workforce and improve working conditions.

Develop a set of solutions to effectively address emergency social relief for poor and vulnerable people who are hurt by natural disasters and accidents.

Expand the official social safety net (health insurance, social insurance, etc.) and encourage the development of the voluntary safety net (school insurance and insurance of crops, diseases, etc.)

Review and strengthen the role of labor unions in protecting worker rights and working conditions.

Improve the targeting mechanisms of programs 133, 135, and 143 and implement them in a more participatory way.

Undertake independent evaluations of these programs and use findings to improve the design of the projects.

\section{Monitoring and Evaluation}

1. Improve macroeconomic statistics

Promulgate the Law of Statistics.

Strengthen statistical agencies at various levels.

Promote transparency and data quality.

Strengthen the statistical database.

Strengthen the national account within 2 years and improve budget data quality to correspond to the Government's fiscal statistical standards.

Present a website of Vietnam in the International Fiscal Statistical Book published by the IMF.

2. Poverty monitoring
Collect high quality data on the poverty situation and trends, and ensure that data and information is publicized and used regularly.

Implement enterprise surveys to collect high quality data on growth and employment trends, and make it publicly available. 